Grand Valley State University

ScholarWorks@GVSU

$12-2012$

\title{
Using Case Studies and Videotaped Vignettes to Facilitate the Development of Critical Thinking Skills in New Graduate Nurses
}

Barbara Louise Hooper

Grand Valley State University

Follow this and additional works at: https://scholarworks.gvsu.edu/dissertations

\section{ScholarWorks Citation}

Hooper, Barbara Louise, "Using Case Studies and Videotaped Vignettes to Facilitate the Development of Critical Thinking Skills in New Graduate Nurses" (2012). Doctoral Dissertations. 7.

https://scholarworks.gvsu.edu/dissertations/7 
Using Case Studies and Videotaped Vignettes to Facilitate the Development of Critical Thinking Skills in New Graduate Nurses

\author{
Barbara Louise Hooper
}

A Dissertation Submitted to the Graduate Faculty of GRAND VALLEY STATE UNIVERSITY

In

Partial Fulfillment of the Requirements

For the Degree of

Doctor of Nursing Practice

Kirkhof College of Nursing

December, 2012 


\section{Dedication}

This scholarly project is dedicated to all of the new graduate nurses who are transitioning to the role of registered nurse. The work you do everyday makes a difference in the lives of the people you care for every day.

A special dedication to my wonderful husband Bill and our two boys, Jacob and Benjamin, I could not have completed this degree without your love and constant support by my side, and to my parents, Larry and Donna, who taught me that anything can be achieved with hard work and perseverance. 


\section{Acknowledgments}

It would have been impossible to complete this dissertation without the support and assistance of several people. I will always be grateful to all of them.

I wish to acknowledge the support of Grand Valley State University in producing this work. I would like to express my deep appreciation to my dissertation chair, Dr. Cynthia Coviak, for her consistent and prudent guidance through this process and always being there. It was truly an honor to enter into a mentorship relationship with a role model of nursing research excellence.

I would like to thank the rest of my dissertation committee, Dr. Linda Scott for providing me with ongoing encouragement. You always reminded me to keep the end in sight, which is exactly what I needed sometimes. Thank you Glenna Decker for your expertise regarding adult learning and steering me in the direction of finding valuable technology resources. Finally, special thanks must go to Janice Hodges, for her wisdom and intellectual nourishment as well as her constant support, suggestions, and encouragement. She mentored me, not only for this scholarly project, but for the year that I worked with her. She took me under her wings and provided me with every learning opportunity she could find.

I would like to thank all the nurse residents who participated in this scholarly project. The work you do every day is amazing and not always easy. I appreciate every thing you 
shared with me, and I recognize the challenges you encountered transitioning from the role of graduate nurse to registered nurse.

To my fellow cohorts; we survived! The support you provided will always be remembered, and the friendships we developed cherished. I will miss seeing everyone on a regular basis and exchanging updates. A special thank you to Kelli; your friendship, support and ability to make me laugh will never be forgotten.

Finally, I would like to thank my family for their love, support, and understanding during this learning process; it's been quite the journey. To my parents, who were always there to provide a fun and loving environment for our children, Jacob and Benjamin. Thank you for the endless chauffeuring you provided getting them to their various activities after school, sometimes with only a few hours notice. I never could have done this program without your help in watching Jacob and Benjamin. To my children, Jacob and Benjamin, thank you for understanding why mom could not always attend every activity and for the times when mom was sometimes "moody". And, finally my heartful gratitude and love especially goes to my husband, Bill. His endless and unwavering support sustained me through this process. Thank you for believing in what I was doing and always being there to cheer me on when I wanted to quit. I could not have down this without your love and support. 


\begin{abstract}
Based on the increasing complexity of health care, nurses are performing extremely skilled and high level cognitive work that requires a solid foundation upon which to build. A variety of educational strategies have been utilized to teach critical thinking. The purpose of this program evaluation was to determine if using case studies with videotaped vignettes helped to facilitate the development of critical thinking skills in new graduate nurses participating in a nurse residency program.

Eighteen nurse residents hired for the July nurse residency program participated in this program evaluation. The Health Sciences Reasoning Test (HSRT) was used to measure critical thinking. A paired samples $t$-test revealed a statistically significant increase $(t=-2.219, \mathrm{p}=.041)$ on the overall HSRT score, indicating the participants' critical thinking did improve after using case studies and videotaped vignettes as an educational strategy for their orientation program. No relationships were found between critical thinking and the variables: age; previous health care experience; location of health care experience; and previous experience with case studies and videotaped vignettes.

It is impossible to prepare new graduate nurses for every situation they could encounter in the clinical practice environment, which is why it is so important for individuals to develop critical thinking skills. Using multiple strategies and embracing technology are options that should be considered when selecting a strategy. The results of this scholarly project are site specific, which precludes the generalizability to other organizations.
\end{abstract}




\section{Table of Contents}

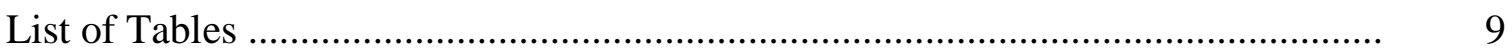

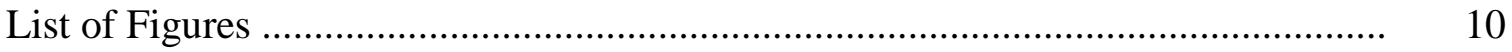

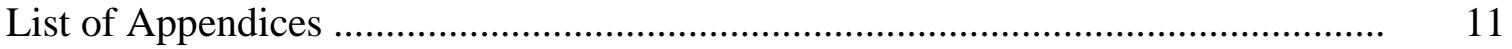

\section{CHAPTER}

$1 \quad$ INTRODUCTION

Statement of Problem ............................................................................ 12

Purpose of the Scholarly Project ............................................................. 17

Significance of this Project ................................................................. 17

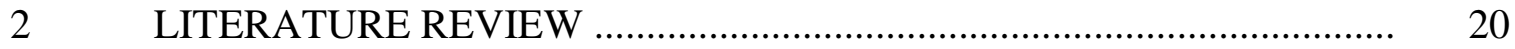

Critical Thinking ............................................................................. $\quad 20$

Measurement of Critical Thinking ….................................................... 25

Standardized Instruments .................................................................... 25

The Watson-Glaser Critical Thinking Appraisal ................................ 26

The California Critical Thinking Skills Test ....................................... 27

The California Critical Thinking Disposition Inventory ....................... 29

Health Education Systems Incorporated Exam .................................... 31

Health Sciences Reasoning Test ........................................................ 33

Holistic Critical Thinking Scoring Rubric ........................................... 34

Minnesota Test of Critical Thinking .................................................. 36

Other Measures ................................................................................. 38

Educational Strategies to Develop Critical Thinking Skills ...................... $\quad 39$

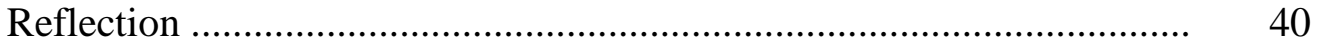

Concept Maps ................................................................................... 43

Case Studies .................................................................................... 50

Problem-Based Learning .................................................................. 53

Questioning .............................................................................. 59

Simulation .................................................................................... 62

Barriers to Implementing Critical Thinking Educational Strategies............ $\quad 72$

Conclusions and Implications for the Project........................................... 73

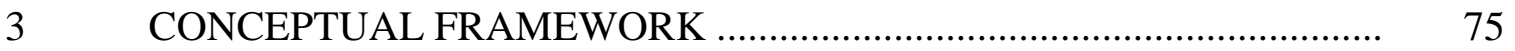

Donabedian's Structure, Process, Outcome Model ................................... $\quad 75$

Conceptual and Operational Definitions ................................................ 84 
Setting

Participants ............................................................................. 88

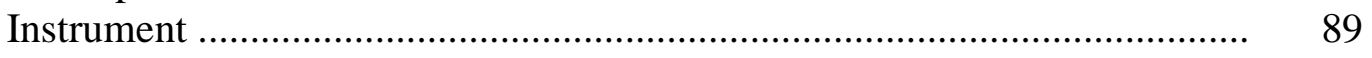

Ethical Considerations ......................................................................... 94

Program Content and Delivery ............................................................... 94

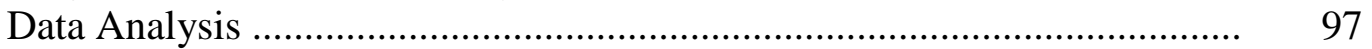

Evaluation ................................................................................ 97

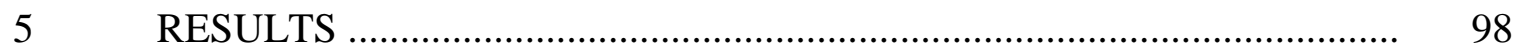

Demographics .............................................................................. 99

Examination of Intervention Effect ........................................................ 100

Examination of Relationships Among Possible Confounding Variables ..... 105

Summary ...................................................................................... 108

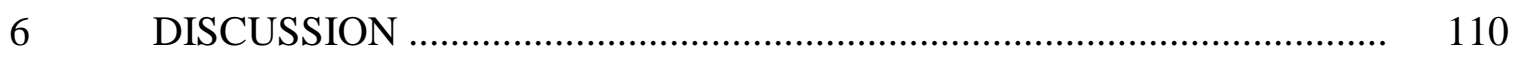

Discussion of Findings ......................................................................... 111

Critical Thinking Scores and the Educational Intervention ....................... 111

Critical Thinking Scores and the Confounding Variables ......................... 117

Limitations ...................................................................................... 118

Influence/Impact of Findings on the Immersion Site .............................. 121

Implications for Practice ........................................................................ 125

The Essentials of Doctoral Education for Advanced Practice Nursing........ 127

Scientific Underpinnings for Practice................................................. 127

Organizational and Systems Leadership for Quality Improvement and

Systems Thinking .......................................................................... 130

Clinical Scholarship and Analytical Methods for Evidenced-Based

Practice ......................................................................................... 133

Information Systems/Technology and Patient Care Technology for the Improvement and Transformation of Health Care ............................... 134

Health Care Policy for Advocacy in Health Care ................................. 135

Interprofessional Collaboration for Improving Patient and Population

Outcomes ..................................................................................... 136

Clinical Prevention and Population Health For Improving the Nation's

Health .............................................................................................. 137

Advanced Nursing Practice .............................................................. 138

Summary and Conclusions ................................................................. 141

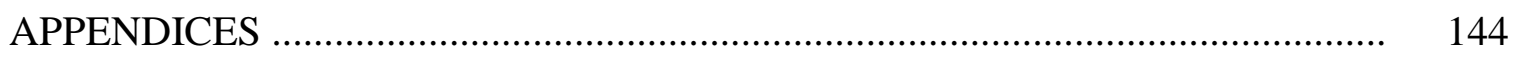

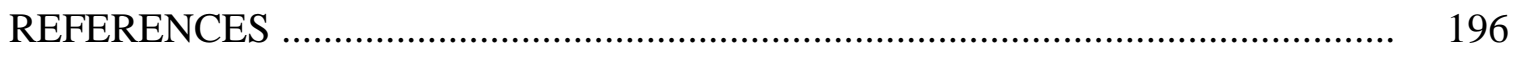




\section{List of Tables}

\section{TABLE}

1 Type of Previous Health Care Experience................................................... 99

$2 \quad$ Length of Time Employed in Health Care.................................................. 100

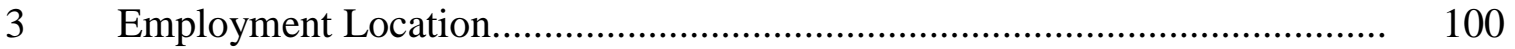

$4 \quad$ Critical Thinking Pre and Posttest HSRT Scores........................................ 101

5 Distribution of Overall HSRT Total Scores in Low, Average and High

Categories................................................................................................. 102

$6 \quad$ Score Distributions for Analysis and Interpretation, Inference, and Evaluation and Explanation Scales in Low, Average and High Categories.... 104

7 Score Distributions for Inductive and Deductive Reasoning Scales in Low, Average and High Categories....................................................................... 105

$8 \quad$ Critical Thinking Paired Samples t-tests................................................... 106 


\section{List of Figures}

\section{FIGURE}

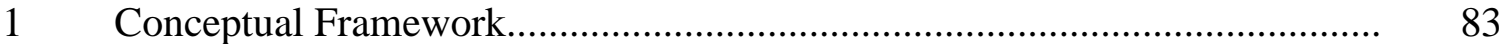




\section{List of Appendices}

\section{APPENDIX}

A Evidence Based Evaluation Tables............................................................. 144

B Institutional Review Board Approval Letter............................................ 181

C Organizational Institutional Review Board Exemption Letter....................... 182

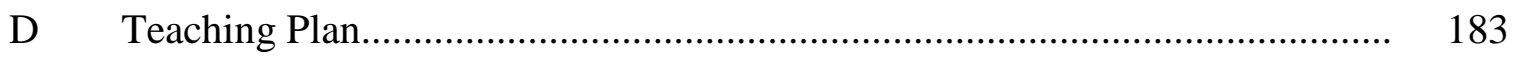

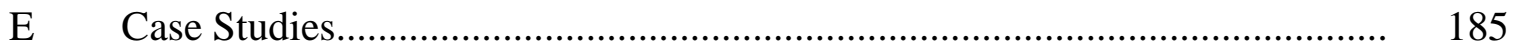

F $\quad$ Demographic Questionnaire............................................................... 194 


\section{CHAPTER 1}

\section{INTRODUCTION}

\section{Statement of the Problem}

Health care is complex and continually changing. Rubenfeld and Scheffer (2010) found that the critical thinking required by nurses is becoming even more sophisticated. An emphasis on critical thinking in health care has become increasingly evident over the past decade. Key issues that require more or better critical thinking include advances in information technology, dwindling resources, cost containment, morbidity and mortality data, patient safety, and failure to rescue (Benner, Hughes, \& Sutphen, 2008; Dyess \& Sherman, 2009; Hoffman, 2008; Rubenfeld \& Scheffer, 2010; Simpson \& Courtney, 2002).

Several reports from multiple organizations have cited quality of care and patient safety as top issues that need to be addressed (Institute of Medicine, 1999, 2001, 2003). Kaiser Health News (2011) reported that in 2008 the "estimated total cost of measurable medical errors in the United States was \$17.1 billion” (np).The goals of health care organizations across the nation, as a result, are focused on building a safer health care system. Nursing is a key player in reaching those goals. Nursing has been identified as having the capability for making a major impact on the transformation of health care delivery with the end result being a safer, higher quality, and more cost-effective health care system (American Association of Colleges of Nursing, 2008; American Nurses Association [ANA], 2004; Day \& Smith, 2007). Mistakes result from errors in critical thinking that affect and impact decision making abilities. Hughes (2008) asserts the 
nurse's ability to make logical and accurate decisions in order to influence patient safety is associated with complex factors including his or her knowledge base.

Nursing can have a substantial effect on patient care outcomes, particularly in preventing not only adverse events, but the lasting effects of comorbidities and subsequent symptoms (Hughes, 2008). Nurses make numerous decisions throughout the course of their day. Frequently, those decisions are made in a matter of microseconds. Yet those decisions can have very serious consequences if the correct decision is not made. There are certain situations when decisions can be made with more time, in consultation with others, or after allowing a search of resources before arriving at a final decision. Most importantly, all decisions, no matter how quickly they are made, need to be accurate and made in a timely manner (Rubenfeld \& Scheffer, 2010). Edwards (2007) states:

To deal effectively with rapid change nurses need to become skilled in higher-level thinking and reasoning. There is not always theoretical evidence to support practice, therefore, nursing needs to incorporate into its practice critical thinking processes to provide new answers to practical questions. Every day nurses sift through an abundance of data and information to assimilate and adapt knowledge for problem clarification in an attempt to find solutions. (p. 303) Benner, Sutphen, Leonard, and Day (2010) state "new nurses need to be prepared to practice safely, accurately, and compassionately, in varied settings, where knowledge and innovation increase at an astonishing rate” (p.1). Based on the increasing complexity of health care, nurses are performing extremely skilled work that requires a solid foundation upon which to build. Meeting the needs of hospitalized patients requires nurse 
executives to recognize that sufficient numbers of well-qualified registered nurses are essential (Hatler, Stoffers, Kelly, Redding, \& Carr, 2011). However, the need to improve the safety and quality of care is not the sole responsibility of nurse executives. Rather, all health care providers, clinicians, and health care leaders have an accountability to ensure patients receive proper care and treatment (Hughes, 2008).

Hughes (2008) identifies nurses as the largest health care workforce. Nurses apply their knowledge, skills, and experience to care for the various and changing needs of patients. Subsequently, recruiting, transitioning, and retaining new graduate nurses are critical. Currently, $60 \%$ of registered nurses are employed in hospitals and they comprise the largest occupation in health care with 2.6 million jobs in 2008 (U.S. Department of Labor, 2010).

Many organizations are concerned about nursing shortages and high turnover rates. Casey, Fink, Krugman, and Propst (2004) and Goode and Williams (2004) found graduate nurses are becoming a significant part of hospital recruitment and staffing strategies. Research by the Healthcare Advisory Board found that as many as $42 \%$ of new hires by hospitals are new graduate nurses (Goode $\&$ Williams, 2004). New graduate nurses, though, are also the most at risk group because they have not yet developed the critical thinking skills necessary to assess and evaluate complex clinical situations in the practice setting (Myers et al., 2010). Graduate nurses often experience stress moving from the role of a student to a practicing professional nurse. New graduate nurses are frequently expected to rapidly make that transition and perform as a competent nurse (Casey et al., 2004; Dyess \& Sherman, 2009; Steen, Gould, Raingruber, \& Hill, 2011). Dyess and Sherman (2009) noted new graduate nurses can now take the National Council 
Licensure Examination for Registered nurses (NCLEX) and within weeks of graduation enter practice as a fully licensed registered nurse. Prior to 1994, new graduate nurses entered practice with temporary licenses and worked with experienced nurses for a number of months. Although these newly licensed nurses have achieved the legal and professional requirements to enter practice, Bratt (2009) and Dyess and Sherman (2009) found many new graduate nurses lack the clinical skills and judgment needed to provide safe, competent care to patients.

Beyea, Von Reyn, and Slattery (2007) found that despite receiving orientation, many new graduate nurses reported low levels of confidence and competence and requested longer supervised orientation periods. Fero, Witsberger, Wesmiller, Zullo, and Hoffman (2009) found, after controlling for years of experience, new graduate nurses were less likely to meet expectations after viewing ten videotaped vignettes showing a change in patient status, compared with nurses with greater than ten years of experience $(p=0.046)$. This supports the work by Benner (1984) who observed new graduate nurses often enter practice at the level of novice or advanced beginner, but clinical experience presents more complex and multiple additional realities than theory can capture alone. Based on this fact, there is the potential that no changes in critical thinking skills may be found between the time of graduation and the completion of nursing orientation.

At the same time, graduate nurse turnover is estimated to range from 35 percent to 61 percent after just one year of employment in the initial registered nurse position (Casey et al., 2004; Delaney, 2003; Halfer \& Graf, 2006; Myers et al., 2010). Costs of turnover can vary, but can easily range from approximately $\$ 22,000$ to more than \$88,000 per turnover (Halfer \& Graf, 2006; C. Jones, 2008; Ulrich et al., 2010). C. Jones 
(2008) also estimated that organizations spend $\$ 300,000$ annually in nurse turnover costs for every $1 \%$ increase in turnover.

Nurse turnover can have other consequences than financial. Turnover can compromise the quality of care due to staff shortages, which can result in high nurse-topatient ratios; lapses in continuity of care; increased patient length of stay; inefficient discharge planning; inconsistent use of policies and procedures; and communication problems. Turnover can result in higher organizational costs in the form of lost productivity and organizational inefficiencies that are a direct consequence of staff instability. Turnover may result in human capital losses if high-performing nurses leave and have to be replaced. Turnover can contribute to nurse burnout and fatigue. Finally, turnover diverts leaders' attention away from and utilizes resources that could be intended for other core business initiatives (American Nurses Association, 2004; C. Jones, 2008; Ulrich et al., 2010). In summary, turnover is detrimental not only to organizational costs and performance, but also potentially to patients and staff.

Critical thinking has been an important theme for many years in nursing practice and education. Hinshaw (2010) offers the position that explaining the critical thinking process is complex and not easily understood. Rubenfeld and Scheffer (2010) indicate nurses who think critically have more confidence in their reasoning. This confidence permits nurses to speak their minds, to openly identify potential errors and near misses, and to provide sound rationale for their decisions. Confidence allows them to make valid contributions and decisions related to patient care. Ultimately, critical thinking empowers decision making skills, enhances job satisfaction through professional integrity, and achieves expertise in practice (Rubenfeld \& Scheffer, 2010). 


\section{Purpose of the Scholarly Project}

The purpose of this scholarly project was to explore educational strategies that may facilitate the development of critical thinking skills in new graduate nurses. A review of the literature was conducted to synthesize and evaluate the different educational strategies that are utilized for developing critical thinking skills to determine if a specific educational strategy has been found through research to be more effective as compared to the other strategies identified. The question that guided the review was What educational strategy best facilitates the development of critical thinking skills in new graduate nurses? Following the review, the Iowa model of evidence-based practice to promote quality care, developed by Marita G. Titler and colleagues (Titler et al., 2001), was utilized to implement and evaluate a pilot of an intervention to assist new graduate nurses in developing critical thinking skills.

\section{Significance of this Project}

The challenges facing the United States (U.S.) health care system have attracted great attention as a result of the publication of several U.S. Institute of Medicine (IOM) reports beginning in 1999. The IOM's mission is to serve as an advisor to the country to improve the health of the nation (IOM, 2011). The reports To Err is Human: Building a Safer Health System; Crossing the Quality Chasm: A New Health System for the $21^{\text {st }}$ Century; Health Professions Education: A Bridge to Quality; Patient Safety: Achieving a New Standard for Care; and Keeping Patients Safe: Transforming the Work Environment of Nurses (IOM, 1999, 2001, 2003) served as the foundation for identifying five health care competencies: quality improvement, patient-centered care, work in interdisciplinary teams, evidence-based practice, and using informatics (Rubenfeld \& Scheffer, 2010). 
Specifically, six aims were described in the Crossing the Quality Chasm: A New Health System for the $21^{\text {st }}$ Century, with the goal of calling health care professionals to action to improve the quality and safety of patient care. The six aims were: health care should be (a) safe, (b) effective, (c) patient centered, (d) timely, (e) efficient, and (f) equitable (IOM, 2001).

The use of critical thinking and clinical judgment skills are essential components of nursing and are crucial to nursing practice. Accrediting bodies and policy makers promote critical thinking (ANA, 2004; Rubenfeld \& Scheffer, 2010). In order for nurses to provide quality care that is not only safe, but will benefit their patients, they must be informed and able to make clinical judgments about good practice for each individual patient. The ability to evaluate information and different scenarios requires the ability to think critically.

Today's health care setting requires new graduate nurses to not only perform competently, but to be able to transfer information to fit a variety of new situations. In a study completed by the Health Care Advisory Board, Goode and Williams (2004) found many new graduate nurses were unable to demonstrate safe clinical judgment. The study defined safe clinical judgment as the ability to identify deviations from normal problems, calling physicians with key data, and initiating nursing actions necessary to validate problems or keep them from getting worse. Research conducted by Berkow, Virkstis, Steward, and Conway (2009) supported the findings by Goode and Williams (2004). They found only $10 \%$ of frontline nurse leaders from a national survey of 5,700 respondents believed their new graduate nurses were fully prepared to provide safe and effective care. Setter, Walker, Connelly, and Peterman (2011) believe educators have a 
professional responsibility to make sure new graduates receive the best possible start in their nursing careers. Based on current research findings, nurse educators are challenged to prepare new graduate nurses who are competent to provide care that is safe and effective, as the complexity of health care increases. 


\section{CHAPTER 2}

\section{LITERATURE REVIEW}

The purpose of the chapter will be to identify the definition of critical thinking followed by a discussion of the instruments that are used to measure critical thinking. Next, a review of the literature will be conducted to examine the different educational strategies that are used to develop critical thinking skills. Then, an appraisal of the barriers to implementing critical thinking educational strategies will be discussed. Finally, a summary of the conclusions and implications for this project will be reviewed.

\section{Critical Thinking}

Critical thinking has been discussed in depth in the literature and despite the agreement regarding the importance of critical thinking, there is no agreement on the definition of critical thinking. Numerous definitions are found in the literature today.

The American Philosophical Association accepts the following definition, which is based on the conclusion of a two year Delphi project directed by Facione (1990). “Critical thinking is the process of purposeful, self-regulatory judgment, which results in interpretation, analysis, evaluation, and inference, as well as explanation of the evidential, conceptual, methodological, criteriological or contextual considerations upon which that judgment is based” (p. 2). This definition was constructed after six rounds of question and answer sessions that included a panel of 46 professionals in the academic disciplines of philosophy, education, social sciences, and the physical sciences. The professionals who were asked to participate in this study were considered to have expertise in assessment, theory, or instruction of critical thinking. 
The Foundation for Critical Thinking (n.d.) defines critical thinking as that mode of thinking about any subject, content, or problem in which the thinker improves the quality of his or her thinking by skillfully analyzing, assessing, and reconstructing it. Critical thinking is self-directed, self-disciplined, selfmonitored, and self-corrective thinking. It presupposes assent to rigorous standards of excellence and mindful command of their use. It entails effective communication and problem-solving abilities, as well as a commitment to overcome our native egocentrism and sociocentrism. (p. 1)

In the nursing literature, there is a wealth of information related to critical thinking, in part, due to the need to be able to think critically to practice professional nursing (Abbate, 2008). The nursing literature also presents numerous definitions of critical thinking. A definition is important because it provides a foundation for nurse educators to implement pedagogical strategies that will facilitate the development of critical thinking and it creates a context for developing evaluative measures for recognizing its effects in practice.

The National League for Nursing (2011) defines critical thinking in clinical nursing practice as "a discipline specific, reflective reasoning process that guides a nurse in generating, implementing, and evaluating approaches for dealing with client care and professional concerns” (p.2). Application of critical thinking to nursing practice is demonstrated by the ability to interpret, analyze, evaluate, infer, and explain (National League for Nursing, 2011).

In response to the need for a consistent definition for critical thinking, Scheffer and Rubenfeld (2000) developed a consensus statement about critical thinking in nursing 
based upon the results of a Delphi Study. A panel of 55 experts in nursing from nine different countries determined

Critical thinkers in nursing exhibit these habits of the mind: confidence, contextual perspective, creativity, flexibility, inquisitiveness, intellectual integrity, intuition, open-mindedness, perseverance, and reflection. Critical thinkers in nursing practice the cognitive skills of analyzing, applying standards, discriminating, information seeking, logical reasoning, predicting and transforming knowledge. (p. 357)

The definition developed by Scheffer and Rubenfeld (2000) will be referenced for this scholarly project.

Critical thinking, clinical decision-making, clinical judgment, clinical reasoning, critical reflection, and problem solving are terms that are often used interchangeably, but there are distinctions between the concepts. Clinical decision-making is concerned with problems of a clinical nature. This is different from problems pertaining to a wide range of conditions that may or may not be clinical in nature (Simpson \& Courtney, 2002). Hynes and Bennett (2004) and Thompson and Stapley (2011) further clarified that decision making is simply one piece of the problem solving process that is concentrated on decisions associated with patient management. These decisions can subsequently result in the nurse deciding to take action by implementing an intervention, or inaction, which Thompson and Stapley (2011) refer to as “watchful waiting” (p. 882).

Clinical judgment, defined by Jackson, Ignatavicius and Case (2006) is the “development of opinions in the clinical practice setting, based on experience and knowledge, to guide the decisions you will make regarding the care of the patient” 
(p. 14). Boychuk-Duchscher (1999) states clinical judgment is "an understanding that knowledge is limited, beliefs change, and conclusions are temporary” (p. 580). Pesut (2001) believes the outcomes of critical thinking in nursing practice are clinical judgments. Pesut states clinical judgments "begin with an 'end' in mind. Judgments are about evidence, meanings, and outcomes achieved” (p.215). These definitions differ from Thompson and Stapley (2011) who believe clinical judgments symbolize evaluation.

Banning (2008) and Benner, Hughes, and Sutphen (2008) define clinical reasoning as a process whereby knowledge and experience are applied when taking into consideration several possibilities to reach the desired goals, while taking into account the patient's circumstances. Rochmawati and Wiechula (2010) provide a more detailed definition by defining clinical reasoning as “the practitioner’s ability to assess patient problems or needs and analyze data to accurately identify and frame problems within the context of the individual patient’s environment” (p. 244). Lastly, Kautz, Kuiper, Pesut, Knight-Brown, and Daneker (2005) define clinical reasoning as

The reflective, creative and critical systems thinking processes nurses use to frame the meaning and facts associated with a client story, juxtapose and test the differences between a patient's present story state and a desired specified outcome state; and make judgments about outcome achievements derived from reflection and self-regulation of thinking. (p. 2)

Critical reflection requires the nurse to examine underlying assumptions and thoroughly question or doubt the validity of arguments, assertions, and even the facts of the case (Benner et al., 2008). Schon (1987) describes two types of reflection. The first is reflection in action, which involves thinking about actions while engaged in them, and 
the second is reflection on action, which involves looking back on a situation to learn from it. Reflection facilitates the assimilation of theory with clinical practice to help the nurse become a critical thinker (Butler, 2004).

Problem solving focuses on a problem and finding solutions to resolve the problem (Boychuk-Duchscher, 1999; Simpson \& Courtney, 2002). Questioning serves as an important tool during the problem solving process (Boychuk-Duchscher, 1999). Questioning helps to identify primary issues; it looks at reasoning, inquires into the uncertainty of the language defining the problem, places importance on the examination of value conflicts, and facilitates the challenging of assumptions (Boychuk-Duchscher, 1999).

Despite the differences in terminology, it is well documented that the ability to think critically is necessary for new graduate nurses. The Essentials of Baccalaureate Education for Professional Nursing (AACN, 2008) states "baccalaureate generalist graduates should be prepared to use critical reasoning and clinical judgment skills to address simple to complex situations” (p. 8). As a result, the Commission on Collegiate Nursing Education (CCNE) requires nursing programs to address all components listed in the Essentials of Baccalaureate Education for Professional Nursing, including critical thinking, for accreditation (CCNE, 2009). In order to maintain accreditation, evidence must be submitted that shows students are meeting these requirements. The National League for Nursing (NLN) requires accredited programs demonstrate that their students are developing the skills of analysis, reasoning, decision making, and independent judgment which are necessary components of the critical thinking process (NLN, 2005; O’Sullivan, Blevins-Stephens, Smith, \& Vaughan-Wrobel, 1997; Stone, Davidson, 
Evans, \& Hansen, 2001; Twibell, Ryan, \& Hermiz, 2005; Vaughan-Wrobel, O’Sullivan, \& Smith, 1997). The American Nurses' Association (2004) also emphasizes critical thinking in its Nursing: Scope and Standards of Practice. The language of critical thinking is addressed in the Association's scope statement and integrated throughout all of the standards.

\section{Measurement of Critical Thinking}

Despite the variety of different educational strategies available, current research findings in the literature document that the effectiveness of their use for developing critical thinking skills is inconsistent. Reliable and valid instruments for measuring critical thinking are needed. Yet, one of the challenges of measuring critical thinking is the lack of instruments designed specifically for nursing.

Standardized instruments. A variety of standardized tests are available for evaluating critical thinking, but they frequently are not based on descriptions of critical thinking in nursing. Instead, they capture more general descriptions of critical thinking (Rubenfeld \& Scheffer, 2010; Staib, 2003). Banning (2008) indicates there is no compelling evidence that critical thinking outcomes can be exclusively explained by scores on standardized instruments. It is important to mention a few of the limitations of utilizing standardized instruments. First, the skills of logic are effectively measured when standardized instruments are administered, while the critical thinking skills necessary for clinical practice may be more difficult to measure. Rubenfeld and Scheffer (2010) found standardized instruments fail to show objectively that students learn critical thinking in nursing school. A key reason for this inability is that standardized tests lack validity for nursing because they are not based on a conceptual definition of critical thinking for 
nursing. Further, Rubenfeld and Scheffer (2010) found the potential exists for a language barrier for nurses who are not fluent in English because many of the instruments are only available in the English language. Despite these limitations and the inconsistent research findings, standardized instruments are still currently used (Rubenfeld \& Scheffer, 2010; Staib, 2003).

The Watson-Glaser Critical Thinking Appraisal The Watson-Glaser Critical Thinking Appraisal (WGCTA) developed by Goodwin Watson and E. M. Glaser in 1925 (Think Watson, 2012) is one of the most widely used standardized tests to measure critical thinking (Banning, 2006; Hicks-Moore \& Pastirik, 2006; Staib, 2003). It produces a single score that denotes critical thinking abilities based upon the assessment of five critical thinking skills: inference, recognition of assumptions, deduction, interpretation, and evaluation of arguments (Banning, 2006; Performance Assessment Network, 2011; Staib, 2003). The original version of the WGCTA is an 80-item self-administered test that can be completed in 60 minutes and has two alternate versions. The shorter form is comprised of 40-items and can be completed in 45 minutes (Performance Assessment Network, 2011).

Results using the WGCTA to measure critical thinking in undergraduate nursing students have been inconsistent and questions regarding the validity of this instrument have been raised (Banning, 2006; Kintgen-Andrews, 1991). Angel, Duffey, and Belyea (2000) utilized the WGCTA to evaluate changes in the acquisition of knowledge and the development of critical thinking skills based on teaching strategies of a structured or unstructured format for a weekly health pattern assessment course. Participants $(n=142)$ showed significant gains in both knowledge $(\mathrm{p} \leq 0.001)$ and critical thinking performance 
$(\mathrm{p} \leq .001)$ from the beginning to the end of the semester. The results, however, indicated that interaction between learner strategy and the characteristics of the learner were more significant in determining knowledge improvement than the particular strategy used.

Daly (2001) completed a study with the purpose of exploring and developing an alternative domain-specific method for identifying critical thinking in student nurses' reasoning processes. The study utilized the WGCTA in addition to a "think-aloud" technique incorporating a videotaped client simulation, a cognitive task, and a stimulated recall strategy. Daly (2001) found no significant differences in the pre- and post-program WGCTA mean scores $(\mathrm{p}=0.7920)$. In regards to the "think-aloud" technique, the sample consistently displayed evidence of reasoning that "reflected an absolutist epistemology portraying limited evidence of critical thinking” (Daly, 2001, p. 120).

The California Critical Thinking Skills Test. The California Critical Thinking Skills Test (CCTST) consists of 34 multiple choice questions designed to be completed within 45 minutes. The CCTST is based on the Delphi Expert Consensus definition of critical thinking (Bondy, Koenigseder, Ishee, \& Williams, 2001; Facione, 1990; Stone et al., 2001). The CCTST provides six scores: five subscales and an overall critical thinking score (Bondy et al., 2001; Stone et al., 2001). Each correct answer is given one point. The five subscales, which are based on the cognitive skills dimension of critical thinking, are analysis and interpretation, inference, evaluation and explanation, inductive reasoning, and deductive reasoning (Hicks-Moore \& Pastirik, 2006; Ravert, 2008; Staib, 2003). It is currently considered one of the premier critical thinking skills tests available today.

To develop the CCTST, a pilot instrument was constructed from a pool of 200 previously piloted multiple choice items (Facione, 1990). The items were developed and 
analyzed as a result of the Delphi Expert Consensus definition of critical thinking. Items selected for inclusion in the pilot instrument were chosen for their abilities to cover the five critical thinking cognitive skills identified by the Delphi experts. Four experiments were done to assess validity and reliability. The Kuder-Richardson-20 (KR-20) internal consistency reliability coefficient for the pretest was .69 and for the posttest was .68. The CCTST is sensitive enough to measure changes in critical thinking skills. One item from the pilot instrument was dropped for lack of discrimination using a point biserial method (Facione, 1990; Facione \& Facione, 1994). A limitation of this instrument for the purposes of the current project is that it does not contain any discipline-specific content.

In a study conducted by Chau et al. (2001) that utilized videotaped vignettes, it was observed that students' knowledge, measured by a nursing knowledge test, significantly improved between years 1 and $2(\mathrm{~F}=23.99, \mathrm{df}=1, \mathrm{p}<0.001)$ of their program. Six experienced nurse teachers and lecturers determined the content and face validity of the nursing knowledge test. No significant difference, however, was found in the pre- and posttest CCTST scores for critical thinking between years 1 and $2(\mathrm{p}=0.93)$.

These results are similar to those obtained by Saucier, Stevens and Williams (2000) who also used the CCTST to evaluate critical thinking scores after using computerassisted instruction as compared to a written nursing process. They found there was no increase in critical thinking scores for either of the two educational strategies. When regressed with the case study strategy, pre-CCTST scores were predictive of post-CCTST ( $r=0.41, \beta=0.468, p=0.0001)$ scores, while the written nursing process strategy was not. Using a multiple regression model, a little over 15 percent of the variance in the postCCTST scores $\left(\mathrm{R}^{2}=0.1571\right)$ was accounted for. 
The above studies differ when compared to the results found by Ravert (2008). Ravert used the CCTST to evaluate critical thinking scores for three different groups of baccalaureate nursing students: a human patient simulator (HPS) group (n = 12), a non-human patient simulator (non-HPS) group $(n=13)$, and a control group $(n=15)$. All three groups experienced a moderate (control group) to large (HPS and non-HPS) effect size change in critical thinking scores.

The California Critical Thinking Disposition Inventory. The California Critical Thinking Disposition Inventory (CCTDI) is designed to measure the affective, attitudinal dimension of critical thinking (Bondy et al., 2001; Stone et al., 2001). It is often used in conjunction with the CCTST. The CCTDI is a 75-item Likert style attitudinal survey that is designed to be completed in 20 to 30 minutes. Individuals respond to items in terms of their level of agreement on a 6-point scale, ranging from strongly disagree to strongly agree (Hicks-Moore \& Pastirik, 2006; Stone et al., 2001; Wangensteen, Johansson, Bjorkstrom, \& Nordstrom, 2010). In the CCTDI, each subscale measures a mental attribute, specifically the seven critical thinking dispositions that were identified by the Delphi panel (Bondy et al., 2001). The seven subscales are truth-seeking, openmindedness, analyticity, systematicity, self-confidence, inquisitiveness, and maturity (Bondy et al, 2001; Stone et al., 2001). A score is reported for each of the seven subscales and an overall score, which is derived from mathematically equal contributions from each subscale (Facione, Facione, \& Sanchez, 1994).

Cronbach’s alpha internal consistency reliability coefficients for the overall CCTDI were .90, .91, and .90 in a sample of diverse college students (Bondy, et al., 2001; Facione et al, 1994). For the seven CCTDI subscales, coefficients ranged from .71 to .80 
in a pilot sample and .60 to .78 in two later samples (Bondy et al., 2001). Factor analysis procedures were utilized to assess the construct validity. Several of the items loaded on more than one factor. Means for each scale’s factor loadings ranged from .39 for analyticity to .528 for self-confidence (Bondy et al., 2001; Facione et al. 1994). As a result, the retention of 75 items that loaded highest on the seven factors were subsequently retained as the seven subscales described above.

Hicks-Moore and Pastirik (2006) acknowledge that the CCTDI has been used in several nursing studies, but has shown conflicting results. Fero et al. (2010) utilized a convenience sample of 36 nursing students to measure critical thinking skills and simulation-based performance using videotaped vignettes (VTV) and high-fidelity human simulation (HFHS). To provide greater study power and to reduce error variance associated with individual differences, Fero et al. (2010) chose a quasi-experimental cross-over design. To compare the VTV and the HFHS performance scores, Fero et al., 2010) chose a Fleiss crossover binary response chi-square method. Lastly, to test the relationship between CCTDI scores and the simulation-based performance scores a Cramer's V was conducted. The relationship between videotaped vignette performance and critical thinking disposition scores was not statistically significant (Cramer's V = $0.145, p=0.683)$. However, a statistically significant relationship was found between overall high-fidelity human simulation performance and CCTDI scores (Cramer's V = $0.413, \mathrm{p}=0.047)$.

Stone et al. (2001) developed a survey to reflect the skills and dispositions of the CCTST and CCTDI instruments. Respondents were asked to indicate, using a 4-point Likert scale, the degree to which they believed each of the listed skills and dispositions 
were essential to practice nursing competently. The survey was distributed to the dean or program director for each NLN-accredited baccalaureate and higher-degree nursing program. A total of 632 surveys were distributed, and 338 surveys were completed and returned for an overall response rate of 53\%. Respondents indicated that the skills and characteristics underlying the framework for the CCTST and CCTDI were important to the practice of nursing, but Stone et al. (2001) found the evidence in this specific study suggested that the critical thinking skills measured by the CCTDI did not relate to critical-thinking skills that are relevant to nursing.

Wangensteen et al. (2010) studied whether background data had any impact on the critical thinking dispositions among new graduate nurses in Norway. They found that graduate nurses had an overall mean CCTDI score of 300.3, which indicates a positive inclination towards critical thinking. In regards to critical thinking and background data, it is interesting to note that a greater proportion $(\mathrm{p}<.001)$ of nurses older than 30 years of age had high CCTDI total scores compared with nurses younger than 30 years of age.

Health Education Systems Incorporated Exam. The Health Education Systems Incorporated (HESI) exam (Elsevier, 2006) was developed to assess students’ knowledge and their ability to apply nursing concepts within specific content areas (Morrison, Adamson, Nibert, \& Hsia, 2008). HESI offers two types of exams. Specialty exams are designed to measure a student’s ability to apply concepts related to specific clinical nursing content areas. These exams usually consist of 50 test items. The other type of exam is the HESI exit exam. The exit exam is more comprehensive and is designed to be administered at or near the completion of an academic program. It is longer, with 150 multiple choice items (Lavandera et al., 2011; Morrison et al. 2008). The exit exam is 
frequently used by nursing programs as a predictor of student preparedness for the National Council Licensure Examination (NCLEX) for registered nurses (Morrison et al., 2008; Spurlock \& Hunt, 2008).

According to Morrison et al. (2008), the concepts from Paul's critical thinking theory and Bloom's cognitive taxonomy serve as the basis for the development of critical thinking test items for both of the HESI exams. The test items, according to Morrison et al. (2008), are written and reviewed by nurse educators and clinicians who evaluate the merit of the items as current measures of nursing practice. Subsequently, all of the test items that are proposed are reviewed by HESI nurse educators and customized, as needed, by HESI editors. Every test item is then categorized by several subject areas and each subject area provides subset scores. The HESI Predictability Model, a proprietary mathematical model, is used to calculate the scores for both HESI exams (Lavandera et al., 2011; Morrison et al, 2008). Test items are individually weighted based on the level of difficulty, which Morrison et al. (2008) indicates "is determined by dividing the number of correct responses to the item by the total number of responses to that item, thereby deriving a percentage of correct responses to the item” (p. 222).

The psychometric properties of the HESI exams are well established. Morrison et al. (2008) indicates HESI determines the reliability of both exams by conducting an item analysis on each exam that is administered and returned to the company for a composite report of the aggregate data. To measure the exams’ overall reliability, a Kuder Richardson Formula 20 is calculated for every exam that is administered. Data obtained from these calculations are subsequently used to estimate the reliability of an exam prior to administration. Reliability estimates are recalculated every time a HESI exam is 
scored. Validity of the HESI exams is an ongoing process and determined by an assessment of content validity, construct validity, and criterion-related validity as described in classical test theory (Morrison et al., 2008). Morrison et al. found this to be a limitation and concluded that additional approaches are necessary to establish quantifiable evidence of validity.

A limitation of this instrument in relation to the current project is that it was not designed to measure critical thinking skills. Rather, it was designed to assess student competency and evaluate achievement of curricular outcomes. It is often used for progression policies and as a predictor of students’ NCLEX outcomes.

Spurlock and Hunt (2008) found the HESI exit exam was not able to accurately predict NCLEX registered nurse outcomes for new graduates. More recent research conducted by Lavandera et al. (2011) and a review of the literature completed by Harding (2010) however, found the HESI exit exam scores were a successful predictor of NCLEX success. It is important to note that in both the Lavandera et al. (2011) study and the Harding (2010) literature review, the HESI scores were not helpful in predicting NCLEX failure.

Health Sciences Reasoning Test. The Health Science Reasoning Test (HSRT) is designed specifically for health sciences and health care professional preparation programs. The test consists of 33 multiple-choice questions designed to be completed in 50 minutes (Insight Assessment, 2011). The HSRT assesses five critical thinking cognitive skills identified by the Delphi experts and includes interpretation, analysis, evaluation, explanation, and inference with subscales for inductive and deductive reasoning (Insight Assessment, 2011; Sullivan-Mann, Perron, \& Fellner, 2009). The 
overall KR-20 for the HSRT was 0.77 to 0.83 (Maneval, et al. 2012; Panns, Sermeus, Hieweg, \& Van der Schans, 2010).

In the HSRT, respondents are required to select one correct choice for each test question. The questions present necessary informational content in text-based and diagrammatic formats (Insight Assessment, 2011). Questions require respondents to draw inferences, make interpretations, analyze information, draw warranted inferences, identify claims and reasons, and evaluate the quality of arguments (Insight Assessment, 2011). Insight Assessment (2011) indicates scores on the HSRT have been found to predict successful professional licensure and high clinical performance ratings.

Insight Assessment (2011), which was established by Peter A. Facione in 1986 as the California Academic Press, indicates the HSRT total score targets the "strength or weakness of one's skill in making reflective, reasoned judgments about what to believe or what to do” (n.p.). Sullivan-Mann et al. (2009) tested the effect of simulation on nursing students' critical thinking scores using the HSRT. The HSRT was given as a pretest and posttest to both the experimental and control groups. The researchers found that for the experimental group, critical thinking scores on the HSRT posttest increased (mean = 21.07, $\mathrm{SD}=3.58, \mathrm{p}<.05$ ), after exposing nursing students to three additional simulation scenarios compared to the control group (mean $=19.73, \mathrm{SD}=3.09, \mathrm{p}>.05)$ who did not answer significantly more questions correctly on the posttest than the pretest. A limitation of this particular study was the small sample size ( $\mathrm{n}=<30$ students in each group).

Holistic Critical Thinking Scoring Rubric. Facione and Facione (2011) developed a four level Holistic Critical Thinking Scoring Rubric (HCTSR) based on the CCTST and CCTDI to assess critical thinking skills and some of the dispositions identified by the 
Delphi project. The HCTSR provides criteria for assigning a rating to one of four levels ranging from strong to weak critical thinking. These four levels can then be used to score critical thinking demonstrated by students in essays, projects, presentations, group decision making activities, or clinical practices. To achieve overall success, many items must come together including critical thinking, content knowledge, and technical skills. In scoring, however, the focus of the evaluation is only on critical thinking, excluding the other two items (Facione \& Facione, 2011).

Utilizing the HCTSR involves training of the raters, usually two, who will be using the tool. The two raters individually evaluate an assignment, and if there is disagreement between the raters there are three possible ways to reach a solution. Facione and Facione (2011) state, "resolution can be achieved by a conversation between the two raters regarding their evaluation; by using an independent third rater; or by taking the average of the two initial ratings” (np). Averaging two ratings though, is strongly discouraged. It is feasible for one rater to utilize this tool, but final ratings should not be assigned until a number of assignments have been reviewed and given preliminary ratings (Facione \& Facione, 2011).

Hicks-Moore and Pastirik (2006) used the HCTSR to measure six key competencies of critical thinking: interpretation, analysis, evaluation, inference, explanation, and self-regulation. They found the HCTSR was a reliable tool for evaluating critical thinking in nursing students. These authors specifically studied critical thinking in regards to developing a concept map. In their study, nursing students $(\mathrm{n}=18)$ developed several concept maps throughout their clinical practice experience, but submitted only their final concept map for scoring. To facilitate consistency in the 
scoring of the concept maps, the clinical instructors attended an informational session, which was led by the two researchers to review scoring concept maps with the HCTSR. The final concept map was then scored by the clinical instructor. The score given by the clinical instructor was blinded and then the two researchers reviewed and rescored the final concept map. An intraclass correlation coefficient of 0.81 was achieved, indicating that both coders were in agreement with the level of critical thinking identified in the concept map the majority of the time (Hicks-Moore \& Pastirik, 2006).

There were limitations to using the HCTSR. First, the HCTSR had not previously been used in nursing. Second, the HCTSR uses generic terms to describe critical thinking competencies, which makes it difficult to translate to nursing and the concept map process. This limitation would require some modification of the tool to increase its applicability and usefulness to nursing practice. Lastly, despite training to the use of the HCTSR, some faculty had difficulty interpreting the terms and applying the rubric specifically to concept maps.

Minnesota Test of Critical Thinking. Edman, Bart, Robey, and Silverman (2000) state the Minnesota Test of Critical Thinking (MTCT) is “designed to measure both critical thinking skills and a key disposition of critical reasoning: the willingness to evaluate arguments that are congruent with one's own goals and beliefs critically” (p.3). The MTCT is a fairly new tool and was designed to measure critical thinking skills consistent with the American Philosophical Association's definition and taxonomy of critical thinking (Edman et al., 2000; Edman, Bart, Robey, \& Silverman, 2004). Two forms of the tool are available. Form A has 64 items and Form B has 61 items. The items address the six skills defined by the Delphi Study: interpretation, analysis, evaluation, 
inference, explanation, and self-regulation (Edman et al. 2000; Edman et al., 2004).

Edman et al. (2004) state "participants are asked to rate each statement in terms of its importance to them in making such a judgment. Ratings are made on a 5-point scale with anchors of 1 = Not at all important and 5 = Extremely Important” (p.5).

Edman et al. (2000) conducted a study with 210 students from a wide range of academic disciplines enrolled in a post-baccalaureate teacher-training program. The overall Cronbach’s alpha for Form A was .76 and .69 for Form B. However, the researchers found instability of the subscales scores (ranging from -.28 to .61) indicating the need for caution in interpretation. These same researchers conducted another study (Edman et al., 2004) involving 151 students from a wide range of academic disciplines. Again, the students were enrolled in a post-baccalaureate teaching training program. This study involved the participants completing both Form A and Form B for a total of 125 items. The overall Cronbach alpha coefficient was .78 with the six subscales ranging from $\alpha=0.29$ (interpretation) to 0.64 (analysis). The Pearson product-moment correlations among the scales and the total score were all positive, and all but two of the correlations were significantly different from $0(\mathrm{p}<.05)$. Specifically, the correlations between the explanation and inference $(r=.11)$ and between the explanation and selfregulation $(\mathrm{r}=.05)$ subscales were not significantly different from 0 .

The low Cronbach alphas suggest that the test items do not all measure the same construct, that they measure different aspects of the construct, or that the items or subscales are unstable. Edman et al. $(2000,2004)$ and Staib (2003) conclude that this instrument has potential, but would benefit from further revisions and refinement. 
Interestingly, no additional research could be found in the nursing literature that utilized this instrument.

Other Measures. Spurlock and Hunt (2008) and Staib (2003) recognize there are also indirect measures of critical thinking ability in nursing. These options include the NLN Diagnostic Readiness Test for registered nurse licensure (National League for Nursing, 2012), and the National Council Licensure Examination for Registered Nurses (NCLEX-RN) exam (National Council of State Boards of Nursing, 2012a). While each of these exams is not specially designed to measure critical thinking, they can provide an analysis of student performance in critical thinking. Staib (2003) describes two other tests that can be used to measure critical thinking. The Ennis-Weir Critical Thinking Essay test (Ennis \& Weir, 1985) uses written essays to evaluate a given argument and the Cornell Critical Thinking Tests (CCTT), which are designed to measure a wide range of critical thinking abilities. A major limitation of both the Ennis-Weir and the CCTT is that they have not been used in nursing research.

Based on this review of instruments to measure critical thinking, there is a need to develop accurate and reliable measures of critical thinking in nursing students and new graduate nurses. The instruments reviewed were not specifically designed to be used in nursing, and as a result, may lack a connection to the unique context of nursing practice, ultimately leading to inconsistent findings in the research that has been conducted . However, based on this review, the Health Science Reasoning Test (HSRT) (Insight Assessment, 2011) has the best potential because it is designed specifically for the health sciences and health care professional preparation programs compared to some of the other instruments reviewed. 


\section{Educational Strategies to Develop Critical Thinking Skills}

A variety of educational strategies have been utilized to teach critical thinking including reflection, concept maps, case studies, problem-based learning, questioning, and simulation (Forneris, 2004; Hoffman, 2008; Profetto-McGrath, 2005; Rochmawati \& Wiechula, 2010; Simpson \& Courtney, 2002; Staib, 2003). Many of these strategies can be implemented either individually or in a group setting. A search of CINAHL, PsycINFO, Cochrane, PubMed, and Google Scholar was conducted to retrieve literature published between 2000 and 2011. Additional searches were then completed expanding the time frame back to 1995 in an attempt to gather more research. Key words to guide the literature search were identified through the formulation of a PICO (Population, Intervention, Comparison, and Outcome) (Melnyk \& Fineout-Overholt, 2011) question related to critical thinking and educational strategies. Specific key words or Medical Subject Headings (MeSH) (U. S. National Library of Medicine, 2012) included: “clinical decision making,” “clinical judgment,” “clinical reasoning,” “emotional intelligence,” “critical thinking,” “problem identification,” "reflection,” “reflective thinking,” “case studie, *” “concept maps,” “PBL,” “problem-based learning,” “question,*” “questioning,” “on-line learning,” “simulation,” “computer simulation,” "patient simulation,” “nurs* student,” “novice nurs, *” "graduate nurs, *” “educational strategies,” “teaching,” and “nursing education.”

Approximately 223 articles were identified by the search strategies. A total of 71 research studies were included in the initial literature review. Studies were excluded that addressed only self-confidence, self-efficacy, individual satisfaction, clinical skills, clinical competence, curriculum revisions, or residency programs. Studies were also 
excluded if they did not measure critical thinking, use a specific educational strategy, or involve nursing students, graduate nurses, or registered nurses. One study, authored by Shepherd, Kelly, Skene, and White (2007), was included although it did not specifically measure critical thinking. It studied the impact of three different educational interventions on knowledge and skill acquisition of graduate nurses. In general, there is a lack of research comparing different types of educational interventions and research involving graduate nurses, which is why this article was deemed important and included in the literature review. Three systematic reviews were included in the review. In addition a systematic review and five articles which could not be obtained via document delivery were excluded. As a result, 35 studies (see Appendix A) were selected for the final literature review.

Reflection. To achieve a consistency of understanding of using reflective learning as an educational intervention, Forneris and Peden-McAlpine (2006) reviewed the work of six contemporary educational theorists who all shared similar perspectives on thinking in practice. Forneris (2004) and Forneris and Peden-McAlpine (2006) identified four core attributes of critical thinking: reflection, context, dialogue, and time. These four attributes are vital to operationalizing the critical thinking process in practice. Forneris and Peden-McAlpine (2006) linked these four attributes to educational strategies which could be utilized in nursing education. The three strategies included narrative exemplars, reflective journaling, and interactive critical conversations which can occur through either group or individual discussions.

Butler (2004), Plack and Santasier (2004), and Teekman (2000) describe two types of reflection based on the work of Donald Schon (1987). Thinking about actions while 
engaged in them is referred to as either reflection-in action or reflective thinking-foraction (Schon, 1987). The second type of reflection is referred to as either reflection-onaction or reflective thinking-for-evaluation, which involves thinking about an event, analyzing what occurred, and trying to get meaning from the experience or situation (Schon, 1987). This type of reflection is most often completed through writing, although it can also occur as a dialogue (Butler, 2004; Rochmawati \& Wiechula, 2010; Sewell, 2008).

Teekman's (2000) research found strong support that reflection was used first for action, no matter whether this thinking occurred prior to, during, or after the action. On the other hand, reflective thinking-for-evaluation occurs following the action after the individual has created meaning for the situation. Although this was not supported in Teekman's study, this type of reflection is considered a higher level of reflection and is assumed to center on critical inquiry. One of the key implications found in Teekman's (2000) research was the individual's use of self-questioning, during the data analysis, even though the individuals were not always aware of it. Teekman proposed that if increased self-questioning was utilized, it would lead to a shift from problem solving to problem posing. Teekman (2000) states

Problem solving tends to be "reactionary" in its approach. Problem posing on the other hand is more anticipatory in that it doesn't require a problem to be present. Knowledge gained from problem posing is more likely to be transferable to other situations, and settings, than that gained from problem solving. (p.1133) Forneris and Peden-McAlpine (2007) found improvements in critical thinking skills when reflective contextual learning interventions were implemented as part of a standard 
nursing orientation program for novice nurses during the first six months of their practice to improve critical thinking during their transition from education to professional nursing practice. Teekman (2000) on the other hand, found no improvement in critical thinking based on the use of reflection. A major difference between the two studies was that Forneries and Peden-McAlpine (2007) studied new graduate nurses with less than one month of experience, while Teekman's sample consisted of registered nurses who were actively working. The length of employment of the registered nurses was unknown. This difference was a major limitation for the Teekman study. Experienced nurses who have been employed for a longer period of time have had more clinical experiences and complex situations, which can help them to develop critical thinking skills, ultimately impacting their ability to make good logical decisions.

Overall, there is a lack of research studying the phenomenon of reflection in nursing. Smith (1998) completed a longitudinal study investigating the ways in which 25 undergraduate student nurses reflected about practice as they progressed through a 3-year program in adult nursing. Students were asked to make a written record of any incident that occurred during their clinical practice experience which had made a particular impression upon them. A total number of 47 records were analyzed. Data were analyzed using open coding and ultimately, 17 main categories were identified. Smith found some evidence that reflection involved the integration of practice experience and academic knowledge and that there is a reassessment of old perspectives so that some views and ideas may be rejected, while others are retained. Limitations of this study for the current project include that it was published in 1998 and the research design. Specifically, in this longitudinal study it failed to differentiate between participants, resulting in the risk of 
concluding that all participants developed critical thinking in the same way, or along an established continuum, which may not be correct.

Concept maps. Concept maps are an educational strategy utilized to promote critical thinking. They have been used in physics, chemistry, biology, psychology, history, engineering, literature, and mathematics education (Hsu, 2004; Wheeler \& Collins, 2003). A concept map is a graphic representation and organization of a specific set of concepts that allows visualization of relationships among concepts (Daley, Shaw, Balistrieri, Glasenapp, \& Piacentine, 1999; Ferrario, 2004; Gul \& Boman, 2006; HicksMoore \& Pastirik, 2006; Hsu \& Hsieh, 2005). Concept maps require students to prioritize concerns, organize a large quantity of patient information, develop nursing interventions, and identify missing data. Joel (2007) suggests there is no right or wrong way to develop a concept map. Various designs can be used to develop a concept map including the spider map, the hierarchical or chronological map, flow charts with linear progress, or a systems map (Joel, 2007). Ferrario (2004) found concept maps promote autonomous, self-regulated thinking, which is necessary for good clinical decision making.

There are benefits to using concept maps as an educational strategy. Gul and Boman (2006) and Hicks-Moore (2005) assert concept maps are thought to enhance understanding about a particular subject because it allows for visualization of concept relationships. In order to create a meaningful concept map, an individual must think about the key concepts, sub-concepts, and how to identify links and cross-links among all of them. It is also possible to evaluate how a student thinks by creating a concept map. Specifically, the idea and words selected by the learner can be analyzed and rated according to predetermined criteria related to a range of possible differences in simple to 
more complex thinking processes (Gul \& Boman, 2006; Hicks-Moore, 2005). Concept maps can link theoretical material with clinical practice. One final benefit of concept mapping is that it is an inexpensive strategy that can be easily included in educational and orientation programs (Wilgis \& McConnell, 2008).

Limitations of concept maps include the amount of time required for students to learn how to develop them. If students are not comfortable with the process, they often report feeling lost while creating a concept map. Initially, faculty also requires more time to learn how to read and interpret concept maps, and the development of these skills can also be time consuming. Also, prior to using this strategy, faculty needs to have a complete understanding of it. The time required to learn and really understand concept maps would be similar to any new educational strategy that is implemented (Gul \& Boman, 2006; Hicks-Moore, 2005; Messecar, 2007).

Several research studies have been conducted examining concept maps and critical thinking. Daley et al. (1999), Hicks-Moore and Pastirik, (2006), Hsu (2004), Hsu and Hsieh (2005), Pilcher (2009), and Wilgis and McConnell (2008) found problem solving and critical thinking skills improved by completing concept maps.

Daley et al. (1999) used concepts maps to develop critical thinking in 54 senior nursing students. The students developed three concept maps as a requirement for a clinical course. The concept maps of 18 students were randomly selected for data analysis and were subsequently scored by faculty. A scoring formula, based on Ausubel, Novak, and Hanesian’s (1986) assimilation theory, awarded points for the students’ ability to create propositional links and analyze and synthesize information. Reliability was established by obtaining two independent scores on each concept map. Correlation 
between the two independent scores equaled .82 . Content validity was judged by two educational researchers. Results demonstrated a statistically significant difference $(\mathrm{p}=$ $.001)$ in concept mapping scores between the first $(\mathrm{M}=40.38)$ and last $(\mathrm{M}=135.55)$ concept maps completed by the students.

Hicks-Moore and Pastirik (2006) observed that concept maps do assist with the development of critical thinking skills. Eighteen second year nursing students enrolled in a five week concentrated hospital-based clinical practicum submitted concept maps throughout the clinical rotation, and their final concept map was scored. The Holistic Critical Thinking Scoring Rubric (HCTSR) scores for the concept maps ranged from 2 to 4 (median $=2.83, \mathrm{SD}=0.71)$. A HCTSR score of 1 reflects low levels of critical thinking and a score of 4 reflects a high level of critical thinking (Hicks-Moore \& Pastirik, 2006). Based on the competencies identified in the HCTSR instrument, Hicks-Moore and Pastirik (2006) found "a score of ' 3 ' demonstrated critical thinking 'most of the time”” (p.7).

To facilitate consistency in the scoring of the concept maps, the clinical instructors attended an informational session, which was led by the two researchers to review scoring concept maps with the HCTSR. The score given by the clinical instructor was blinded and then the two researchers reviewed and rescored the final concept map. Scores given by the clinical instructors and those given by the researchers were then compared to further establish interrater reliability. An intraclass correlation coefficient of 0.81 was achieved, indicating that both coders were in agreement with the level of critical thinking identified in the concept map the majority of the time (Hicks-Moore \& Pastirik, 2006). 
Limitations in this study included that the HCTSR had not previously been used in nursing. Additionally, Hicks-Moore and Pastirik (2006) indicated the HCTSR used generic terms to describe critical thinking competencies, making it difficult to translate to nursing and the concept map process. This limitation would require some modification of the tool to increase its applicability and usefulness to nursing practice. Lastly, despite training to the use of the HCTSR, some faculty had difficulty interpreting the terms and applying the rubric specifically to concept maps, thereby decreasing fidelity to the method and reliability in scoring.

In an experimental study, Hsu (2004) randomly assigned participants to either a control $(n=49)$ or experimental group $(n=43)$. Students in the experimental group participated in six problem-based learning scenario discussions during the 16-week semester, while the control group received traditional teaching. Students in the experimental group received significantly higher proposition $(\mathrm{p}<0.000)$ and hierarchy ( $p<0.000$ ) scores for their concept maps than the control group. There were, however, no significant differences in cross-links $(p=0.386)$ or example $(p=0.274)$ scores between the two groups. It is important to note that in this study, most of the participants, 26 out of 43 in the experimental group, and 46 out of 49 in the control group, obtained low scores (scores of 10 or less, when the maximum possible was 30) (Hsu, 2004). The authors indicated they thought the reason for the low scores was directly related to how the concept maps were scored by the raters.

Interrater reliability was a major limitation in this particular study. One rater assessed the concept maps in such a strict manner that unless the concept map was completely correct, the student received a zero in the category of examples. To address 
this limitation, both raters should have scored a concept map simultaneously and independently recorded their scores. Then, the scores should have been compared, and agreement between raters should have been calculated. In addition, a correlation coefficient could have been computed to demonstrate the strength of the relationship between one rater's scores and another's. The intraclass correlation coefficient could also be used to assess interrater reliability (Polit \& Beck, 2012).

Wilgis and McConnell (2008) studied a small convenience sample of graduate nurses $(n=14)$ to assess differences between concept maps completed before and after a hospital 2-day nursing orientation program. Pre-concept maps were completed on the first day of orientation. Post concept maps were created at the end of the orientation program on the second day. Schuster's concept map care plan evaluation tool (Schuster, 2002) was adapted by Wilgis and McConnell to reflect key program objectives and case studies used for the concept maps. Subsequently, this tool was used to score the concept maps. The post-concept map mean score was substantially higher (16.43) compared to the preconcept map mean score (14.07). A paired sample $t$-test revealed a significant improvement in the post-concept maps $(t=-2.797 ; d f=13 ; \mathrm{p}=0.008)$. Only one of the graduate nurses in this study had prior experience in developing maps. In addition, this particular individual was also the only graduate nurse with a baccalaureate degree. A few limitations of this study include the small sample size, potential threat to internal validity due to how the study was conducted, and the number of raters involved in scoring the concept maps was not disclosed to determine if interrater reliability was an issue.

Two studies indicated concept maps helped critical thinking skill development, but both study reports lacked specific data analysis details. Hsu and Hsieh (2005) studied 
43 nursing students enrolled in a 2-year program and Pilcher (2009) studied seven newly hired inexperienced nurses. Hsu and Hsieh (2005) failed to report specific results from the data analysis. They described the process used for grading the concept maps, but no scores were reported. Pilcher (2009) specific details regarding how the participants scored on both the pretest and posttest concept maps. Therefore, caution needs to be used when evaluating the results of these two particular investigations.

Wheeler and Collins (2003) conducted a quasi-experimental, pretest-posttest design with a control group $(\mathrm{n}=32)$ to determine whether baccalaureate nursing students who used concept mapping to prepare for clinical experiences during one semester (15 weeks) of their junior year would show greater improvement in critical thinking skills than those who did not. The experimental group $(n=44)$ was taught to use concept mapping of patient information to prepare for clinical experiences while the control group did not have experience with concept mapping. The California Critical Thinking Skill Test (CCTST) was used to measure critical thinking skills. Analysis of covariance (ANCOVA) was performed on pretest and posttest scores of the overall CCTST and the subscales, with pretest scores used as a covariate; a significant $F$ was obtained for each of the tests. Post hoc tests found that the mean experimental group score on the posttest did significantly differ $(\mathrm{p}=0.02)$ from the pretest mean score on the overall CCTST, but the scores were not significantly different for the control group $(\mathrm{p}=0.52)$. Since no statistically significant difference was found between the groups, this suggests that both methods of clinical preparation were effective in helping students develop critical thinking skills. 
A limitation of this study was the study design. The experimental group was exposed to the traditional method during the second half of the semester prior to measuring critical thinking skills with the CCTST, which could have influenced the overall CCTST scores. Another limitation of the study was the potential threat to validity as a result of potential contamination of the control group by the experimental group.

Clayton (2006) completed a systematic review of seven studies that used concept maps as an educational strategy in nursing education, but not necessarily as a strategy for developing critical thinking skills. In three studies, students using concept maps were able to attain higher mean exam scores as compared to other students. In two other studies that examined changes in scores among nursing students for concept maps, comparing initial concept maps with later ones, only one of the groups of researchers reported a significant increase in scores $(t=5.69, p=0.001)$. One study that utilized concept mapping as part of an independent learning package to teach science to registered nurses $(n=14)$ returning for their baccalaureate degrees suggested student thinking changed from the beginning of the course to the end of the course. However, the findings were not supported by reporting of any statistical information. Also, the control of other extraneous factors, such as situational or participant variables, was not addressed by the study designs. The last study involved a small sample size $(n=6)$ and identified that beginning nursing students had difficulty linking concepts of the nursing process and basic science. An important conclusion regarding this systematic review was that using concept maps to improve critical thinking skills was an appropriate educational strategy. A limitation of all but two of these studies, for purposes of informing the current project, was that they involved nursing students rather than new graduate nurses. Wilgis 
and McConnell (2008) studied new graduate nurses and Pilcher (2009) studied both new graduates and nurses who were new to working in a neonatal intensive care unit, but these studies were limited by small sample sizes, the use of convenience sampling, and a lack of specific data results. Overall, many of the studies had small sample sizes; lacked randomization; and lacked instrument and/or rater reliability and validity. Finally, differences in the educational strategies utilized make it difficult to generalize the findings of the various studies.

Case studies. Case studies are another educational strategy that applies theoretical and educational subject matter to replications of real-life situations (DeSanto-Madeya, 2007; Hoffman, 2008; Popil, 2011; Tomey, 2003). Case studies are similar to problembased learning, but in case studies the knowledge precedes the problem (Joel, 2007). The focus of case studies is the application of knowledge rather than simple recall of content. After a brief clinical scenario is presented, the case study continues with a series of questions for the learners to address (Hoffman, 2008). Case studies are intended to be used with groups of learners and have been used to teach nursing, health care, law, business, and social science students (Popil, 2011). This approach to learning assists with the development of critical thinking skills by offering students the opportunity to analyze a case, identify problems, compare and evaluate different actions and consequences, and decide how to handle the situation, keeping in mind the outcomes of those actions (DeSanto-Madeya, 2007; Popil, 2011; Tomey, 2003). Case studies can be delivered through a variety of different educational strategies including written, oral, and video tape modalities, and most recently, in conjunction with simulation (Grossman, Krom, \& O’Connor, 2010; Tomey, 2003). 
Popil (2011) and Tomey (2003) found many benefits to using case studies. Case studies promote active learning and result in the development of critical thinking and effective problem-solving skills. Learners are exposed to complex situations where they can discuss and debate courses of action with other learners. Case studies help learners build on prior knowledge, integrate knowledge, and consider application for future situations. Case studies can encourage teamwork and accountability among group members.

While there are many benefits to using case studies, Popil (2011) and Tomey (2003) found there are also limitations. They cite lack of learner motivation, unprepared facilitators, and the need to have appropriate resources to develop good case studies as important to outcomes. Finally, case studies were found not to be an appropriate strategy for teaching concrete facts (Popil, 2011; Tomey, 2003).

Grossman et al. (2010) found there was a statistically significant difference $(\mathrm{t}=-4.05, \mathrm{p}<0.0001)$ on final exam scores between groups of nursing students who had been taught with case studies $(\mathrm{n}=32)$, compared to students who had less exposure to case studies ( $\mathrm{n}=49)$. However, earlier Abbate (2008) had employed case studies as a collaborative online educational strategy with baccalaureate students $(n=57)$ participating in an online pharmacology course and measured critical thinking in a pretest-posttest design using the Assessment Technologies (ATI) Critical Thinking Assessment Exam and her findings differ from Grossman et al. (2010). The mean difference (1.5087) on overall critical thinking ability did not change $(p=.214)$ between students' pretest $(M=70.7895)$ and posttest scores $(M=72.2982)$. Additionally, no differences were achieved in the six critical thinking skills of the exam, which included 
interpretation (pre- 69.6018, posttest 72.8105, p = .182); explanation (pre- 74.4696, posttest 75.2339, $\mathrm{p}=.7581$ ); inference (pre-56.6772, posttest 57.0491, $\mathrm{p}=.857$ ); evaluation (pre- 74.1228, posttest 76.3158, $\mathrm{p}=.358$ ); self-regulation (pre- 84.6491, posttest 86.8421, $\mathrm{p}=.440$ ); and analysis (pre- $\mathrm{M}=76.6070$, posttest $\mathrm{M}=75.8123, \mathrm{p}=$ .789). Of interest, however, because of its parallel to literature addressing the natural development of critical thinking, is the finding that the correlation between pretestposttest differences in the overall score and the students' ages did not attain significance, despite apparent trending in a positive direction $(r=.257, \mathrm{p}=.058)$.

Howard, Ross, Mitchell, and Nelson (2010) conducted a quantitative, quasi-experimental, two-group pretest-posttest design to compare learning gained from case studies delivered by one of two teaching strategies, human patient simulator (HPS) or by a faculty facilitated interactive case study (ICS) approach. Both case study scenarios covered the same subject matter. Senior nursing students $(n=49)$ from three different nursing programs were randomly assigned to one of the two teaching strategy groups, HPS or ICS. The adjusted mean posttest scores for students in the HPS group were significantly higher $(\mathrm{p} \leq 0.05)$ on a custom designed Health Education Systems, Inc. (HESI) examination that focused on critical thinking test questions, compared to the adjusted mean posttest HESI scores for the students who participated in the ICS group. Additionally, an ANCOVA was used to determine if posttest HESI scores varied among baccalaureate, accelerated baccalaureate, and diploma program students. No significant differences were found in posttest HESI scores for the senior level nursing students recruited for the study. It is important to note regarding this study that both strategies utilized a case study format; the actual delivery format of the case study was different. 
Saucier, Stevens and Williams (2000) compared using a case study delivered via a computer assisted instruction (CAI) to a written nursing process. Students $(n=59)$ did not demonstrate a significant increase $(\mathrm{p}=0.9112)$ in critical thinking based on pre and post CCTST scores using the case study approach via computer assisted instruction. The authors suggested that while CAI was indeed a time-efficient strategy, it did not compromise critical thinking as an outcome.

Of the four studies that employed case studies, the investigation by Saucier et al. (2000) was somewhat older compared to the other three. The sample sizes were small ( $n=49$ to 153), limiting the generalizability of the findings. All of the studies utilized different measurement tools and data analysis techniques. Finally, with the exception of one study, all of the studies included baccalaureate or diploma nursing students rather than graduate nurses, which were the focus of the current project.

Problem-based learning. Problem-based learning (PBL) is similar to case study learning. One of the main differences between PBL and case studies is that PBL is not necessarily dependent on prior knowledge (Joel, 2007). Individuals working with PBL should identify what they already know and more significantly, what they do not know. PBL removes the passive transfer of information from the teacher to the learner and replaces it with active participation, making individuals responsible for their learning regarding a particular situation or question (Bechtel, Davidhizar \& Bradshaw, 1999; Messecar, 2007). PBL uses real-life situations to take advantage of an individual's prior knowledge that can be used for the development of new concepts and reasoning (Bechtel et al., 1999; Chunta \& Katrancha, 2010; M. Jones, 2008; Wells, Warelow, \& Jackson, 
2009). The foundation of PBL is built upon the utilization of critical thinking skills to make decisions in the clinical setting (Garret \& Callear, 2001).

PBL involves using carefully designed and written problems that require a variety of skills from the learner. Examples of problem-based learning might involve the educator providing initial data regarding the patient's condition, either through a case study or simulation, and giving the graduate nurse time to collect data, analyze the data set, and arrive at the appropriate conclusion. Garrett and Callear (2001) suggest it is important to incorporate problem-based learning with competency-based education for assisting with the critical thinking and clinical judgment skills of new graduates (Bechtel et al., 1999). PBL is specifically designed for individuals to work in small groups to seek solutions to the problem (M. Jones, 2008; Oja, 2011; Wells et al., 2009; Yuan, Kunaviktikul, Klunklin, \& Williams, 2008). PBL is student centered and students take responsibility for their own learning. Consequently, Lyons (2008) advises a lack of student motivation could be an issue because students are accountable for their own learning.

Wells et al. (2009) identifies there are many benefits to PBL. PBL encourages students to think about an issue based on its individual merits. Students subsequently have to solve the issue by collecting and reflecting upon both the empirical and theoretical knowledge base and then bundling the data in a meaningful way. This skill is important for individuals working in health professions. The ability to solve problems is critical when dealing with a variety of unique and challenging situations often found in health care. Wells et al. (2009) also found PBL increases motivation, encourages team work, and shows an individual how to learn by "developing strategies for sourcing 
definitions, gathering rigorous academic information, data-analysis and hypothesis building and articulating the salience of their views within a multidisciplinary framework in a professional and confident manner substantiating their health care using an evidence based approach” (p. 193).

There are some difficulties in utilizing PBL as an educational strategy that must be mentioned. Wells et al. (2009) found that a small number of students do not succeed in a PBL learning environment. A few of the challenges in utilizing PBL include making sure each member of the group participates in the learning process; ensuring that the scenario or case study is well designed; and addressing potential group facilitator issues that may exist.

Overall, the research evidence is quite positive in regards to utilizing PBL as an educational strategy to increase critical thinking skills. The following studies, M. Jones (2008), Tiwari, Lai, So and Yuen (2006), and Yuan, Kunaviktikul, Lunklin, and Williams (2008) all reported statistically significant increases in the development of critical thinking skills when PBL was utilized as an educational strategy. Each study is described below in further detail.

M. Jones (2008) conducted a quasi-experimental, pretest-posttest study design to study the use of PBL as a teaching strategy and its impact on the development of critical thinking and communication skills in 60 second-year nursing students enrolled in a maternal-newborn nursing course at an associate degree college. Clinical groups were assigned to either the control group $(n=30)$ or the experimental group $(n=30)$ based on a coin toss. Both groups had the same course of study for the first two weeks, but during week three, students in the experimental group were verbally told during pre-conference 
about PBL strategies, the objective of PBL, and the evaluation process. The PBL strategies were continued throughout the remainder of the semester with the experimental group. Care plans and communication interactions were assessed at the beginning of the semester (pretest) and at the end of the semester (posttest) using Bloom’s cognitive and affective learning domains. Students in the experimental group were asked to keep reflective journals and the journal entries were categorized by common themes and student comments. Both groups showed improvement, but the students in the intervention group demonstrated a significantly greater increase in critical thinking and communication levels compared with the control group $(\mathrm{p}<0.000)$. Student feedback indicated it was easier to learn from the real experiences offered by PBL compared to the textbook. Limitations of this particular study include the lack of reliable and valid measurement tools, and no use of blinding of the facilitator to the intervention, which could have impacted the study results.

Tiwari et al. (2006) compared the effects of PBL and lecturing approaches on the development of students' critical thinking in year 1 undergraduate nursing students who were enrolled in a 4-year nursing program. The California Critical Thinking Disposition Inventory (CCTDI) was used to measure the students’ critical thinking in this study. A pretest CCTDI was administered to all nursing students $(\mathrm{N}=79)$ before randomly assigning students to either the PBL $(n=40)$ or the lecture $(n=39)$ groups. Students assigned to the PBL group underwent a 2-semester course on nursing therapeutics using PBL as the educational approach, while students in the lecture group also underwent a 2semester course on nursing therapeutics, using lecturing as the educational approach. The CCTDI was administered on completion of the PBL or lecture experience three additional 
times: at the end of the second semester (second time point), and repeated at 1-year (third time point) and 2-year intervals (fourth time point).

In examining the results, the PBL students had a significantly greater difference in overall CCTDI scores as compared with the lecture students at the second time point ( $\mathrm{p}=$ $0.048)$ and third time point $(\mathrm{p}=0.0083)$. At the fourth time point, 2 years later, the PBL students still had significantly greater differences in two subscale scores, Truthseeking $(\mathrm{p}=0.0173)$ and Systematicity $(\mathrm{p}=0.0440)$, as compared to the students who had received lecture. Additionally, individual interviews were conducted at each time point. Analysis of the qualitative interview data revealed differences in the students' perceptions of their learning experiences. The PBL students reported active participation during the learning process compared to the lecture students who reported passive listening. The PBL students found the experience enjoyable, inspiring and self-fulfilling, while the opposite was expressed by the lecture students, who expressed negativity regarding their learning experience.

Yuan et al. (2008) conducted a quasi-experimental, two group pretest-posttest design to study the effect of PBL on the critical thinking skills of 46 year 2 undergraduate nursing students. The students were equally and randomly assigned to either the experimental group $(n=23)$ or the control group $(n=23)$. The CCTST was used to measure critical thinking skills. The PBL approach was used as the educational strategy for the experimental group, while the lecture approach was used in the control group. In the PBL group, the students did small group work with five learning packages two hours a week for 18 weeks. In the control group, the teachers verbally delivered course content for two hours a week for 18 weeks. The same course content and core concepts were 
addressed in both groups. There was no significant difference in critical thinking skills at pretest $(\mathrm{p}=0.429)$, but a significant difference was found in critical thinking skills between the PBL and lecture groups at posttest $(\mathrm{p}=0.003)$.

To further examine PBL for use in the current project, two systematic reviews were evaluated. Oja (2011) completed one systematic review with five studies to determine if the use of PBL as an educational strategy had an effect on critical thinking outcomes. Only one study did not find a significant effect for PBL on critical thinking outcomes. This coincides with a study completed by Lyons (2008). Lyons conducted an experimental pre- post treatment comparative group design that studied the effects of two teaching methods on the critical thinking skills of fourth semester nursing students enrolled in a 17-week NCLEX-RN review course. A stratified random sampling technique was utilized. The treatment group $(n=27)$ received 12 PBL case scenarios and the control group $(n=27)$ received the traditional teaching method of lecture. The ATI Critical Thinking Test (Assessment Technologies Institute, 2002) was used to measure critical thinking skills prior to the beginning of the fourth semester in all 54 participants, and again after completion of the 17-week review course. An ANCOVA was performed on the posttest scores using pretest scores as the covariate. There were no observable differences in critical thinking scores when PBL was used, compared to the traditional lecture method $(\mathrm{p}=0.413)$. All of the other studies, however, showed a positive relationship between the use of PBL and nursing students' critical thinking skills, which were measured by a variety of standardized instruments including the Watson-Glaser Critical Thinking Appraisal (WGCTA), the California Critical Thinking Disposition Inventory (CCTDI), and the California Critical Thinking Skills Tests (CCTST). 
Different results were noted in a systematic review completed by Yuan, Williams, and Fan (2008). These authors found three studies reported some improvement, one study had mixed results, and one study did not show any improvement in critical thinking skills when PBL was utilized as an educational strategy. While Yuan et al. (2008) indicate that in theory PBL can promote students' critical thinking skills, the systematic review did not provide strong evidence about the effect of PBL on nursing students' critical thinking development. The authors indicate more research is needed before determining if this educational approach is really appropriate for developing critical thinking skills.

One of the challenges Yuan et al. (2008) identified in their review was the utilization of different standardized instruments to measure critical thinking skills. The tests may capture different dimensions of critical thinking. Also, validity and reliability of the instruments varied, which would have impacted the outcome measures.

Questioning. Questioning is another educational strategy that facilitates the development of critical thinking skills (Barnum, 2008; Boswell, 2006; Messacar, 2007; Phillips \& Duke, 2001; Simpson \& Courtney, 2002). Questioning helps new graduate nurses learn how to transfer theoretical knowledge into applied knowledge experience (Messacar, 2007). Bloom's taxonomy (Bloom, 1956) divides the way individuals learn into three domains. One of these is the cognitive domain, which emphasizes intellectual outcomes. Questions can be further divided into categories that are arranged progressively from the lowest level of thinking, simple recall, to the highest, creating new idea (Anderson \& Krathwohl, 2001; Barnum, 2008; Boswell, 2006). Questions can also be viewed as concrete, abstract, or creative. Finally, questions can also be classified as 
hypothetical, telling, planning, organizing, and Socratic (Boswell, 2006; Oermann, Truesdell, \& Ziolkowski, 2000).

Rubenfeld and Scheffer (2010) indicate the importance of Why questions. "Why questions imply a search for reason, purpose, meaning, and value. The word why is frequently used to initiate inquiry, provide logic, justify conclusions, and find causes” (p.2). When a nurse questions why something is happening to a patient, it can result in being a life-saving inquiry. Both clinicians and educators believe why questions encourage critical thinking (Rubenfeld \& Scheffer, 2010). In addition, the type of questioning is viewed as equally as important. Strategic, or high-level, questioning needs to be incorporated into the classroom, clinical and online environment. Questioning is a skill that needs to be taught and developed. To make this teaching strategy effective, faculty and preceptors need to carefully plan the questions they wish to incorporate into their teaching (Boswell, 2006; Messecar, 2007).

Barnum (2008) focused on a total of 712 questions posed between instructors and students during 23 observation periods. She identified the use of two distinct questioning patterns, nonstrategic and strategic questioning. Nonstrategic, or low-level, questioning supports knowledge and comprehension while strategic, or high-level, questioning appears to support critical thinking. Strategic questioning involves higher cognitive level questioning. Strategic questions were sequenced to initially target basic application and comprehension knowledge and allowed the instructor to estimate the students' knowledge and skill bases. Additional questions then targeted higher-level cognitive processes suitable for the students' academic knowledge and skill levels. These questions supported students in developing a process for thinking that allowed them to critically examine the 
situation (Barnum, 2008). An important conclusion from Barnum's study was that the majority of questions posed by the instructors (70.37\%) were classified as nonstrategic, which target lower-level cognitive processing skills, and only $17 \%$ were classified as strategic cognitive questions. The remaining $12.64 \%$ questions were classified as other and a specific definition was not provided.

In a study conducted by Phillips and Duke (2001), 585 questions from clinical faculty and preceptors representing three different scenarios were analyzed. Clinical faculty were found to ask a greater $(\mathrm{p}<0.001)$ number of questions overall than preceptors. In addition, clinical faculty asked more questions (34.9\%) from a higher cognitive level ( $\mathrm{p}<0.01)$ when compared to preceptors $(12.6 \%)$. Despite this finding, the authors noted that they believed both the clinical faculty and preceptors did not ask enough higher level questions, although, they did not report what they believed to be an appropriate number of questions to be asked.

These findings were similar to results reported by Barnum (2008) and Sellappah, Hussey, Blackmore, and McMurray (1998). Sellappah et al. (1998) studied the number and type of questions asked during two post-clinical conferences. The first post-clinical conference occurred between weeks 2 and 4 of the first rotation and the second postclinical conference occurred between weeks 2 and 4 of the final rotation. During both post-clinical conferences, clinical teachers asked more low level questions (92.2\%), specifically knowledge questions, than high level questions (4.4\%). Other results, which were statistically significant $(p=0.01)$, revealed more questions were asked at the second post-clinical conference compared to the first post-clinical conference. There was a significant difference in the number of low level questions asked at the first post-clinical 
conference compared to the second post-clinical conference $(p=0.01)$. Finally, there was no significant difference in the number of high level questions asked at the first postclinical conference compared to the second post-clinical conference $(p=0.66)$.

A limitation of questioning as an educational strategy is the lack of research related to the development of critical thinking skills based on the use of questioning. Research studies in the literature focused on the types and levels of questions asked, but they did not address their relationship to developing critical thinking skills. Additional research related specifically to the development of critical thinking skills based on the use of questioning is needed in order to validate the effectiveness of this educational strategy.

Simulation. Simulation is an educational strategy used to develop critical thinking skills and increase confidence levels. Simulation is currently being used by a wide variety of health care disciplines, and is becoming more popular (Hyland \& Hawkins, 2009; Krautscheid, Kaakinen, \& Warner, 2008; Notarianni, Curry-Lourenco, Barham, \& Palmer, 2009). Simulation can involve a variety of techniques and delivery methods which allow individuals to demonstrate critical thinking and decision making skills (Jeffries \& Rogers, 2007). Simulation is used to replace actual patient experiences with guided practices that replicate significant aspects of the real world in a realistic, yet safe clinical environment.

Simulation techniques can range from low-fidelity to high-fidelity. Low-fidelity is frequently used to practice psychomotor skills and is useful for beginning students (Hovancsek, 2007). In addition to psychomotor skills, moderate-fidelity also offers students the opportunity to auscultate and learn different lung sounds, heart sounds, and bowel sounds. This provides students with an opportunity to familiarize themselves with 
working on a patient and detecting what is normal and abnormal (Broussard, 2008). High-fidelity simulation involves a manikin based patient simulator that can be used with realistic simulated scenarios. These simulated scenarios can provide a wide range of educational opportunities. High-fidelity simulations respond physiologically to computer commands. A clinical scenario could involve programming different cardiac arrhythmias with subsequent vital sign changes. Subsequently, the student would have to assess and treat the patient. Based on their actions, the computer could be programmed to either convert or precede to a different cardiac rhythm with further changes in the vitals signs resulting in additional action that would be reflective of the student's critical thinking abilities.

Simulations can involve role-playing, interactive videos, and manikins that facilitate learning, allowing individuals to demonstrate critical thinking and decision making skills (Jeffries \& Rogers, 2007). Simulation provides an opportunity for individuals to practice new approaches to health care, develop cognitive, associative, and psychomotor skills in a safe, non-threatening, and realistic environment before entering the clinical setting (Wotton, Davis, Button, \& Kelton, 2010). Nurse educators are integrating all forms of simulation into nursing and hospital programs to promote critical thinking skills.

Broussard (2008), Campbell (2006), and Durham and Alden (2008) state there are numerous benefits to using simulation in addition to developing critical thinking skills. Benefits include:

- encouraging teamwork

- promoting effective communication 
- providing a bridge between theory and clinical practice

- working in a controlled environment with reproducible results

- the ability for individuals to make mistakes without the fear of harming a live person

- increased self-confidence

- improved psychomotor skills

- identifying gaps in an individual's knowledge and experience base

The main limitation of using simulation according to Broussard (2008), Campbell (2006), and Durham and Alden (2008) is related to its cost, which is prohibitive for many institutions. Costs include not only purchasing the equipment, but appropriate space allocation, supporting equipment, maintenance of the equipment and technology support. Other limitations identified include the complex nature of the technology requiring a commitment to train educators in the use of the patient simulator. In addition, student anxiety related to the use of patient simulation limits its usefulness.

Ravert (2008) wished to determine whether measures of critical thinking showed differences among three groups (simulator, non-simulator, and control) of baccalaureate nursing students. The simulator group $(\mathrm{n}=12)$ received the regular educational program and participated in five patient scenarios using a high-fidelity patient simulator. The nonsimulator group $(\mathrm{n}=13)$ also received the regular educational program and participated in five small group discussions regarding the patient scenarios. The control group $(\mathrm{n}=$ 15) received only the regular educational program. Critical thinking skills were measured by the CCTST. Critical thinking scores for disposition and skills increased in all three groups studied, but there was no statistically significant difference among the groups 
$(p=0.94)$ indicating factors, other than simulation, may have impacted the critical thinking scores.

These results differed from those found by Shepherd, Kelly, Skene, and White (2007) who also compared three similar groups of graduate nurses assigned to different learning activities. One group was assigned to a self-directed learning package (SDLP) $(n=25)$; the second group was assigned to a SDLP plus two scenario-based PowerPoint workshops $(\mathrm{n}=26)$; and the last group was assigned to a SDLP plus two simulation education sessions using a manikin with low-fidelity capabilities $(n=23)$. Statistical analysis using ANOVA for comparison of mean scores among the three groups revealed a significant difference $(\mathrm{p}<0.001)$ for the nurses in the simulation group compared to those in the SDLP group and the SDLP plus PowerPoint group. The mean score $(\mathrm{M}=$ 135.52) for the SDLP plus simulation group was significantly higher than both the SDLP $(M=107.42)$ and the SDLP with PowerPoint $(M=102.77)$ intervention groups. A major limitation of this study was the lack of interrater reliability. Due to the large number of graduate nurses, several nurse educators were required to run each scenario and it was logistically impossible to have the same two staff perform all of the test scenarios. Recording the scenarios for evaluation after completion may have been helpful in establishing interrater reliability.

Burns, O’Donnell, and Artman (2010) and Sullivan-Mann, Perron, and Fellner (2009) found statistically significant differences between pretest and posttest scores after students participated in simulation ( $\mathrm{p}<0.001$ and $\mathrm{p}<0.05$, respectively). Burns et al. used a pretest-posttest design to study the efficacy of using high-fidelity simulation to facilitate understanding of problem-solving skills among $1^{\text {st }}$ year nursing students $(\mathrm{n}=$ 
84) of a baccalaureate program. Students completed a 10-item multiple-choice pretest to assess knowledge and understanding of the nursing process one week after receiving a 2-hour lecture on the nursing process. The test items were developed and selected through consensus of an expert faculty and clinical panel. Following the pretest, students participated in a 3-hour simulation experience. One week following the simulation experience, a 10-item multiple choice posttest was administered. Data analysis was done using the nonparametric Wilcoxon's signed rank test because the data were not normally distributed. Knowledge attainment was significant $(\mathrm{p}<.001)$.

Limitations of the Burns et al. (2010) study were the lack of a comparison group, (the students acted as their own control group); lack of a reliable and valid instrument; and in consideration of the current project, critical thinking skills were not specifically measured. Students, however, indicated they were very satisfied with the simulation experience on end-of-course evaluations, which may have been reflective of the educational preferences for this generation of learners who have grown up with information technology.

Sullivan-Mann et al. used a 2 (groups) x 2 (times) mixed-model design to test the effect of simulation on nursing students' critical thinking scores on the Health Sciences Reasoning Test (HSRT), which was administered as a pretest and posttest to experimental and control groups. There was not a significant difference between the experimental and control groups at pretest $(\mathrm{p}>.05)$. After randomization, both the control group $(n=26)$ and the experimental group $(n=27)$ followed an established curriculum, which included two simulation scenarios scheduled during weeks 1 and 15 of 
the semester. The experimental group received three additional scenarios during weeks 7 , 11, and 13. After the final simulation, all students took the HSRT as a posttest.

One-factor ANOVAs were conducted on the total HSRT scores at pretest and posttest. On the posttest, the experimental group answered significantly more questions correctly than they did at pretest $(\mathrm{p}<.05)$. Although the control group improved, it did not answer significantly more questions correctly on the posttest than the pretest $(p>.05)$. Limitations of this particular study included the influence of clinical instructors during clinical hours. Students in clinical groups with a strong, knowledgeable instructor could potentially be more challenged at the bedside, resulting in an increase in critical thinking skills compared to clinical groups who had a new or inexperienced clinical instructor. Ideally, the control group would not have received the two scenarios and the experimental group would have been compared to a control group who had not received any scenarios.

Fero et al. (2010) completed a quasi-experimental, cross-over design to study the relationship between metrics of critical thinking skills and performance in simulated clinical scenarios. A convenience sample of 36 nursing students participated in measurement of critical thinking skills and simulation-based performance using videotaped vignettes, high-fidelity human simulation, California Critical Thinking Disposition Inventory (CCTDI) and the California Critical Thinking Skills Test (CCTST). The researchers found there was no statistically significant relationship between videotaped vignette performance and CCTDI scores $(\mathrm{p}=0.683)$ or CCTST scores $(p=0.372)$ in nursing students. Additionally, there was no relationship between overall HFHS performance and CCTST scores $(\mathrm{p}=0.647)$. A statistically significant 
relationship (Cramer’s V = 0.413) was found, however, between overall high-fidelity human simulation (HFHS) and CCTDI scores ( $\mathrm{p}=0.047)$.

Chau et al. (2001) also used videotaped vignettes to determine the effects of using them in promoting nursing students' critical thinking abilities in managing different clinical situations. A pretest-posttest design was used with a combination of 83 first and second year nursing students in a 4-year baccalaureate program. A pilot study $(\mathrm{n}=23)$ with third year students was initially completed to determine the feasibility of the study. Critical thinking skills were measured with the CCTST and a knowledge test was used to determine the students' knowledge for each of the topics in the videotaped vignettes. The researchers found no statistically significant correlations between the critical thinking scores and the demographic variables of the nursing students in year one and year two. They did find a significant improvement in posttest knowledge for year $1(\mathrm{p}<0.01)$, but not year 2 ( $p>0.05$ ) when students completed a faculty developed nursing knowledge test. An important limitation to note on this study was that the teaching approach was used for only four weeks of the semester. It is unknown whether if by using the method the entire semester, the study results would have been different.

Kaddoura (2010) used an exploratory qualitative descriptive design, employing a semi-structured interview method, to obtain new graduate nurses' perceptions of critical thinking promotion in the context of clinical simulation during critical care nursing training that lasted six months. A convenience sample of 10 new graduate nurses from the intensive care unit participated. All of the participants had at least a baccalaureate degree in nursing. The new graduates were taught using clinical simulation for one 8hour day every three weeks over the course of the training program. After the program 
was completed, the new graduates participated in semi-structured interviews that were audiotaped and transcribed verbatim. The author found simulation served as an integrator of learning. It brought together the theoretical base from students' classes and readings, as well as the psychomotor skills from the skills lab.

In another study by Johannsson and Wertenberger (1996), results were not as consistent. Eighteen nursing students in a diploma program reviewed six video simulations, followed by completion of a 'What If' exercise, and concluding with five additional video simulations. Eight weeks after data collection, a debriefing session of 30 minutes was conducted and audiotaped with each participant. After viewing a variety of videotaped vignettes, there was repeatedly a difference between knowing what a problem was, and knowing what to do about it.

Several issues limit the conclusions of this study in relation to the current project. First, the sample consisted of diploma students whose program outcomes and goals may differ from a baccalaureate program. Second, the video simulations used were not designed for nursing students. Third, the potential for substantial subjectivity in the evaluation of participant responses was also an issue as the researchers quickly learned the instrument did not provide all of the information needed for evaluating the participant responses. In addition, this particular study was older than all of the other studies reviewed.

Two relatively recent systematic reviews were examined, Cant and Cooper (2010) and Lapkin, Levett-Jones, Bellchambers, and Fernandez (2010). In the Lapkin et al. (2010) review, eight studies were examined, but only three (Howard, 2007; Ravert, 2008; Schumacher, 2004) specifically examined the effectiveness of using human patient 
simulation manikins to develop critical thinking abilities in undergraduate nursing students. All of these studies, except Schumacher (2004), were summarized above. Schumacher conducted a quasi-experimental study to compare critical thinking abilities of junior level baccalaureate nursing students $(\mathrm{n}=36)$ and learning outcomes utilizing three different educational interventions (classroom teaching, human patient simulation manikins, and a combination of classroom teaching and simulation). Students were assigned using randomization into the three groups. The HESI exam was administered as a pretest and posttest immediately following the educational intervention. A one-way ANOVA was conducted to determine the effect of instructional strategies on critical thinking ability and learning outcomes. Bonferroni post-hoc comparisons were employed to evaluate significant $(\mathrm{p}<.05)$ differences between groups. There were no statistically significant differences between critical thinking abilities ( $\mathrm{p}>.08$ ) or learning outcomes $(\mathrm{p}>.12)$ of nursing students when classroom teaching was utilized to deliver a learning activity. The HESI exam scores were higher and statistically significant differences $(\mathrm{p} \leq 0.002)$ were found between critical thinking abilities $(\mathrm{p} \leq .002)$ and learning outcomes $(\mathrm{p} \leq .001)$ of nursing students when human patient simulation manikins or a combination of simulation and classroom were used to deliver a learning activity.

Cant and Cooper (2009) examined 12 studies. Eleven of these assessed critical thinking directly or via a proxy of self-reported confidence in the ability to make clinical judgments. One study included multi-professional groups of nursing and medical staff, but results were not statistically significant. A second study was comprised of only experienced registered nurses. In this study, no statistically significant difference was found between the experimental group that used simulation, compared to the control 
group that used a case study seminar and developed a care plan. A third study, Shepherd et al. (2007), involved new graduate nurses and was described earlier in this chapter (p. 65). The remaining nine studies involved undergraduate nursing students. Only six of these directly evaluated critical thinking and of those, half reported statistically significantly results for the experimental group compared to the control group. Overall, the results of this systematic review were mixed.

Unfortunately, there is a lack of quantitative research to validate simulation as the best teaching method as it relates to critical thinking outcomes. The majority of quantitative studies found in the literature have inconclusive or conflicting findings. One of the challenges is that a variety of instruments are used to measure critical thinking skills. Three of the studies used the CCTST (Chau et al., 2001; Fero et al., 2010; Ravert, 2008); one study used the HSRT (Sullivan-Mann et al., 2009); one study used the CCTDI (Ravert, 2008); and one study used the HESI exam (Howard et al., 2010). Other studies used a variety of non-standardized instruments to measure critical thinking skills. Qualitative studies, on the other hand, have provided more positive results.

There were many limitations in the studies reviewed. First, many of the sample sizes are small and they often consist of nursing students and not new graduate nurses transitioning to the role of registered nurse. Second, the educational content is different in every study. Third, the meaning of simulation can vary among studies. Some studies use videotaped vignettes, whereas others use human patient simulator manikins. Finally, length of exposure to the educational intervention varies in all of the studies. Critical thinking was measured in time frames from six months to immediately following an educational intervention. 
Howard et al. (2010) found that by exposing graduate nurses to highly critical, but low incidence simulation scenarios, new nurses can practice their clinical decisionmaking without jeopardizing safety. If new nurses have the opportunity to practice these low occurring situations, it should result in fewer errors and improve the safety of health care for patients, which is a goal of many organizations, including the IOM. Anxiety may interfere with critical thinking skills, and possibly harm actual patients. Ultimately, new nurses will become more confident with these decision-making skills and experience less anxiety on the clinical unit.

Other educational strategies were found in the literature including online learning, role playing, narrative discussions, story telling, and inquiry based learning, but there is limited research on these strategies and the overall effectiveness of using them for developing critical thinking skills is unknown. It is also important to note that these strategies, or components of them, are often employed in the other educational strategies discussed above. As a result, they were not included in this literature review.

\section{Barriers to Implementing Critical Thinking Educational Strategies}

Perceived barriers to implementing critical thinking educational strategies were identified in studies conducted by Shell (2001) and Mangena and Chabeli (2005). Results of the Shell (2001) study revealed respondents reported three major barriers to the implementation of critical thinking strategies. The barriers included student characteristics such as resistance, attitudes, and expectations; inadequate time; and the perceived need to cover content and dispense information. Other possible barriers that Shell (2001) found to be less important included faculty resistance to changing teaching styles, institutional barriers, lack of knowledge of the concept of critical thinking, and self 
efficacy in the ability to teach critical thinking. Interestingly, these were similar to barriers identified by Mangena and Chabeli (2005). They found educators' lack of knowledge; negative feelings and thoughts of the educators and their resistance to change; cultural and instructional language incompetence; inappropriate selection process and poor educational background that did not facilitate critical thinking; and inadequate socialization were all barriers (Mangena \& Chabeli, 2005). To address potential barriers, educators need time to plan, prepare, and learn innovative teaching strategies associated with the development of critical thinking skills.

\section{Conclusions and Implications for the Project}

There is a significant amount of research focused on the different educational strategies that are designed to help nurses develop critical thinking skills. Most studies have yielded results suggesting that the different educational strategies are effective for developing critical thinking skills. Despite the variety of educational strategies available, however, current research literature does not provide evidence of the effectiveness of one specific educational strategy over another for developing critical thinking skills.

Howard (2007) found that through the application of critical thinking skills, nurses can begin to make competent clinical decisions based on previous experiences and patient situations. The development of critical thinking skills, and therefore, competent clinical decision-making, is not achieved through one educational method alone, but through the implementation of a variety of educational strategies. An individual's competent clinical decisions are also dependent upon his or her confidence in the ability to apply these critical thinking skills (Howard, 2007). Unfortunately, there are a limited number of research studies that compare different educational strategies for developing 
critical thinking skills. These comparative studies are necessary in determining which educational strategy is the best.

A few overall challenges remain, including the fact that the majority of research is focused on nursing students and not new graduate nurses; a variety of definitions for critical thinking are available; and perhaps an even more complex issue remains, regarding the measurement of critical thinking. Comparing the effectiveness of the different educational strategies was difficult in this literature review because critical thinking was measured using a variety of methods and instruments in all of the studies.

Nonetheless, based on this review of the literature to evaluate the effectiveness of evidence-based educational interventions for the development of critical thinking skills in new graduate nurses, it appeared that simulation had the potential to offer the most opportunity to impact critical thinking skills because simulation techniques could involve a wide range of activities including role-playing, interactive videos, and manikins. One of the main challenges of simulation is related to the cost (Broussard, 2008; Campbell 2006; Durham \& Alden, 2008). Unfortunately, the organization where the intervention was implemented did not have the resources to support simulation as an educational strategy for this scholarly project. As a result, based on the needs assessment of the new graduate nurses and the organization, case studies with videotaped vignettes was selected as the best educational strategy for this evidence based project. 


\section{CHAPTER 3}

\section{CONCEPTUAL FRAMEWORK}

\section{Donabedian’s Structure, Process, Outcome Model}

Donabedian's Structure, Process, Outcome model (1997) was chosen as the theoretical framework for this scholarly project because of its focus on quality of care. Donabedian envisioned quality as the product of two factors. The first factor was the science and technology of health care and the second factor was the actual application of that science and technology in practice (Donabedian, 2003). He proposed that the quality of care achieved was the direct result of these two factors. One additional aspect that needs to be mentioned is that technical care provided by health care professionals is dependent on the knowledge, judgment, and skill of those individuals who offer it (Donabedian, 2003). If outcomes are going to be improved, an organization needs to know which factors influence those outcomes.

Donabedian defines quality assurance as "all actions taken to establish, protect, promote, and improve the quality of health care” (Donabedian, 2003, p. xxiii). Quality assurance activities can be divided into two parts. The first part is system design and resources, and the second part is performance monitoring and readjustment (Donabedian, 2003). Most organizations interpret quality assurance as activities that are done to collect information about the level of quality produced. Based on that information, organizations take necessary actions to specifically improve that quality. The actions taken fall into one 
of two forms: activities meant to educate and motivate individuals directly; or readjustments in system resources and design (Donabedian, 2003). The readjustments that are made are those that are expected to influence individual behaviors indirectly. It is important to note that these two components of quality assurance are interrelated.

Donabedian's model (2003) offers a three-part approach to assessing quality of care: structure, process, and outcome. The first part of the approach is structure. Donabedian refers to structure as the conditions under which care is provided (Donabedian, 2003). Structure can include material resources, such as facilities and equipment. Human resources, such as the number, variety, and qualifications of professional and support personnel. Organizational characteristics such as the organization of the medical and nursing staff, the presence of teaching and research functions, kinds of supervision and performance review or methods of paying for care. (Donabedian, 2003, p. 46) It is difficult to provide excellent care without resources of sufficient quantity and good quality.

The second part of the approach is process. Process implies what is done in giving and receiving care. Process can include "diagnosis, treatment, rehabilitation, prevention, and patient education” (Donabedian, 2003, p. 46). These processes are usually completed by health care personnel, but may also include contributions made by patients and their families (Donabedian, 1997).

The last approach to assessing quality of care is outcome. Outcome refers to the effects of care, which can be positive or negative on the health status of patients and populations (Donabedian, 1997). Outcomes can include: 
- changes in health status;

- changes in knowledge acquired by patients and family members that may influence future care;

- changes in the behavior of patients or family members that may influence future health and;

- satisfaction of patients and their family members with the care received and its outcomes. (Donabedian, 2003, p. 47)

Donabedian (2003) clarifies that structure, process, and outcome are not attributes of quality, but rather kinds of information that can be gathered. Based on that information, an organization can conclude whether quality is good or not. Conclusions about quality are not feasible unless there is a predetermined link between the three approaches. Specifically, structure influences process and process influences outcome, as illustrated in the following simple diagram:

$$
\text { structure } \rightarrow \text { process } \rightarrow \text { outcome }
$$

Donabedian (2003) indicates the relationships between the three parts are probabilities and not certainties. These probabilities can be large or small and they can be well recognized by scientific evidence or mainly presumed. Donabedian (2003) suggests the higher the probabilities are, and the more firmly established they are by scientific evidence, the more credible our judgments of quality can be. On the contrary, the weaker the probabilities and the more imperfectly supported by the evidence, the more tentative the judgments of quality will be. At the extreme, if nothing is known or surmised about the relations in questions, no reasonable judgments can be made using this model. (p. 49) 
A limitation of this model is that it was designed specifically to assess clinical practice and although it has performed well when assessing clinical practice, it is unknown how this model performs in relation to activities outside of clinical practice. This model has been used successfully by a variety of researchers including Hatler, Stoffers, Kelly, Redding, and Carr (2011) who utilized Donabedian’s model when evaluating the work environment of a nursing unit.

The use of critical thinking skills is an essential component of nursing and is crucial to nursing practice. In order for nurses to provide quality care that is not only safe, but will benefit their patients, they must be informed and able to make clinical judgments about good practice for each individual patient. The ability to evaluate information and different scenarios requires the ability to critically think.

When applying Donabedian’s model to this scholarly project, the concepts structure, process, and outcome need to be defined at both the macro and micro system levels (Nelson et al., 2007). At the macro level, structure is defined as the environment, specifically the nurse residency program, in which the new graduate nurse operates. It consists of three elements: material resources, human resources and organizational characteristics. Material resources include

- the educational department, including the nursing education classroom and skills lab;

- individual medical-surgical and step-down nursing units;

- equipment that is readily available;

- availability of reference materials including electronic and paper resources;

- financial and time resources. 
Human resources include

- the number of nurse educators, clinical nurse specialists, and preceptors;

- individual unit staffing;

- number of preceptors assigned per orientee;

- preceptor and orientee staffing assignments including the number of patients assigned and their complexity;

- staffing mix of licensed and unlicensed personnel;

- educational level of the staff nurse.

Organizational characteristics include

- staffing philosophy as defined by the organization's Professional Employee Council Contract (PECSH);

- competing priorities;

- leadership support for the orientee;

- length of orientee orientation;

- clinical learning support including variety of clinical assignments;

- preceptor development including preceptor qualifications, selection process, and preceptor development classes;

- organizational support including length of time on home unit prior to being pulled to other units for staffing purposes.

Process is defined as the specific educational strategies utilized to educate new graduate nurses in developing critical thinking skills. Educational strategies include lecture, story telling, journaling, skills labs, and clinical time on the medical-surgical and 
step-down units. Educational strategies are presented individually and in a more formalized group setting.

At the macro level, outcome is defined as the outcomes measured by the National Database of Nursing Quality Indicators (NDNQI) (American Nurses Association, 2012), including

- patient falls;

- patient falls with injury;

- pressure ulcers including community, hospital, and unit acquired;

- catheter-associated urinary tract infections;

- restraint prevalence;

- skill mix;

- nursing hours per patient day;

- registered nurse job satisfaction and practice environment survey; - nurse turnover.

An additional outcome would include patient satisfaction, measured by the Hospital Consumer Assessment of Healthcare Providers and Systems (HCAHPS) survey (Agency for Healthcare Research and Quality, 2012). The survey is a national, standardized, publicly reported survey of patients’ perspectives of hospital care.

At the micro level, structure is defined as one component of the nurse residency program, specifically one of the new employee support team (NEST) meetings. Process is defined as the educational strategy, case studies with videotaped vignettes, and outcome is defined as the development of critical thinking skills. 
The microsystem, in this scholarly inquiry dissertation, functions as one of the building blocks for developing and transitioning new graduate nurses who will be able to provide safe and high-quality patient care and ultimately impact patient outcomes in a positive manner. The mission of the nurse residency program is to achieve the best possible patient care outcomes by preparing and orienting new graduate nurses who can think critically in a complex and continually changing health care environment. Nelson et al. (2007) states the "microsystem has a semipermeable boundary that mediates relationships with many other support services and other microsystems. It is embedded in, influences, and is influenced by the larger organization, the macrosystem” (p. 10).

Figure 1 graphically represents the three concepts in relation to this scholarly project. The overall assumption of this model assumes that the structural elements of health care will influence what is and is not done in the process, as well as how well it is done. Process in turn, influences the outcome patients experience as a result of their encounters with the processes (Aday, Begley, Lairson, \& Balkrishnan, 2004).

It is important for nurse executives to understand how the three concepts influence the development of critical thinking skills in new graduate nurses. Positive outcomes will only be achieved if there are effective structures and processes in place. In the event of unsatisfactory outcomes, the nurse executive needs to analyze where along the model there are issues to be addressed.

In addition to Donabedian's structure, process, and outcome approach, orientation programs should be based on principles of adult learning. The six principles of andragogy according to Knowles are (a) the learner's need to know; (b) self-concept of the learner; (c) prior experience of the learner; (d) readiness to learn; (e) orientation to learning; and 
(f) motivation to learn (Knowles, Holton, \& Swanson, 1998). Adult education must be responsive to the needs and goals of the individual, the institution, and society (Knowles, et al., 1998). Case studies, as an educational strategy, incorporate Knowles principles of adult learning. Adult learning is most effective when it is problem centered, active, and related to real life, which are all attributes of case studies.

Specifically, Knowles refers to the learner’s need to know (Knowles et al., 1998). Adults become more ready to learn when they experience a need to learn in order to effectively handle real life issues. In regards to the specific educational content for this scholarly project, registered nurses must know how to delegate in order to provide health care to individuals that is affordable, accessible, and of high quality.

A second principle is prior experience of the learner (Knowles et al., 1998). In most academic programs, there is little or no opportunity to delegate in the clinical setting. This information is supported by the National Council of State Boards of Nursing (2012b). They found one contributing factor was the lack of educational opportunities for nurses to learn how to work with others effectively. As a result, nurses are often reluctant to delegate (National Council of State Boards of Nursing, 2012b). Yet, once they enter the practice environment, they are expected to do so.

Finally, Knowles talks about readiness to learn and the motivation to learn (Knowles et al., 1998). In conversations with past and current nurse residents, many verbalized excitement to learn more about delegation. If adults are not interested in the topic, they are less likely to be engaged in the learning process. Goodman (1997) found adult learners, compared to younger learners, are more self-directed, problem-centered, 


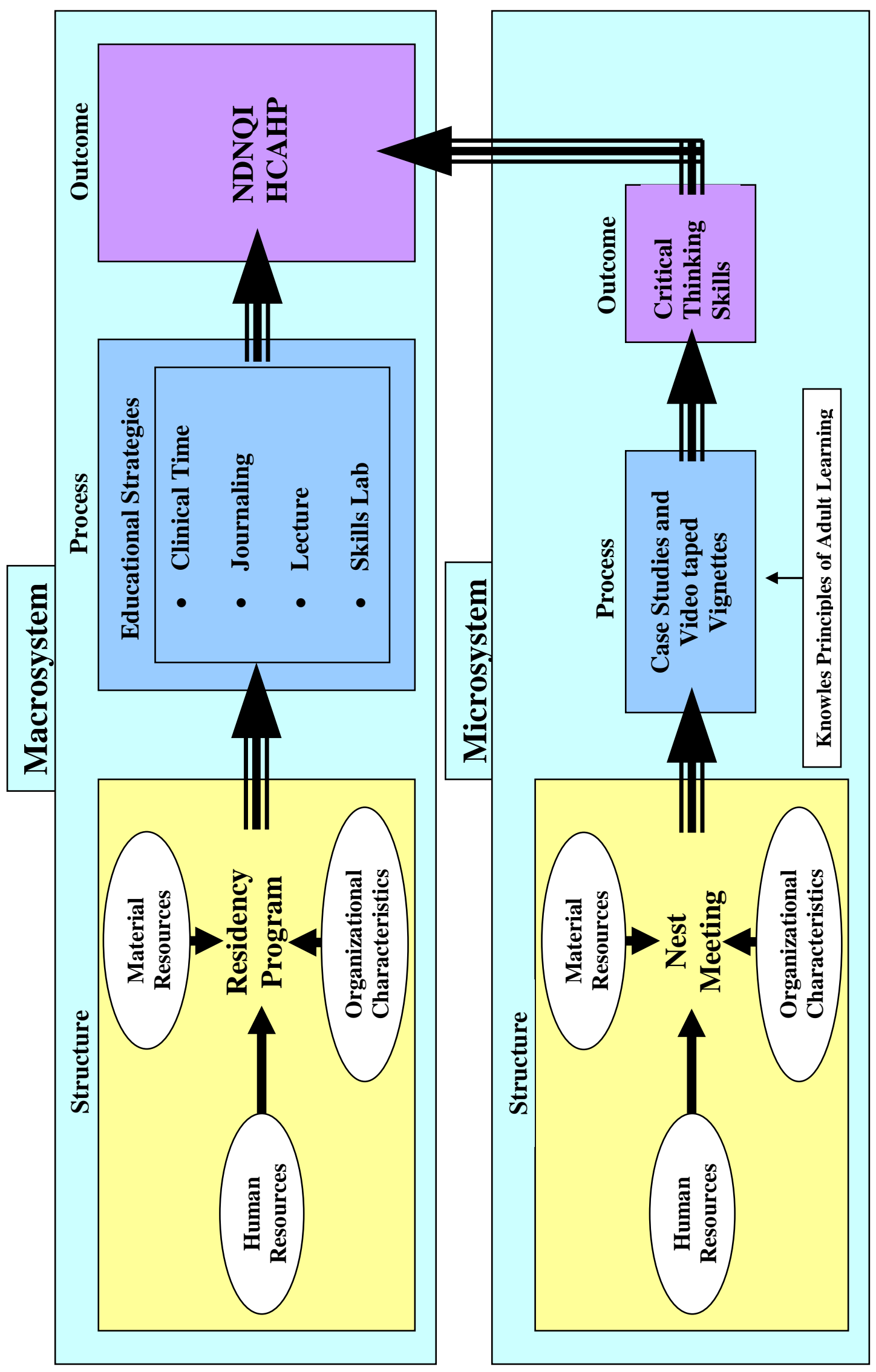


and internally motivated. These characteristics encourage and promote continued learning, which is fundamental in nursing.

\section{Conceptual and Operational Definitions}

For the purpose of this scholarly project, the following conceptual and operational definitions will be utilized:

\section{Residency Program:}

Conceptual: A program designed for orienting and transitioning new graduate nurses to the role of registered nurse.

Operational: A six month program of orientation for new registered nurses that includes a two-week didactic component, one week of clinical orientation on ten different medical-surgical units, and additional clinical orientation time once the registered nurse is placed permanently on a specific medical-surgical unit.

\section{New Employee Support Team (NEST) Meeting:}

Conceptual: A meeting designed to present a specific topic to new graduate nurses during the nurse residency program.

Operational: A two and half hour class to discuss delegation and prioritization.

\section{Graduate Nurse:}

Conceptual: An employee hired by an organization, who has no prior experience working as a registered nurse in an acute care setting, but has passed the National Council Licensure Examination for Registered Nurses (NCLEX-RN) (National Council of State Boards of Nursing, 2012a).

Operational: A new graduate nurse who is hired into the residency program. 


\section{Educational Strategy}

Conceptual: An instructional strategy used to facilitate the development and promotion of critical thinking that can be delivered individually or to a group of individuals.

Operational: Case studies and videotaped vignettes.

Critical Thinking Skills

Conceptual: Cognitive skills, such as analysis, synthesis, evaluation and inference.

Operational: Health Science Reasoning Test (HSRT) (Insight Assessment, 2011) scores for critical thinking. 


\section{CHAPTER 4}

\section{PLAN AND METHODS}

The Iowa model of evidence-based practice to promote quality care developed by Marita G. Titler and colleagues (Titler et al., 2001), guided this scholarly project. The Iowa model is based on the problem-solving steps in the scientific process and is widely recognized for its applicability and ease of use. It offers guidance in making decisions about day-to-day practices that affect patient outcomes (Ciliska et al., 2011). Research has shown the use of critical thinking skills are an essential component of nursing and are crucial to nursing practice. The literature also indicates new graduate nurses are also the most at risk group because they have not yet developed the critical thinking skills necessary to assess and evaluate complex clinical situations in the practice setting (Myers et al., 2010).

\section{Setting}

The setting for this scholarly project was a 697-bed not-for-profit community governed urban acute care hospital located in the southern third of Michigan’s lower peninsula. In 2009, the organization received Magnet certification by the American Nurses Credentialing Center recognizing the organization for its quality patient care, nursing excellence, and innovations in professional nursing practice. Currently, Magnet recognition has only been achieved by $6.74 \%$ of all registered hospitals in the United States (American Nurses Credentialing Center, 2012).

The first step in the Iowa model encourages clinicians to isolate practice questions or "triggers" through identification of a clinical problem or from new knowledge (Ciliska et al., 2011). Questioning of current practice can often identify important triggers. 
Delegation and prioritization, the educational topic for this scholarly project, was identified through discussions with past and current participants of the nurse residency program. Some nurse residents verbalized that their academic programs had not covered the concept of delegation, while others said it was covered during the last one or two semesters of their educational programs. One nurse resident stated she was unfamiliar with the concept of delegation and another nurse resident stated she had learned about delegation only a couple months earlier when she attended a NCLEX review course.

The Doctor of Nursing Practice (DNP) student had the opportunity to participate in three new employee support team (NEST) meetings over the course of several months. The purpose of these meetings is to provide ongoing support for the new nurse residents and to discuss a variety of topics. During one of these meetings, the nurse residents indicated that they did not know the specific duties that could be completed by the patient care technicians (PCTs). However, some stated they knew specific skills they could not do. When questioned about the PCTs' job description, the nurse residents indicated they had not had the opportunity to review it. One nurse resident voiced the opinion that the PCTs were "useless." Upon further questioning, the nurse resident stated that the PCTs "sit at the desk and do nothing."

The second step in the Iowa model is to secure a commitment from the organization that a particular topic would be beneficial to address (Ciliska et al., 2011). The DNP student met with the Director of Nursing Education, Practice and Research and obtained full support for this scholarly project focus and the proposed educational strategy. In addition, the nurse educators responsible for executing the nurse residency program fully supported both the scholarly focus and the educational strategy. 
The next step in the Iowa model is to assemble relevant research and related literature (Ciliska et al., 2011). In addition to a literature review, the content of the current nurse residency program was evaluated by attending portions of the program, talking with the nurse educators responsible for implementing the residency program, and speaking to previous participants of the nurse residency program. Feedback was obtained that was helpful in overall evaluation and design of this scholarly project.

\section{Participants}

All new graduate nurses hired for the July 30, 2012 nurse residency program participated in this scholarly project. The goal was to recruit as many new graduate nurses as possible. The larger the group size, the more representative the sample would be of the population of new graduate nurses likely to be hired at this particular institution. Practical limitations such as time and organizational constraints, including a limited number of residency orientation programs offered throughout the year, and the number of new graduate nurses hired, ultimately impacted the size of the group. In mid-May the department of Human Resources prepared and presented thirty offers of employment. Twenty-three new graduate nurses accepted positions. The residency program is capped at 25 participants; however, due to a variety of circumstances, 18 nurse residents ultimately began the residency program on July 30 .

Participants in the residency program were required to (a) have successfully completed the National Council Licensure Examination (NCLEX-RN); (b) be a new nurse graduate without prior nursing experience; (c) have obtained a baccalaureate degree in nursing, unless currently employed with the organization. Exclusion criteria for the nurse residency program included (a) registered nurses who had passed NCLEX-RN and 
had previously been employed as a registered nurse, regardless of the amount of time they were employed in the position; (b) new graduates who were hired who had an associate degree in nursing. Those who were not eligible for the residency program were not eligible for inclusion in this scholarly project.

Sampling bias could include selection bias, but the presence of confounding variables could also affect the group. Prior exposure to different teaching strategies during a graduate nurse's academic preparation could be a confounding variable. The level of nursing education attained, at the Associate or Bachelor's degree level could also be a confounding variable. Prior employment experience working in a health care setting as a nursing assistant or technician could impact the individual's ability to think critically. Finally, age of the new graduate nurse could be a confounding variable. Older graduates will have more life experiences, in general, that could potentially impact their ability to think critically (Jackson, Ignatavicius, \& Case, 2006). Cohen (2005) describes three types of thinking that actually improve with age. They include relativistic thinking, dualist thinking and systematic thinking, all of which impact the ability to critically think.

\section{Instrument}

A standardized instrument was selected to measure critical thinking. There are a variety of standardized instruments available for measuring critical thinking skills. Previous reports of the reliability and validity of the standardized instrument were evaluated to ensure the best instrument was selected for this program evaluation.

In the research studies reviewed, the California Critical Thinking Disposition Inventory (CCTDI) and the California Critical Thinking Skills Test (CCTST) were the instruments used most frequently. The Health Sciences Reasoning Test (HSRT) was not 
used as frequently, but it was designed specifically for health sciences and health care professional preparation programs. Moreover, it was developed specifically for the health sciences as part of the California Critical Thinking Test family of instruments (Facione, Facione, \& Winterhalter, 2011).

The HSRT test questions are framed in the context of health science settings or everyday health concerns, but they do not require any specialized health knowledge. All of the necessary information needed to answer the question correctly is presented in the question. As a result, the HSRT was determined to be the best instrument for this scholarly project. In addition, Facione et al. (2011) state the HSRT has been used to gather valid and reliable evidence about the performance of groups of people when evaluating the effectiveness of instructional approaches or educational materials.

The HSRT is composed of 33 multiple choice questions ranging in difficulty and complexity. Questions are multidimensional and interrelated so that test results can provide important insights into specific critical thinking skills (Facione et al., 2011). Participants are directed to select one answer for each question, which, in their judgment, is the best selection of the ones provided (Facione et al., 2011). One point is given for each correct answer and no points are deducted for incorrect or missing answers. If a participant accidentally selects two answers, no points will be given, even if one of the answers is correct. In addition, participants are given 45 minutes to complete the test. If a participant has not completed the test at the end of the 45 minutes, he or she is instructed to stop and the instrument is collected at that time. One of the limitations of the instrument is that individual organizations do not have the ability to score the instrument. 
Rather, it must be scored by the distributor of the instrument and a variety of data reporting services are available.

The HSRT provides six individual measures of critical thinking skills. It yields a total score and five scale scores: (a) Analysis and Interpretation, (b) Inference, (c) Evaluation and Explanation, (d) Deductive Reasoning, and (e) Inductive Reasoning. The total score on the HSRT indicates an individual's overall critical thinking skill level (Facione, et al., 2011).

The first three scale scores on the HSRT, analysis and interpretation, inference, and evaluation and explanation, represent the key core skills identified in the theory of critical thinking. These three scales are based on the conclusion of a two year Delphi project directed by Facione (1990) on the definition of critical thinking. The concept of reasoning is separated into the last two scales, inductive and deductive reasoning (Facione et al., 2011). A brief description of each scale is provided in the following paragraphs.

The analysis and interpretation scale measures skills that are used to carefully examine ideas; to identify assumptions, reasons and claims; and to gather detailed information from charts, graphs, diagrams, and paragraphs. These skills are also used when determining the specific meaning of a sentence, passage, text, or idea in a known context and for a known purpose (Facione et al., 2011).

The inference scale measures the capability of drawing conclusions based on reasons and evidence. Inferences can be skillfully drawn from a broad diversity of things including information, data, beliefs, opinions, facts, conjectures, definitions, principles, images signs, behaviors, documents, or testimony (Facione et al., 2011). 
The evaluation and explanation scale measures skills that are used to assess the credibility of claims and the strength or weakness of arguments. Evaluation skills can also be applied to form judgments about the quality of inferences, analyses, interpretations, options, beliefs, and ideas. Explanation, on the other hand, entails providing one's reasons, methods, assumptions or rationale for one's beliefs and conclusions (Facione et al., 2011).

The inductive reasoning scale represents the ability to derive reasonable conclusions regarding what is most likely true or not true, given the information and the context that is available (Facione et al., 2011). Lastly, the deductive reasoning scale involves moving from the assumed truth of a set of beliefs or premises to a conclusion. In a valid deductive argument, the conclusion cannot possibly be false if the evidence is correct. Deductive reasoning skills are used on activities that require following rules, definitions, laws or diagrams (Facione et al., 2011).

The data from validation studies for the overall HSRT produced a KuderRichardson (KR-20) internal consistency coefficient ranging from 0.77 to 0.84 , and an overall internal consistency of 0.81 (Facione et al, 2011; Sullivan-Mann et al., 2009). In instruments that have multidimensional scales, like the HSRT, a KR-20 above .70 indicates a high level of internal consistency (Facione et al., 2011). The HSRT, with an overall reliability coefficient of .81 , is therefore more than adequate to encourage confidence in the internal consistency of its items to measure critical thinking.

Content validity refers to the ability of the HSRT to measure the domain of critical thinking, which was defined by the 1990 American Philosophical Association Delphi Consensus Definition (Facione et al., 2011). Facione et al. (2011) identified that the items 
selected for "inclusion in the HSRT cover the domain of the critical thinking cognitive skills identified by the Delphi experts and include interpretation, analysis, evaluation, explanation, and inference” (p.37).

Construct validity for the HSRT refers to the extent to which the HSRT measures the American Philosophical Association Delphi conceptualization of critical thinking. Facione et al. (2011) state "most, if not all, authors of measurement texts agree that higher order cognitive skills, such as critical thinking, can be measured validly and reliably by well crafted multiple choice items” (p. 37). To determine if the HSRT test items were performing as intended, psychometric item analysis methods were used to examine responses to the test items. Lastly, improvement in students’ HSRT scores after they have taken a course in critical thinking or an educational program training them in the critical thinking portion of clinical reasoning have also provided evidence for the construct validity of the HSRT (Facione, et al., 2011).

Criterion validity refers to the ability of the HSRT to predict some criterion behavior external to the test itself. For example, criterion validity would be evident for the HSRT if it is able to predict some meaningful measure for the preparation of a nurse's successful licensure or successful transition to practice. Facione et al. (2011) reports that criterion validity has just begun to emerge for the HSRT.

A questionnaire containing demographic information was also completed for the purposes of conducting additional statistical analysis of possible confounding variables. Specific data collected included age; educational preparation, including previous degrees or certifications; the name of the academic institution from which the degree was earned; 
previous health care experience; length of time employed in health care; and previous exposure to case studies and videotaped vignettes during the academic program.

\section{Ethical Considerations}

Human subjects were protected and Institutional Review Board approval was obtained from Grand Valley State University (see Appendix B). Exempt status was attained since the scholarly project involved minimal risk and it involved evaluating the effectiveness of a specific educational strategy on human subjects in a setting where established educational practices are utilized. The hospital did not require Institutional Review Board approval because the scholarly project was a program evaluation (see Appendix C).

\section{Program Content and Delivery}

In preparation for delivery of the content, a teaching plan on delegation and prioritization was developed that included objectives, materials needed, and methods (see Appendix D). Case studies (see Appendix E) were developed based on experiences the DNP student had encountered during her time as a nurse manager at a large urban acute care hospital with personnel and clients similar to those in the project setting. In addition, case studies were reviewed in Prioritization, Delegation \& Assignment by LaCharity, Kumagai, and Bartz (2006) and adapted to meet the needs of this specific organization. Six videotaped vignettes on the concept of delegation produced by the National Council of State Boards of Nursing were selected for use in the teaching sessions (National Council of State Boards, 2010). The teaching plan was reviewed by members of the DNP student's dissertation committee, which included a member with extensive experience teaching adult learners and a faculty member certified as a nurse educator by the National 
League for Nursing. In addition, the nurse educators at the organization reviewed and approved the teaching plan.

The program evaluation involved three phases. The first phase required all of the new nurse residents hired for the July 30 nurse residency program to complete the HSRT as a pretest on their first day of employment. Demographic information (see Appendix F) was also collected at this time. Prior to the beginning of the testing, the DNP student emphasized confidentiality and emphasized that no individuals in the organization would have access to the completed surveys. In addition, to prevent linking results back to a specific individual, participants were instructed to not put any identifying personal information on the instrument. Lastly, it was communicated that the organization would only receive a report based on the program evaluation results.

The second phase, which occurred nine days later, involved the delivery of the content material over a three-hour NEST meeting which occurred during a regularly scheduled orientation day. The nurse residents were divided into six groups; each group was composed of three nurse residents. The participants were shown short videotaped vignettes (National Council of State Boards, 2010) on delegation ranging in length from 2:09 minutes to 7 minutes. Following each videotaped vignette, a case study with specific questions related to that vignette was given to the nurse residents to answer and discuss. Following the small group discussion, a brief group discussion on each case study was completed with all of the nurse residents prior to moving on to the next videotaped vignette.

During this phase, the nurse residents appeared to be fully engaged in the group discussion and appeared not only open-minded, but inquisitive regarding the case studies 
that were presented and discussed. The nurse residents were actively analyzing the material presented both in their small groups and during the larger group discussion. The nurse residents were able to apply the standards of delegation to the questions presented in the case studies. Finally, the nurse residents were reflective and often spoke of past experiences or observations regarding delegation, which contributed to the overall value of the discussion. All of these actions reinforced the nurse residents' ability to think critically in the manner described in the definition provided by Scheffer and Rubenfeld (2000).

The last phase occurred twelve days after the program content was delivered and involved taking the HSRT as a posttest. Participants were provided a short break from orientation sessions prior to the testing. Participants were given 45 minutes to complete the test, which was comprised of 33 multiple choice questions. In addition the participants were provided with an opportunity to ask questions before testing began. Participants who finished early handed in their test booklet and scoring forms and quietly left the room. The DNP student remained in the room and visibly vigilant during the testing to deter cheating and to ensure that the participants remained focused. After 45 minutes, the DNP student announced that the testing period was completed and that it was time for anyone still working to return the test booklet and scoring form. All scoring sheets were checked to ensure that each participant had completed the ID section and group code correctly. Data were sent via certified mail to Insight Assessment for scoring purposes. 


\section{Data Analysis}

A paired $t$-test for dependent groups was the statistical method chosen for analysis. A variety of demographic information was collected and statistically analyzed to determine the effects of the confounding variables previously mentioned. These analyses are reported in Chapter 5.

\section{Evaluation}

Piloting an innovation is an essential step in the Iowa model process (Ciliska et al., 2011). A comparison of pre-pilot and post-pilot data for this scholarly project was completed using a one group pretest-posttest design. The intervention variable was the educational strategy (case studies and videotaped vignettes) and the dependent variable was critical thinking skills.

The last step in the Iowa model is to determine if the change will be appropriate for implementation in the future (Ciliska et al., 2011). Based on the results of this program evaluation, a decision will be made by the organization to determine if this educational strategy should be implemented in future nurse residency orientations. 


\section{CHAPTER 5}

\section{RESULTS}

The purpose of this scholarly project was to determine which educational strategies facilitate the development of critical thinking skills in new graduate nurses. The specific aim of this program evaluation was to determine if there was a significant difference between the pre- and posttest critical thinking scores on the Health Sciences Reasoning Test (HSRT) (Insight Assessment, 2011) when using case studies with videotaped vignettes as an educational strategy. The intervention variable for this program evaluation was the educational strategy, case studies and videotaped vignettes, and the dependent variable was critical thinking skills.

Eighteen nurse residents hired for the July nurse residency program participated in this program evaluation. It is important to note that according to the HSRT criteria for interpreting test scores, some test scores may need to be discarded as false tests. Critical thinking skills do not deteriorate over short periods of time, unless there is an intervening cognitive injury (Facione, Facione, \& Winterhalter, 2011). A significant drop of 3 or more points in total score from pretest to posttest is an indicator of a false test and should be discarded. One participant had a difference of 5 points from pretest to posttest and was removed from the data analysis after consultation with Insight Assessment. As a result, data from seventeen nurse residents were included in the data analysis. Statistical Package for the Social Sciences (SPSS) version 18.0 was used to analyze the data. 


\section{Demographics}

The average age of the nurse residents was $25.59(\min =21, \max =45, \mathrm{SD}=$ 6.104). Twelve participants (70.6\%) had previous health care experience and two participants indicated experience in more than one type of position (Table 1). Table 2 shows the actual length of time those participants were employed in a health care setting. Length of time ranged from a minimum of 9 months to a maximum of 48 months $(\mathrm{M}=$ $24, \mathrm{SD}=13.477)$. Location of employment for the participants who had some type of health care experience is shown in Table 3. It is important to note that some participants indicated they had worked in more than one type of location. Lastly, $64.7 \%$ of the participants reported they had previous experience with case studies and/or videotaped vignettes during their academic preparation.

Table 1

Type of Previous Health Care Experience

Position

n $\quad \%$

Nurse Assistant or Patient Care Technician

8

47.1

Pharmacy Technician

2

11.8

Surgical Technician

0

0

Laboratory Technician

0

0

Unit Secretary

1

5.9

Emergency Medical Technician

0

0

Other

4

23.5

Note. Total percentage does not equal $100 \%$ because some participants had experience in more than one type of position. 
Table 2

Length of Time Employed in Health Care

\begin{tabular}{lcc}
\hline Months & $\mathrm{n}$ & $\%$ \\
\hline & & \\
9 & & 16.7 \\
12 & 2 & 16.7 \\
18 & 2 & 16.7 \\
24 & 2 & 16.7 \\
36 & 2 & 16.7 \\
42 & 2 & 8.3 \\
48 & 1 & 8.3 \\
\hline
\end{tabular}

Table 3

Employment Location

\begin{tabular}{lcc}
\hline Location & $\mathrm{n}$ & $\%$ \\
\hline Hospital & 6 & 35.3 \\
Nursing Home & 2 & 11.8 \\
Rehabilitation Center & 1 & 5.9 \\
Home Care & 3 & 17.6 \\
Other & 3 & 17.6 \\
\hline
\end{tabular}

Note. Total percentage does not equal $100 \%$ because some participants worked in multiple locations.

\section{Examination of Intervention Effect}

The standard of significance for this program evaluation was set at $\mathrm{p}<.05$. A paired $t$-test for dependent groups was completed to determine if there was a significant difference in the critical thinking scores on the pre- and posttest HSRT scores. The HSRT 
provides six measures of critical thinking scores, the overall score and five scales. Data were analyzed to determine if there was a significant difference in the total overall critical thinking score and the five scale scores. Table 4 shows the scores for the pre- and posttests.

Table 4

Critical Thinking Pre- and Posttest HSRT Scores

\begin{tabular}{lcccc}
\hline Scale & M & SD & Min & Max \\
\hline & & & & \\
Overall & 21.00 & 3.536 & 13.0 & 27.0 \\
$\quad$ Pretest & 21.94 & 3.473 & 15.0 & 27.0 \\
Posttest & & & & \\
Inductive Reasoning & 7.53 & 1.546 & 5.0 & 10.0 \\
$\quad$ Pretest & 7.94 & 1.713 & 4.0 & 10.0 \\
$\quad$ Posttest & & & & \\
$\quad$ Deductive Reasoning & 6.53 & 2.183 & 1.0 & 9.0 \\
$\quad$ Pretest & 6.94 & 2.015 & 2.0 & 9.0 \\
$\quad$ Posttest & & & & \\
Analysis and Interpretation & 4.29 & 1.213 & 2.0 & 6.0 \\
$\quad$ Pretest & 4.53 & 1.179 & 2.0 & 6.0 \\
$\quad$ Posttest & & & & \\
Inference & & & \\
$\quad$ Pretest & & & \\
$\quad$ Posttest & 2.82 & 0.728 & 1.0 & 4.0 \\
$\quad$ Evaluation and Explanation & & 0.562 & 1.0 & 4.0 \\
$\quad$ Pretest & 4.94 & 1.249 & 2.0 & 6.0 \\
$\quad$ Posttest & 5.06 & 1.345 & 2.0 & 6.0 \\
\hline
\end{tabular}

Note. $\mathrm{n}=17$

In regards to the overall score, scores above 24 are considered high while scores below 15 are considered low. The mean total score on the pretest was 21.00 and 21.94 on 
the posttest. Total scores of 25 or above indicate strong core critical thinking skills. These individuals are capable of independent learning and complex problem solving (Facione et al., 2011). Table 5 shows the distribution of scores across the three categories for the pretest and posttest on the total overall score. One individual scored a score of 25 or higher on the pretest while four individuals scored a score of 25 or higher on the posttest. Table 5

Distribution of Overall HSRT Total Scores in Low, Average and High Categories

\begin{tabular}{lccc}
\hline Score & $<15$ & 15 to 24 & $>24$ \\
& 1 & 15 & 1 \\
Pretest & 0 & 13 & 4 \\
\hline
\end{tabular}

Note. $\mathrm{n}=17$

Total scores in the mid range, 15 to 24, are associated with demonstrated competence in critical thinking in most situations and are typical of persons suitable of learning and employee development with appropriate instructional guidance, experience, and the desire to perform up to expectations (Facione et al., 2011). In this group, most of the participants scored between 15 and 24 on the pretest and the posttest.

Finally, total scores of 14 or lower are considered to be very low scores suggesting fundamental weaknesses in core critical thinking skills. These weaknesses may result in unsuccessful transitions to college and the workplace (Facione et al., 2011). In this group 
of new graduate nurses, on the pretest, one individual scored a 13, but no participants scored less than 14 on the posttest.

On the analysis and interpretation scale, a score of 5 or higher indicates analytical and interpretive reasoning strength, while a score of 2 or lower reveals weak skills (Facione, Facione, \& Winterhalter, 2011). The group participants’ mean score for analysis and interpretation on the pretest was 4.29 and 4.53 on the posttest. In this group, no one scored less than 2, and most scored between 2 and 5. Table 6 shows the range of scores for the analysis and interpretation scale.

For the inference scale, a score of 5 or higher is associated with strong inference skills, and a score of 2 or lower indicates weak inference skills (Facione et al., 2011). On this scale, no participants scored above 5 on either the pre- or posttest. With the exception of one participant who scored below a two on the pretest, all participants obtained a score between 2 and 5 on both the pretest and the posttest. Table 6 shows the distribution of scores in the low, average and high ranges for the inference scale.

On the evaluation and explanation scale a score of 5 or higher indicates strong evaluative and explanatory reasoning skills, while a score of 2 or lower indicates weak skills (Facione et al., 2011). This was the scale with the greatest number of scores in the high range. No participants scored below a 2 on the evaluation and explanation scale. These score distributions show evaluation and explanation to be an area of strength for critical thinking skills in these participants. Table 6 shows the distribution of scores in the low, average, and high ranges for the evaluation and explanation scale. 
Table 6

Score Distributions for Analysis and Interpretation, Inference, and Evaluation and Explanation Scales in Low, Average, and High Categories

\begin{tabular}{lccc}
\hline Score & $<2$ & 2 to 5 & 5 \\
& & & \\
\hline & & & 3 \\
Analysis and Interpretation & 0 & 14 & 4 \\
$\quad$ Pretest & 0 & 13 & 0 \\
Posttest & & & 0 \\
Inference & 1 & 16 & 8 \\
Pretest & 0 & 17 & 9 \\
Posttest & & 9 & \\
Evaluation and Explanation & 0 & 8 & \\
Pretest & 0 & & \\
Posttest & & & \\
& & & \\
\hline
\end{tabular}

Note. $\mathrm{n}=17$

On the inductive reasoning scale a score of 8 or higher indicates strong inductive reasoning skills, while a score of 5 or lower indicates weak inductive reasoning skills (Facione et al., 2011). On this scale, only one participant scored below a 5, and that was on the posttest. Table 7 shows the distribution of scores in the low, average, and high ranges for the inductive reasoning scale.

Lastly, on the deductive reasoning scale a score of 8 or higher indicates strong deductive reasoning skills while a score of 5 or lower indicates weak deductive reasoning skills (Facione et al., 2011). For this scale, identical distributions of scores were obtained for the pre- and posttests. Only two participants scored in the low range on this scale. Table 7 shows the distribution of scores in the low, average, and high ranges for the deductive reasoning scale. 
Table 7

Score Distributions for Inductive and Deductive Reasoning Scales in Low, Average and High Categories

\begin{tabular}{lrrr}
\hline Score & $<5$ & 5 to 8 & $>8$ \\
\hline $\begin{array}{l}\text { Inductive Reasoning Scale } \\
\quad \text { Pretest } \\
\text { Posttest }\end{array}$ & 0 & 13 & 4 \\
Deductive Reasoning Scale & 1 & 9 & 7 \\
$\quad$ Pretest \\
$\quad$ Posttest & 2 & & 3 \\
& 2 & 12 & 3 \\
\hline
\end{tabular}

Note. $\mathrm{n}=17$

To determine if there was a significant difference in the critical thinking scores between the pre- and posttest HSRT scores for the overall score and five scales paired t-tests for dependent groups were completed. Results are shown in Table 8. The analyses revealed a statistically significant $(\mathrm{p}=.041)$ increase in the mean score on the overall critical thinking score for the HSRT. However, paired samples $t$-tests revealed no significant $(\mathrm{p}<.05)$ difference in the pre- and posttest scores on the five scales.

\section{Examination of Relationships Among Possible Confounding Variables}

The following variables, age; educational preparation, including previous degrees or certifications; the name of the academic institution from which the degree was earned; previous health care experience; length of time employed in health care; and previous exposure to case studies and videotaped vignettes during the academic program were collected to determine if any of these variables impacted critical thinking scores. It was hypothesized that these variables could potentially impact the development of critical 
Table 8

Critical Thinking Paired Samples t-tests

\begin{tabular}{lcccccc}
\hline \multicolumn{1}{c}{ Scale } & $\begin{array}{c}\text { Mean } \\
\text { Difference }\end{array}$ & SD & $95 \%$ CI & $T$ & df & Sig. \\
& & & & & & \\
\hline Overall Score & -9.41 & 1.749 & {$[-1.840,-.042]$} & -2.219 & 16 & .041 \\
$\begin{array}{l}\text { Inductive } \\
\text { Reasoning }\end{array}$ & -.412 & 1.121 & {$[-.988, .165]$} & -1.514 & 16 & .150 \\
$\begin{array}{l}\text { Deductive } \\
\text { Reasoning }\end{array}$ & -.412 & 1.417 & {$[-1.140, .317]$} & -1.198 & 16 & .248 \\
$\begin{array}{l}\text { Analysis and } \\
\text { Interpretation }\end{array}$ & -.235 & 1.300 & {$[-.904, .433]$} & -0.746 & 16 & .466 \\
$\begin{array}{l}\text { Inference } \\
\begin{array}{l}\text { Evaluation and } \\
\text { Explanation }\end{array}\end{array}$ & .059 & 0.659 & {$[-.280, .397]$} & 0.368 & 16 & .718 \\
\hline
\end{tabular}

thinking skills. In regards to academic institution, the seventeen participants represented eleven different academic programs. However, there were too few participants from any particular academic program to complete a statistical analysis.

A Spearman's correlation was calculated to determine if there was a relationship between age and improvement on test scores. No correlation was found $(\mathrm{Rho}=0.099$, $p=0.704)$ among these variables. There was no indication that the overall pretest or posttest scores were related to age.

An independent 2-sample $t$-test was conducted to determine if there was a difference in the overall pretest and posttest HSRT scores among participants who had previous health care experience compared to participants who did not. Health care 
experience could have involved employment in a variety of health care locations. Twelve participants had previous experience working in health care while five did not. However, no statistically significant difference was found in the overall HSRT scores between participants who had health care experience and those who did not on the pretest $(t=0.146, \mathrm{p}=0.866)$ or the posttest $(t=-0.105, \mathrm{p}=0.918)$.

To obtain a different view of the participants' performance, a mean difference score was calculated by subtracting the pretest score from the posttest score on all of the independent 2-sample $t$-tests. If the score was positive, it indicated the participants performed better, however if the score was negative, it indicated the participants did not do as well. No statistical difference $(t=-0.507, p=0.620)$ was found for the mean difference between the overall pretest and posttest HSRT scores among participants who had previous health care experience compared to participants who did not.

An independent 2-sample $t$-test was then conducted to determine if there was a difference between those with health care experience in a hospital and those with experience elsewhere on the overall pretest and posttest HSRT scores. Six individuals reported they had worked in a hospital and nine reported working elsewhere. Some individuals had worked in more than one location. No statistically significant difference was found between those who had worked in a hospital and those who had not on the overall pretest HSRT score $(t=1.161, \mathrm{p}=0.264)$ or the overall posttest HSRT score $(t=1.459, \mathrm{p}=0.165)$. Additionally, no statistical difference $(t=0.466, \mathrm{p}=0.648)$ was found for the mean difference in the overall pretest and posttest HSRT scores among participants who had previously worked in a hospital compared to participants who had not. Statistical testing could not be completed for participants with experience in other 
employment locations (nursing home, rehabilitation center, home care, and other) because of the small number of participants in each category (3 or less).

For participants with work experience in a health care setting, the length of time working ranged from 9 to 48 months. A Spearman’s correlation was calculated to determine if there was a relationship between length of time employed in a health care setting and improvement on test scores. No correlation was found $(\mathrm{Rho}=-0.377, \mathrm{p}=$ 0.227) between these variables. There was no indication that the overall pretest or posttest scores were related to length of time employed in a health care setting.

Finally, participants had been asked whether they had previous experience with case studies and videotaped vignettes. Eleven participants reported having these experiences, while only three reported having none. Three participants did not answer the question. Although the mean difference in pretest and posttest scores appeared greater in the group who had previous experience with case studies and videotaped vignettes ( $\mathrm{M}=$ $1.00, \mathrm{SD}=1.732)$ compared to those who $\operatorname{did}$ not $(\mathrm{M}=0.33, \mathrm{SD}=1.293)$, there were too few participants to conduct a statistical analysis.

\section{Summary}

The results of this program evaluation demonstrated a statistically significant increase in the overall HSRT score for the development of critical thinking following the educational intervention using case studies and videotaped vignettes. No statistical significant relationships were found among critical thinking scores and age, critical thinking and previous health care experience, critical thinking and location of that health care experience, and critical thinking and length of time working in health care. Due to the small number of participants in this program, statistical analysis to explore 
relationships between critical thinking and previous experience with case studies and videotaped vignettes could not be completed. 


\section{CHAPTER 6}

\section{DISCUSSION}

This chapter will discuss the findings of this scholarly project and implications for nursing practice. Today's health care setting requires new graduate nurses to not only perform competently, but to be able to transfer information to fit a variety of new situations. It is expected that new graduate nurses know how to think critically; however, this group of nurses are also the most at risk, because they have not yet developed the critical thinking skills necessary to assess and evaluate complex clinical situations in the practice setting (Myers et al., 2010). As a result, nurse educators in practice settings are challenged to prepare new graduate nurses who are competent to provide care that is safe and effective as the complexity of health care increases.

This program evaluation measured critical thinking using performance on the Health Sciences Reasoning Test (HSRT) of new graduate nurses participating in a nurse residency program. The HSRT was administered before and after an educational session on delegation and prioritization, which utilized case studies and videotaped vignettes as the educational strategy. All new graduate nurses hired for the July 30, 2012 nurse residency program participated in this program evaluation.

This chapter will begin with a review of the findings as they relate to this specific scholarly project, including the limitations that were encountered. Then, the influence and impact of these results on the immersion site will be discussed. Next, implications for practice, including the role of the doctoral prepared advanced practice nurse will be examined. The chapter will end with overall conclusions and a summary of this scholarly project. 


\section{Discussion of Findings}

Few studies were found in the literature that focused on critical thinking and new graduate nurses. Most research focused on nursing students. In this scholarly project, a statistically significant difference between pre- and posttest scores was found on the total overall HSRT score, indicating the participants' critical thinking did improve after using case studies and videotaped vignettes as an educational strategy. No relationships were found among the confounding variables and critical thinking.

Critical thinking scores and the educational intervention. Facione, Facione and Winterhalter (2011) state the total overall HSRT score "is the most valid global measure of overall strength in the core critical thinking skills used in problem solving and reflective decision making” (p. 27). These authors also indicate that to score well on the HSRT, an individual must do extremely well in the overall integration of core critical thinking and reasoning skills and have no major weaknesses (Facione et al., 2011). Overall test scores in the range of 15-24 are associated with demonstrated competence in critical thinking in the majority of situations (Facione et al., 2011).

The mean posttest overall score for these participants was 21.94, placing them closer to the upper end of the mid range (15-24). This level of critical thinking provides the capability to benefit from staff development or educational programs which are focused on developed reasoning and decision making. Individuals who score at this level should be able to integrate specialized content knowledge with problem based learning demands (Facione et al., 2011). Facione et al. (2011) note that in college graduates, a total score of 25 or higher indicates very strong critical thinking skills. Four participants, or $24 \%$ of the group, scored 25 or higher on the posttest on the total overall score. 
Thirteen participants scored in the mid range between 15 and 24 and no participants scored below 14 .

It is important to note that all participants, except one, in this program evaluation had earned a baccalaureate degree. Studies of nursing practice have established that better patient outcomes are attained in hospitals staffed by a greater percentage of nurses with a baccalaureate degree and a smaller share of nurses with an associate degree (Benner, Sutphen, Leonard, \& Day, 2010). It is not surprising then that the Institute of Medicine (2011) has recommended that hospitals increase the number of baccalaureate degree nurses to 80 percent by 2020 (Institute of Medicine, 2011). It is unknown if the mean overall score would have been lower if more participants had been prepared with an associate degree in this program evaluation.

Finally, total scores of 14 or lower are very low, suggesting fundamental weaknesses in core critical thinking skills. These weaknesses may result in unsuccessful transitions to college and the workplace (Facione et al., 2011). In this group, on the pretest, one individual scored a 13, but no participants scored less than 14 on the posttest. It is important to note that individuals who fell in this range failed professional licensure examinations more than $60 \%$ of the time in one aggregate analysis (Facione et al., 2011). However, one of the requirements for participation in this residency program was successful completion of the National Council Licensure Examination for Registered Nurses (NCLEX-RN). It could be hypothesized that new graduate nurses who may have scored a lower total overall score were already excluded from participating in this residency program through the hiring process. 
Three scales on the HSRT: analysis and interpretation, inference, and evaluation and explanation, represent the key core skills identified in the theory of critical thinking. These three scales are based on the conclusion of a two year Delphi project directed by Facione (1990) on the definition of critical thinking. The concept of reasoning is separated into the last two scales, inductive and deductive reasoning (Facione et al., 2011).

The analysis and interpretation scale measures skills that are used to carefully examine ideas; to identify assumptions, reasons and claims; and to gather detailed information from charts, graphs, diagrams, and paragraphs. These skills are also used when determining the specific meaning of a sentence, passage, text, or idea in a known context and for a known purpose (Facione et al., 2011). A score of 5 or higher shows analytical and interpretive reasoning strength, while a score of 2 or lower shows weak skills (Facione, Facione, \& Winterhalter, 2011).

The group's mean score for analysis and interpretation on the pretest was 4.29 and 4.53 on the posttest indicating relatively strong analytical and interpretive reasoning strength. On the pretest, three individuals scored greater than 5 and fourteen participants scored between 2 and 5. Minimal improvement was noted on the posttest. On the posttest, four participants scored greater than 5 and thirteen participants scored between 2 and 5 . No participants scored less than 2 on either the pretest or the posttest. Analytical and interpretive reasoning abilities are important skills for nurses to exhibit. They involve properly categorizing information, decoding the significance of that information, and clarifying what something means, which are all steps a nurse uses when assessing a 
patient. Data are compared to previously collected data to assist in identifying a change in a patient's condition.

The inference scale measures the capability of drawing conclusions based on reasons and evidence. Inferences can be skillfully drawn from a broad diversity of things including information, data, beliefs, opinions, facts, conjectures, definitions, principles, images, signs, behaviors, documents, or testimony (Facione et al., 2011). A score of 5 or higher shows strong inference skills and a score of 2 or lower indicates weakness in these skills (Facione et al., 2011). The group’s mean score for inference on the pretest was 2.82. It was 2.76 on the posttest, which falls on the lower end of the mid-range. Specifically, all of the participants scored between 2 and 5 on both the pretest and posttest, except one participant who attained a score of 1 on the pretest.

Overall, the group's lowest scores were on the inference scale, which is important to note since nurses draw conclusions based on a variety of sources of evidence. Graduate nurses often lack the knowledge and experience necessary for developing this skill because of the limited amount of clinical exposure prior to graduation. Benner (1984) found new graduate nurses often enter practice at the level of novice or advanced beginner, but clinical experience presents more complex and multiple additional realities than theory can capture alone. Clinical experiences will help develop the skill of inference. According to Benner (1984), most new nurses require two to three years to transition through the levels of novice and advanced beginner before becoming competent. Casey, Fink, Krugman, and Propst (2004) reported that new graduate nurses need 12 months of support before they are confident in their role as a registered nurse. As a result, it was not surprising that no improvement was noted after just twelve days. 
The evaluation and explanation scale measures skills that are used to assess the credibility of claims and the strength or weakness of arguments. Evaluation skills can also be applied to form judgments about the quality of inferences, analyses, interpretations, options, beliefs, and ideas. Explanation, on the other hand, entails providing one's reasons, methods, assumptions or rationale for one's beliefs and conclusions (Facione et al., 2011). A score of 5 or higher indicates strong evaluative and explanatory reasoning skills, while skills are weak among those who score 2 or lower (Facione et al., 2011). The group's mean score for evaluation and explanation on the pretest was 4.94. The participants scored 5.06 on the posttest. These scores indicate strong evaluative and explanatory reasoning skills. There was little overall difference from the pretest to the posttest. Nine participants scored between 2 and 5 on the pretest compared to eight on the posttest, and eight participants scored higher than 5 on the pretest compared to nine on the posttest.

Nurses use the skills evaluation and explanation throughout the course of a day when caring for patients. They make decisions based on their assessment, identifying what issues are significant, and determining what interventions would best accomplish the desired outcome. Based on that outcome, different interventions may need to be implemented (Jackson, Ignatavicius, \& Case, 2006). The participants scored the highest on this scale, signifying they have strong evaluative and explanatory reasoning skills.

The inductive reasoning scale represents the ability to derive reasonable conclusions regarding what is most likely true or not true, given the information and the context that is available (Facione et al., 2011). A score of 8 or higher indicates strong inductive reasoning skills whereas a score of 5 or lower denotes weak inductive 
reasoning skills (Facione et al., 2011). The group demonstrated strong inductive reasoning skills on both tests. On the pretest, thirteen participants scored between 5 and 8 $(\mathrm{M}=7.53)$ compared to nine on the posttest $(\mathrm{M}=7.94)$. However, one individual scored less than 5.

Jackson, Ignatavicius, and Case (2006) indicate nurses are often able to predict what will happen to a patient based on past experiences with similar circumstances. This supports the work completed by Facione and Facione (2008) who indicate individuals can rely on externally developed protocols and internal mental scripts to assist in deciding what to believe and what to do about a problem. While this group of participants scored high on inductive reasoning skills, it is unknown how well they would perform if they encountered an unfamiliar situation that deviated from the norm. Benner (2004) indicates the novice nurse who encounters a problem will attempt to recognize key relationships in the data that is presented. The novice nurse will then apply interventions and knowledge that would be most relevant to the situation.

The deductive reasoning scale involves moving from the assumed truth of a set of beliefs or premises to a conclusion. In a valid deductive argument, the conclusion cannot possibly be false if the evidence is correct. Deductive reasoning skills are used on activities that require following rules, definitions, laws or diagrams (Facione et al., 2011). Strong deductive reasoning skills are noted in participants who score 8 or higher while weak deductive reasoning skills are found in participants who score 5 or lower (Facione et al., 2011). The group’s mean score for deductive reasoning on the pretest was 6.53 and 6.94 on the posttest indicating the participants fell in the mid-range for deductive reasoning skills. There was no change from the pretest to the posttest scores on the 
deductive reasoning scale. Two participants scored less than 5, twelve participants scored between 5 and 8, and three participants scored greater than 8 .

The results of this scholarly project show this group of new graduate nurses scored in the mid range for overall critical thinking, signifying demonstrated competence in critical thinking in most situations. It is important to note that the participants scored quite high on the pretest. As a result, the degree to which the scores could really improve on the posttest is debatable and needs to be considered when interpreting the results. In addition, the participants scored high on four of the five scales (analysis and interpretation, evaluation and explanation, and inductive and deductive reasoning), indicating areas of strength. The participants, however, scored low on the inference scale demonstrating the need for additional clinical experiences and time to help develop this skill. Based on the results of this scholarly project, it would be beneficial to develop additional educational programs aimed at helping new graduate nurses develop the skill of inference.

Critical thinking scores and the confounding variables. In this scholarly project, critical thinking scores were not related to age, previous health care experience including location of that experience, or length of time employed in health care. Additional statistical analysis to determine if there was a relationship between critical thinking scores and prior experience with case studies and videotaped vignettes could not be completed because of the small number of participants in this program evaluation. It is important to note that if a positive relationship had been found between critical thinking scores and participants who had prior experience with case studies and videotaped 
vignettes, it could be conjectured that prior experience with this educational strategy does impact the development of critical thinking.

In regards to age, based on the literature, one might assume that critical thinking skills would increase as one ages (Cohen, 2005). However, in this program evaluation, the average age of the nurse residents was 25.59 and no relationship was found between critical thinking and age. However, there might not have been enough variability in age of the participants to note a change in the development of critical thinking skills.

\section{Limitations}

This scholarly project had several limitations. First, the conditions under which the testing of critical thinking occurred was a limitation. The initial testing was completed at the end of the nurse residents' first day of orientation, which may have impacted their ability to concentrate. This ultimately may have resulted in lower pretest scores compared to what might have be expected if the testing had been completed at the start of the day when the nurse residents were potentially more rested and alert. After sitting all day listening to a variety of information presented in lecture style format, participants may not have taken the time to analyze and carefully select answers. They potentially were tired, possibly hungry, and ready to leave for the day. While this is just an observation, nonetheless, it is a limitation of the implementation of this scholarly project.

A second limitation revolved around the lack of resources available to the organization for enhancing the development of nurses. Due to space limitations, a skills lab was not readily available for the nurse educators to use. The skills lab had recently been moved to open up space for a 24-hour patient clinical decision unit. As a result, the lab was relocated across the street in another building, which decreased the convenience 
of its use. In addition, due to an upcoming system wide implementation of an electronic medical record, a massive educational rollout was in process, further limiting available space. This rollout resulted in limited access to the computer lab. Finally, there was a lack of simulation equipment in the organization.

Based on recent research, simulation has the potential to offer the most opportunity to impact critical thinking skills, but a major barrier of utilizing simulation is related to its costs. Costs include not only purchasing the equipment, but appropriate space allocation, supporting equipment, maintenance of the equipment, and technology support. These costs can be prohibitive for many organizations, including this one. Given the prohibitive nature of the costs related to simulation, an educational strategy had to be selected to fit the resources that were currently available in the organization. While videotaped vignettes are one basic type of simulation, there are many other simulation techniques available that could potentially provide greater opportunities to foster the development of critical thinking skills.

A third limitation was that this program evaluation was conducted with a very homogenous group of new graduate nurses in relation to their level of education. In this nurse residency program participants were required to hold a baccalaureate degree, unless they were current employees of the organization. As a result, with the exception of one associate degree graduate nurse, the participants in this program evaluation were exclusively baccalaureate prepared graduate nurses. The importance of this issue to the organization will be discussed in the next section.

It is important to note that on the pretest this group of nurse residents scored quite high on overall critical thinking skills and four of the five scales. Regardless of the 
educational strategy used, with these high scores on the pretest, it may have been impossible for the posttest scores to improve significantly without some other type of intervention. What is known as a "ceiling effect" may have been encountered with this project. In the domain of testing, a ceiling effect can occur when a measure possesses a definite upper limit for potential responses and a large percentage of participants score at or near this limit, reducing the possibility of measuring improvement (Hessling, Traxel, \& Schmidt, 2012).

Another potential explanation for the minimal change in scores may be related to the reliability in this sample. The HSRT has a Kuder-Richardson (KR-20) internal consistency coefficient ranging from 0.77 to 0.84 , and an overall internal consistency of 0.81 (Facione et al, 2011; Sullivan-Mann et al., 2009). It is important, however, to note that a KR-20 related to this sample could not be conducted due to the small sample size and prohibitive cost.

Lastly, and probably of greatest importance, the number of participants in the nurse residency program was small. The results of this evidence-based project are site specific, which precludes generalization to other organizations. While this educational strategy could be implemented in other organizations, a variety of factors may preclude similar results. First, testing conditions could not be replicated. Second, besides potential differences in numbers of orientees, demographics of the participants may not be similar. The majority of the nurse residents in this organization were Caucasian, female, and in their early 20s (Mode = 22). A more heterogeneous group, for example, increasing the number of males, hiring older nurses, or increasing the ethnic diversity of the participants, could affect the variability. 


\section{Influence/Impact of Findings on the Immersion Site}

The Iowa model of evidence-based practice to promote quality care (Titler et al., 2001) was used as the implementation framework for this scholarly project. The last step in the Iowa model is to determine if the change will be appropriate for implementation at a broader scale (Ciliska et al., 2011). Based on the results of this program evaluation, a decision was made that the educational strategy would be used in the next residency program that started the following fall.

At this setting, following the implementation of this project, the general nursing orientation was currently under revision due to the implementation of an electronic medical record. The use of case studies is being planned for many of the content areas, which is new for the organization. The possibility of including videotaped vignettes in a couple of the content areas is currently being explored as well. In the past, lecture and story telling were the main educational approaches used during general orientation and the nurse residency program. Based on the review of the literature for this scholarly project, the organization has recognized the benefits of including other educational modalities and is very open to implementing new pedagogical strategies.

One of the advantages of this specific educational strategy is that both case studies and videotaped vignettes could be applied to other educational topics that are covered in both the residency program and in general nursing orientation. Case studies can be developed quite easily compared to other educational approaches (i.e. simulation) and do not require a lot of additional resources. In addition, case studies could be developed to expose new graduate nurses to situations and clinical experiences that are not frequently encountered, helping to develop the skill of inference. Videotaped vignettes do require 
greater resources for their development, but several options are available. For example as was the case for this project, there may be excellent resources on the internet, many of which are available free of charge.

One unexpected result of this program evaluation was discovering the lack of effective delegation observed by the DNP student through conversations with previous and current participants of the nurse residency program. Learning how to delegate effectively is a skill that is not just limited to new graduate nurses; rather it is a skill that benefits all registered nurses in the organization, regardless of length of time they have been a registered nurse. The importance of working with others and the ability to delegate, assign, manage and supervise is critical and challenging due to the current health care environment (2012b). As a result, the organization made a decision to include this content in future general orientations beginning in December, 2012.

Consequently, the organization has an opportunity to use this educational strategy and content not only during future residency programs and general orientation, but as an educational rollout for all registered nurses. One mechanism to achieve this would be the annual competency fair. This might be beneficial for the organization in light of a recent report released by the Michigan Department of Community Health’s Task Force on Nursing Practice. This report recommends clarifying the delegation of nursing functions (Michigan Department of Community Health, 2012). This recommendation is just one of ten listed to improve access to safe, high quality health care to the residents of Michigan.

Overall, in regards to the specific HSRT test results, this particular group of nurse residents scored in the upper range of average to high on four of the five scales. With this finding, how reasonable is it to expect scores to improve significantly through this type of 
intervention? It may be beneficial to use the Health Sciences Reasoning Test (HSRT) (Insight Assessment, 2011) to obtain a baseline for critical thinking for all new nurses hired. Based on the nurse residents' performance and the small amount of change in scores that was observed, perhaps resources could be allocated to develop other programs if new employees also were found to attain high HSRT scores.

The importance of employing baccalaureate prepared nurses in the acute care setting has been well documented. The Institute of Medicine’s (IOM) goal is to increase the proportion of nurses with a baccalaureate degree working in hospitals to 80 percent by 2020 (Institute of Medicine, 2011). This recommendation was made by the IOM because nurses are caring for sicker patients in hospitals with increased complexity and using more sophisticated, life-saving technologies. As a result, a more educated nursing workforce is necessary to meet the demands of the evolving health care system (Institute of Medicine, 2011).

However, in reality, there are many factors that limit the capacity of colleges and universities to meet the staffing demands of hospitals, resulting in a workforce with many associate degree nurses. This organization currently hires new graduate nurses who have obtained an associate's degree. However, these individuals are not eligible to participate in the nurse residency program and as a result, receive a significantly shorter orientation that is not specifically geared towards new graduate nurses. This project was not able to establish whether associate degree graduate nurses were hired with similar critical thinking skills, nor whether the intervention could improve critical thinking scores in that group of nursing graduates. It would be valuable to know how these individuals scored on either the HSRT or a similar type of test. Then, orientation programs could be 
developed to meet the needs of all new graduate nurses, recognizing that some may need more support than others. In addition, obtaining this baseline information would help determine the type of support the new graduate nurse needs. The goal of this organization should be to prepare all new graduate nurses, regardless of educational preparation, to provide safe quality care to all patients.

Currently, the organization may be spending valuable resources on a group of individuals who are already exhibiting a fairly high level of critical thinking when another group of new graduate nurses is more at risk. The possibility of tailoring an orientation program in regards to content and overall length based on the specific needs of the new graduate nurse is a possibility that the organization should explore.

While the results of the deductive reasoning scale fell in the mid-range, the results were still surprising, considering new graduates in the residency program are instructed to follow all policies and procedures to ensure patient safety. They are taught how to access policies and the importance of asking questions when in doubt. It is also important to note that during one of the new employee support team (NEST) meetings with previous nurse residents, many stated they did not have time to review policies and procedures. Instead, they seek guidance from others or just complete the task to the best of their ability based on their current level of knowledge. Unfortunately, this can have serious implications for the overall care that is provided to the patients.

Currently, preceptors have full patient assignments when they work with new orientees. One course of action for the organization to consider would be to revise how new graduate nurses are precepted. It is difficult, if not unrealistic, for a preceptor to orient a new graduate nurse when he or she has a full patient assignment. A preceptor is 
unable to spend meaningful time explaining and reviewing policies and procedures under those circumstances. The complexity and acuity of the current acute care patient population makes this a challenging situation. However, this option would need to be carefully analyzed to determine the costs associated with implementation of a reduced patient load for preceptors. In addition, in this organization, there are collective bargaining issues that would need to be investigated as well.

The nurse residents scored the lowest on the inference scale. Consequently, the organization may need to consider developing additional programs that assist new graduate nurses in making inferences. Presenting actual patient case studies would be one option. Another option would be to increase the visibility of clinical nurse specialists or nurse educators on the unit. Currently, one clinical nurse specialist is responsible for six medical-surgical units and each nurse educator is responsible for three medical-surgical units. This workload does not permit time for them to work with specific nurses. As a result, their focus is primarily on departmental responsibilities or "putting out fires."

\section{Implications for Practice}

An individual's ability to apply critical thinking skills is not only developed by experience, but it is also fostered in the classroom setting (Kowalczyk, Hackworth, \& Case-Smith, 2012). As a result, educators in practice and academia need to keep informed of changes in educational strategies that may impact the development of critical thinking skills. It is impossible to prepare new graduate nurses for every situation they could encounter in the clinical practice environment, which is why it is so important for individuals to develop critical thinking skills (Kaddoura, 2010). The development of critical thinking skills, and therefore, competent clinical decision-making, is not achieved 
through one educational method alone, but through the implementation of a variety of educational approaches (Howard, 2007).

This program evaluation used two different educational strategies, case studies and videotaped vignettes. Using multiple approaches is one option that should be considered when selecting an education strategy. Technology should be embraced. Opportunities exist to create online case studies and online self-learning modules. Designing scavenger hunts that use technology to ensure individuals know how to access and find information in policies or procedures would be another possibility. Otherwise, if a process is created that leaves little to no room for alternative strategies to be tried, the organization runs the risk of missing opportunities to potentially do things more effectively and efficiently (Jackson, Ignatavicius, \& Case, 2006).

Individuals are unique and not all individuals learn the same way. This is why using a variety of educational approaches would be beneficial. Additionally, the educational content will also guide the selection of the educational strategy to be used. Not all topics can be delivered effectively and efficiently using case studies or videotaped vignettes. For example, teaching nurse residents how to correlate lab values with specific medications may be achieved by other educational tactics including questioning by the preceptor. However, in order for this approach to be effective, a program would need to be developed for the preceptors on the skill and art of questioning. Questioning is a skill that needs to be taught and developed, yet little guidance is provided to preceptors regarding this educational tactic. 
The Essentials of Doctoral Education for Advanced Practice Nursing. The Doctor of Nursing Practice (DNP) degree has been adopted as the terminal practice degree in nursing (AACN, 2006). The Essentials of Doctoral Education for Advanced Nursing Practice are the foundational outcome competencies considered core for all DNP graduates (AACN, 2006). The following section will discuss the eight DNP Essentials and how they relate to this scholarly project.

Scientific underpinnings for practice. This essential describes the scientific foundations of nursing practice, which are centered on the natural and social sciences (AACN, 2006). In accordance with this essential, this scholarly project was based on a scientific foundation of theory and research. Specifically, Donabedian’s Structure, Process, Outcome model (Donabedian, 2003) and Knowles’ six principles of andragogy (Knowles, Holton, \& Swanson, 1998) were used as the conceptual frameworks to guide this scholarly project.

In regards to Donabedian's (2003) model and structure, this scholarly project was implemented in a nurse residency program in a 697 licensed bed, not-for-profit community governed hospital located in lower mid-Michigan. The organization provided the necessary support to implement this scholarly project. Material resources included providing a location for testing that was situated away from the inpatient units to ensure a quiet environment for the nurse residents to complete the pre- and posttest. The Department of Nursing made available a copy machine to provide each nurse resident with a copy of the case studies. In addition, the room was prepared with a laptop, large screen, and speakers for accessing the videotaped vignettes. 
From a human resources perspective, the organization designated time in the nurse resident's schedule to implement the educational intervention and provided the financial support for the residents to attend all three phases of implementation of this scholarly project. This was critical, considering the number of competing priorities in the nurse residency program and having only a designated amount of time.

Organizational characteristics included providing leadership support for the DNP student from both the nurse educator responsible for the nurse residency program, and the Director of Nursing Education, Practice and Research. The organization was committed to the success of this scholarly project and worked collaboratively with the DNP student to ensure a successful implementation, despite competing priorities and the need to cover specific content within a specific time frame.

The process involved using case studies and videotaped vignettes as an educational intervention to facilitate the development of critical thinking skills in graduate nurses. Knowles’ six principles of andragogy (Knowles, Holton, \& Swanson, 1998) guided the educational content of the case studies to ensure the engagement of the nurse residents. One of the principles Knowles refers to is the learner's need to know (Knowles, Holton, \& Swanson, 1998). Registered nurses must delegate in order to provide health care to individuals that is affordable, accessible, and of high quality. When delegation is performed according to the law and standards, the efficiency of health care can be enhanced. It was evident, based on conversations with past and current nurse residents, that many lacked a good foundation in regards to the concept of delegation. A second principle is prior experience of the learner (Knowles, Holton, \& Swanson, 1998). In most academic programs, there is little or no opportunity to delegate 
elements of care in the clinical setting. As a result, nurse residents have had limited experience delegating to others. Yet, once they enter the practice environment, they are expected to do so.

Finally, Knowles talks about readiness to learn and the motivation to learn (Knowles, Holton, \& Swanson, 1998). Based on conversations with past and current nurse residents, many verbalized excitement to learn more about delegation. The desire to learn more was most evident during the actual educational intervention. All of the nurse residents were fully engaged and actively participated in the discussion. Informal feedback from the nurse residents after the session was very positive.

The outcome of the intervention was the statistically significant difference between the pretest and posttest scores on the overall HSRT score. After using case studies and videotaped vignettes as an educational approach, participants' critical thinking did improve. The educational strategy selected for this program evaluation, case studies and videotaped vignettes, was based on the review of the literature. Although the review of the literature was inconclusive, case study methods with the addition of videotaped vignettes were identified as generally effective methods for increasing critical thinking scores among nursing students. However, their infrequent use in orientation programs limited the ability to ascertain their effectiveness among graduate nurses participating in a nurse residency program. On the other hand, based on this review of the literature to evaluate the effectiveness of evidence-based educational interventions for the development of critical thinking skills in new graduate nurses, it appears likely that high fidelity simulation has the potential to offer the most opportunity to impact critical 
thinking skills. However, organizational limitations prohibited the selection of this approach.

\section{Organizational and systems leadership for quality improvement and systems}

thinking. In order for the DNP graduate to impact and improve health care delivery and patient care outcomes, it is critical that individuals are prepared in organizational and systems leadership that "emphasizes practice, ongoing improvement of health outcomes and ensuring patient safety” (AACN, 2006 p. 10). After attending three new employee support meetings (NEST) and talking with both current and former nurse residents, it became very clear that new graduate nurses were struggling with delegation to assistive personnel. Yet, nurses must delegate in order to provide health care to consumers that is affordable, accessible and of high quality. When delegation is performed according to the law and standards, the efficiency of health care can be enhanced (LaCharity, Kumagai, \& Bartz, 2006).

Approximately six weeks after the educational intervention and posttest were completed, the DNP student continued to work on delegation with the nurse residents by meeting with them and reading their weekly journals. The journals had to include an example of delegation. Effective delegation requires critical thinking, and the nurse residents struggled. Nurses have to make judgments about the stability of each patient and delegate accordingly (Jackson, Ignatavicius, \& Case, 2006).

Delegation was not an easy concept for them to implement. There were several reasons for this, including working with preceptors who many times stepped in and worked side-by-side with the nurse resident, decreasing their need to delegate. In many situations, the lack of delegation role modeling from other nurses on the unit hindered the 
process because the nurse residents were not able to see the steps of delegation put into action. Resistance from the patient care technicians and lack of leadership skills and selfconfidence by the nurse residents also impacted the ability to delegate. Often, it was easier for the nurse residents to just do the task on their own because that is what they were accustomed to doing during their academic preparation. Finally, an overall lack of experience delegating to assistive personnel inhibited their ability to delegate. Delegation is a concept that is often covered in the final semester in many academic programs and, according to some nurse residents, not covered at all. The National Council of State Boards of Nursing (2012b) indicates delegation skills are developed over time, so it was not surprising that the new graduate nurses struggled. Mastering the skill and art of delegation will take time, but it is a vital step on the journey to nursing excellence (National Council of State Boards of Nursing, 2012b).

It also became evident during this scholarly project that the role and responsibilities of the patient care technician were unclear. While there is a patient care technician job description, it is very vague and would benefit from having a skills list added as an addendum for each specialty area. In addition, it became obvious to the DNP student that it was not only the nurse residents who were struggling with delegation. For the most part, the majority of the nurses in this organization appeared to have difficulty with delegation. Multiple factors exist, but the complexity of this activity will require ongoing follow-up. It is important to note that based on personal observations in other organizations, this DNP student believes this issue is not isolated to this organization.

This organization, like others, needs to be concerned about patient safety and quality of care. Nursing competency plays a significant role in promoting patient safety, 
and critical thinking is thought to be a vital component of nursing practice (Fero et al., 2010). Case studies and videotaped vignettes, in this scholarly project, were found to be an effective method for improving critical thinking skills in new graduate nurses. However, with the exception of one graduate, all of the participants in this program evaluation had a baccalaureate degree. It would be important to determine if new graduate nurses with an associate's degree would exhibit similar results.

It would be important for the organization to know whether educational preparation impacts critical thinking. This knowledge may be helpful in determining adequate staffing patterns. Differences in educational preparation could impact hiring decisions made by the organization and further support the Institute of Medicine (IOM) goal that the proportion of nurses with a baccalaureate degree working in hospitals be increased to 80 percent by 2020 (Institute of Medicine, 2011). This recommendation was made by the IOM because nurses are caring for sicker patients in hospitals with increased complexity and using more sophisticated, life-saving technologies. As a result, a more educated nursing workforce is necessary to meet the demands of the evolving health care system (Institute of Medicine, 2011).

Currently, approximately $38 \%$ of the registered nurses in this organization have a baccalaureate degree. The organization is currently offering 100 percent tuition reimbursement for individuals returning to school for their baccalaureate degrees in order to increase the number of baccalaureate prepared nurses in the organization. This is an extraordinary level of financial support for the institution's associate degree nurse. 
Clinical scholarship and analytical methods for evidence-based practice. The DNP graduate is engaged in advanced nursing practice and provides leadership for evidence-based practice. As a result, competence is required in the following knowledge application activities: "the translation of research into practice, the evaluation of practice, improvement of the reliability of health care practices and outcomes, and participation in collaborative research” (AACN, 2006, p. 11). An extensive review of the literature was conducted for this scholarly project to identify a definition of critical thinking, review instruments that are used to measure critical thinking, and finally, to examine different educational approaches that can be used to develop critical thinking. Although the current research literature did not provide evidence of the effectiveness of one specific education strategy over another for developing critical thinking skills, based on the existing literature, case studies and videotaped vignettes were identified as generally effective methods for increasing critical thinking scores. The educational strategy was implemented and then formally evaluated using the Health Sciences Reasoning Test (HSRT). Based on the results, recommendations were provided for implementation in future orientation programs.

Another key responsibility of the DNP graduate, and a step in the Iowa model, is to disseminate findings of evidence-based projects (Ciliska et al, 2011). In addition to a presentation at the organization, the DNP student plans to present this scholarly project at conferences and to publish at least one manuscript. The DNP student will hopefully have the opportunity to use a variety of educational approaches in her future career in academia. In addition, the DNP student has plans to become involved with a state-level initiative on delegation. 


\section{Information systems/technology and patient care technology for the}

improvement and transformation of health care. DNP graduates are prepared to "use

information systems/technology to support and improve patient care and health care systems, and provide leadership within health care systems and/or academic settings"

(AACN, 2006, p. 12). One significant issue that requires more or better critical thinking includes advances in information technology. Today's learners are more technologically experienced compared to early generations of learners (Burns, O’Donnell, \& Artman, 2010). Educational approaches must be developed with this in mind in order to meet the needs of this generation of learners. Integrating simulation with case studies, as an educational strategy, can contribute to patient safety and optimize outcomes of care (Durham \& Alden, 2008), while at the same time meeting the needs of these learners.

Because of limited resources in this organization, simulation was not a feasible approach for this scholarly project. However, based on the review of the literature, simulation does appear to be a more effective and promising approach. The organization recognizes the importance of simulation and is in the process of opening a Center for Innovation in collaboration with a major academic university. Creating an environment that fosters innovation and places emphasis on continuous learning benefits everyone from the student to the patient. Simulation can involve a variety of techniques which allow individuals to demonstrate critical thinking and decision making skills (Jeffries \& Rogers, 2007). This organization will have significant opportunities once the Center for Innovation is fully operational. 
Health policy for advocacy in health care. DNP graduates are leaders in the practice field and can provide a vital interface between practice, research, and policy (AACN, 2006). Innovative teaching strategies, including the use of case studies and simulation like videotaped vignettes, require resources. Due to the limited financial funding available in most organizations, advocacy for additional funding for organizations to implement simulation programs may be beneficial in order to address and implement recommendations made by various accreditation agencies and the Institute of Medicine. Based on the review of the literature completed for this scholarly project, simulation has the potential to offer the most opportunity to impact critical thinking skills. However, the cost makes it prohibitive for many organizations to implement (Broussard, 2008; Campbell, 2006; Durham and Alden, 2008), which was the case in this organization.

Additional funding is needed to support educational research. There are a limited number of research studies that compare different educational strategies for developing critical thinking skills. These comparative studies are necessary to help determine if there is an educational approach that is the best at facilitating the development of critical thinking skills. In addition, most research is focused on nursing students, yet in a study completed by the Health Care Advisory Board new graduates were unable to demonstrate safe clinical judgment (Goode \& Williams, 2004). Additional research is needed that focuses specifically on new graduate nurses. The evidence from that research could then be used to guide changes in academic programming and, subsequently, the choices for action at the organizational level. 
The organization that was the setting for this scholarly project supports a nurse residency program and has published research surrounding the success of this particular residency program. There is a need for development of effective residency programs that offer support for new graduate nurses to ease their transition into practice. This is vital because many new graduate nurses leave the nursing profession within the first two years of graduating (Bratt, 2009). The costs of their education, as well as the loss of their important skills, ultimately impact health care quality and expenditures in adverse ways.

\section{Interprofessional collaboration for improving patient and population health}

outcomes. Within the complexity of today's health care environment, DNP graduates are prepared to assume leadership roles in establishing interprofessional teams to facilitate collaboration and team building (AACN, 2006). As a result, the DNP prepared nurse is able to undertake a key role in interprofessional teams with the goal of building strong clinical teams and improving health outcomes (Ogrinc et al., 2012). In the acute care setting, nurses interact with many other disciplines to provide care to the patient. The DNP nurse is an excellent source to lead interprofessional teams with a clinical focus to address complex administrative and clinical issues.

Based on some of the situations experienced by the nurse residents, opportunities exist for collaboration between the registered nurses and patient care technicians in this organization. A DNP graduate would be prepared to analyze complex organizational issues through leadership and work collaboratively to find solutions to ensure quality patient care is delivered to every patient, every time. The complexity of this issue is immense in this organization, and representation by two separate bargaining units further complicates the relationships among these members of the health care team. 
Interprofessional education is further supported by the Institute of Medicine (Interprofessional Education Collaborative Expert Panel, 2011) and is also addressed in the Essentials of Baccalaureate Education for Professional Nursing Practice (American Association of Colleges of Nursing, 2008). In the academic setting, interprofessional education has the opportunity to address multiple issues ranging from understanding the training and background of other health professionals, to learning how to effectively communicate with them. Opportunities exist in the acute care setting to work with nurse residents and in particular, with physicians, since in their weekly journals many of the nurse residents verbalized anxiety about communicating with physicians. The DNP graduate is prepared to develop and lead teams to address these types of challenges with the objective of improving care and health outcomes for patients. These are concerns that unite all health care professions (Ogrinc et al., 2012).

\section{Clinical prevention and population health for improving the nation's health.}

DNP graduates have a foundation in clinical prevention and population health which prepares them to participate in health promotion and risk reduction activities from a nursing perspective (AACN, 2006). In regards to this specific project, the DNP prepared nurse is in an excellent position, based on his or her academic preparation, to facilitate the professional growth of nurses who work at the bedside by evaluating and implementing the best evidence-based practices for staff development. When new graduate nurses are able to critically think, it will contribute to improving care and ultimately patient outcomes. 
Advanced nursing practice. Effective and dynamic leadership skills of DNP prepared nurses specializing in nursing administration and health care systems are essential for developing and implementing well-planned organizational programs. The role of the nurse executive is multifaceted and requires broad-level thinking. The American Organization of Nurse Executives Standards of Practice and Professional Performance (American Nurses Association 2009) describe the duties nurse executives are expected to competently perform. The goal of nurse executives is to develop and implement programs that are focused on safety and quality that seek to meet the expectations of the nursing profession, the consumer, and society.

Key elements of the nurse executive role for this scholarly project included the following standards of practice:

- conducting an assessment of the nurse residency program (Standard 1: Assessment);

- identifying new graduate nurses struggling with the concept of delegation (Standard 2: Identifies Issues, Problems, or Trends);

- recognizing the use of critical thinking skills are essential components of nursing and are crucial to nursing practice (Standard 3: Outcomes Identification);

- utilizing evidence-based practice to guide the selection of the educational strategy (Standard 4: Planning);

- implementing the educational strategy (Standard 5: Implementation);

- evaluating the effectiveness of the educational strategy (Standard 6: Evaluation). Standards of professional performance that were enacted during this scholarly project included: 
- leading a program evaluation that supported the organization and nursing core values and objectives of providing safe, quality care to all patients (Standard 7: Quality of Practice);

- researching current information on the topic of delegation and prior experience working with students and registered nurses led to the development of an educational teaching plan (Standard 8: Education);

- the DNP student collaborated with the Director of Nursing Education, Practice and Research and the nurse educator responsible for the nurse residency program to ensure a successful program implementation and evaluation (Standard 11: Collaboration);

- the DNP student reviewed the literature to evaluate the effectiveness of evidencebased educational interventions for the development of critical thinking skills (Standard 13: Research);

- financial costs related to the educational strategy were carefully considered in order to promote future sustainability of the program (Standard 14: Resource Utilization);

- excitement and passion for this scholarly project was demonstrated by the DNP student. The DNP student remained flexible with dates in order to ensure overall success of the program implementation. In addition, the educational content was designed to effect change in practice and ultimately outcomes (Standard 15: Leadership).

Knowledge in nursing administration and health care systems provided the foundation to implement this scholarly project. The DNP prepared nurse is educated in 
the use of many different theories and frameworks to assist in organizational development. Specific examples of theories this DNP student had previously used during her academic program included health services research, the open systems model, the theory of complexity science, implementation science, and structural contingency theory. The DNP prepared nurse specializing in nursing administration needs to carefully view the concepts of effectiveness, efficiency, and equity. These concepts should be used as specific criteria for evaluating policies and practices at the clinical level to determine if they actually result in substantial health improvements (effectiveness), are the best use of limited resources (efficiency), and disperse benefits and costs equitably across groups (Aday, Begley, Lairson, \& Balkrishnan, 2004). These concepts are vital when evaluating the best evidence-based methods of orienting new graduate nurses.

The review of the literature suggests that multiple strategies can be utilized to facilitate the development of critical thinking skills. The specific educational approach that is selected may be based on the content that is to be delivered because one strategy will not fit all situations or content areas. In addition, leadership support is critical. As noted in this program evaluation, while the educational strategy was significant in developing critical thinking skills, the nurse residents still needed additional follow-up regarding the actual content.

Evidence obtained during this program evaluation revealed it is also important to know the audience for interventions. In this project, with the exception of one nurse, all of the nurse residents had baccalaureate preparation. Overall, on the pretest, this group of nurse residents scored quite high on many of the scales of the critical thinking instrument. When an individual is already performing at a high level, how much additional 
improvement is realistic within a short period of time and with low impact interventions? By obtaining an individual baseline on each participant, resources could be designated to develop programs for individuals requiring greater assistance. For example, general registered nurse orientation could be designed with several tracks to address the different needs of individuals that are based on a pre-assessment of their critical thinking abilities.

Finally, mentoring is an important role of the DNP prepared nurse and one that the DNP should embrace. The DNP student had the opportunity to informally mentor one of the educators responsible for the nurse residency program in an effort to maintain excellence in nursing practice. In addition, the DNP student encouraged the educator to try new and innovative ways of educating nurses.

\section{Summary and Conclusions}

The intent of this program evaluation was to determine if using case studies and videotaped vignettes helped to facilitate the development of critical thinking skills in new graduate nurses participating in a nurse residency program. Critical thinking skills were measured using the HSRT. The program evaluation found a statistically significant increase in the overall score on the HSRT. Using case studies and videotaped vignettes was found to improve critical thinking in new graduate nurses participating in this organization's nurse residency program.

Today's health care settings require graduate nurses to not only perform competently, but to be able to transfer information to fit a variety of new situations. This requires the ability to think critically. It is important for nurse executives to understand how the concepts of structure, process, and outcome influence the development of critical thinking skills in new graduate nurses. Organizations have many competing priorities, but 
positive outcomes will only be achieved if there are effective structures and processes in place.

In the event of unsatisfactory outcomes, the nurse executive needs to analyze where problems exist in the care model so effectiveness and efficiency can be increased. If there are challenges with the structures in place, these would need to be addressed.

Commitment to an educational strategy, including appropriate resource allocation for the purchase of equipment and supplies, must be considered. In addition, time must be allocated for educators to prepare the appropriate material, like case studies. If resources are not available at the start, the effectiveness of an educational approach could be impacted.

Nurse executives must also consider other factors. For example, in regards to this specific program evaluation, at what point in the residency program should the topic of delegation be presented? Is there a difference if it is presented at the beginning, middle, or end of the program? If there are issues with the process, like the educational strategy utilized is not effective, other strategies will need to be investigated and implemented. In addition, nurse executives need to carefully analyze how new graduate nurses are oriented to ensure suitable programs and supports are available to ensure their success. While the results of this program are site specific, other organizations could modify this program to meet the needs of their unique setting to promote the development of critical thinking skills in new graduate nurses. In addition, there are implications for nurse executives working in academic settings involved in the development and implementation of undergraduate education. This educational approach could be implemented throughout the curriculum. 
A variety of educational approaches can be used to facilitate the development of critical thinking. Nurses, both new and experienced, benefit from continuously challenging their thinking. Education is one of the most significant resources for nurses, but what is especially important is that nurses actually learn and can apply the information that is taught to them (Jackson, Ignatavicius, \& Case, 2006).

Finally, it is important to note that critical thinking skills in new graduate nurses take time to develop. Benner (1984) states new graduates often enter practice at the level of novice or advanced beginner, but clinical experience provides more complex situations and presents more compelling realities than theory can capture alone. In addition, educators only have two to four years, depending on the academic program, to help students develop appropriate critical thinking skills. For many, if not all graduates, that is just not enough time. Organizations, and the nurse executives that lead them, have important roles in continuing the development of graduate nurses through mentoring and coaching long after orientation is completed (Jackson, Ignatavicius, \& Case, 2006).

A career in nursing involves life-long learning. Individuals need to be accountable for their own learning, but the DNP prepared nurse has the opportunity to impact and make a difference in the lives of new graduate nurses in multiple ways. The actions of the DNP nurse executive in these situations can ultimately lead to a safer health care system and better outcomes for patients. 
APPENDICES 



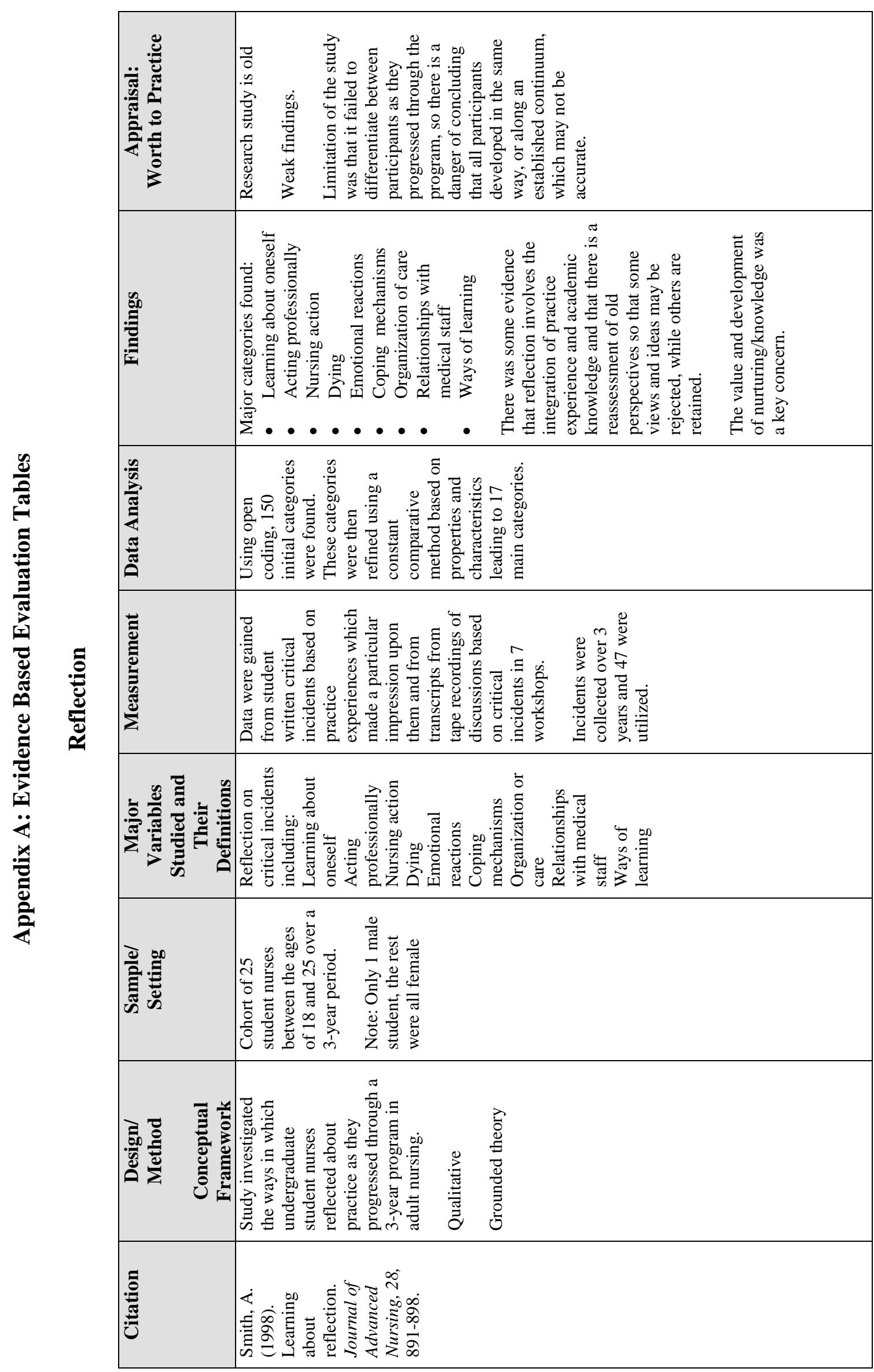




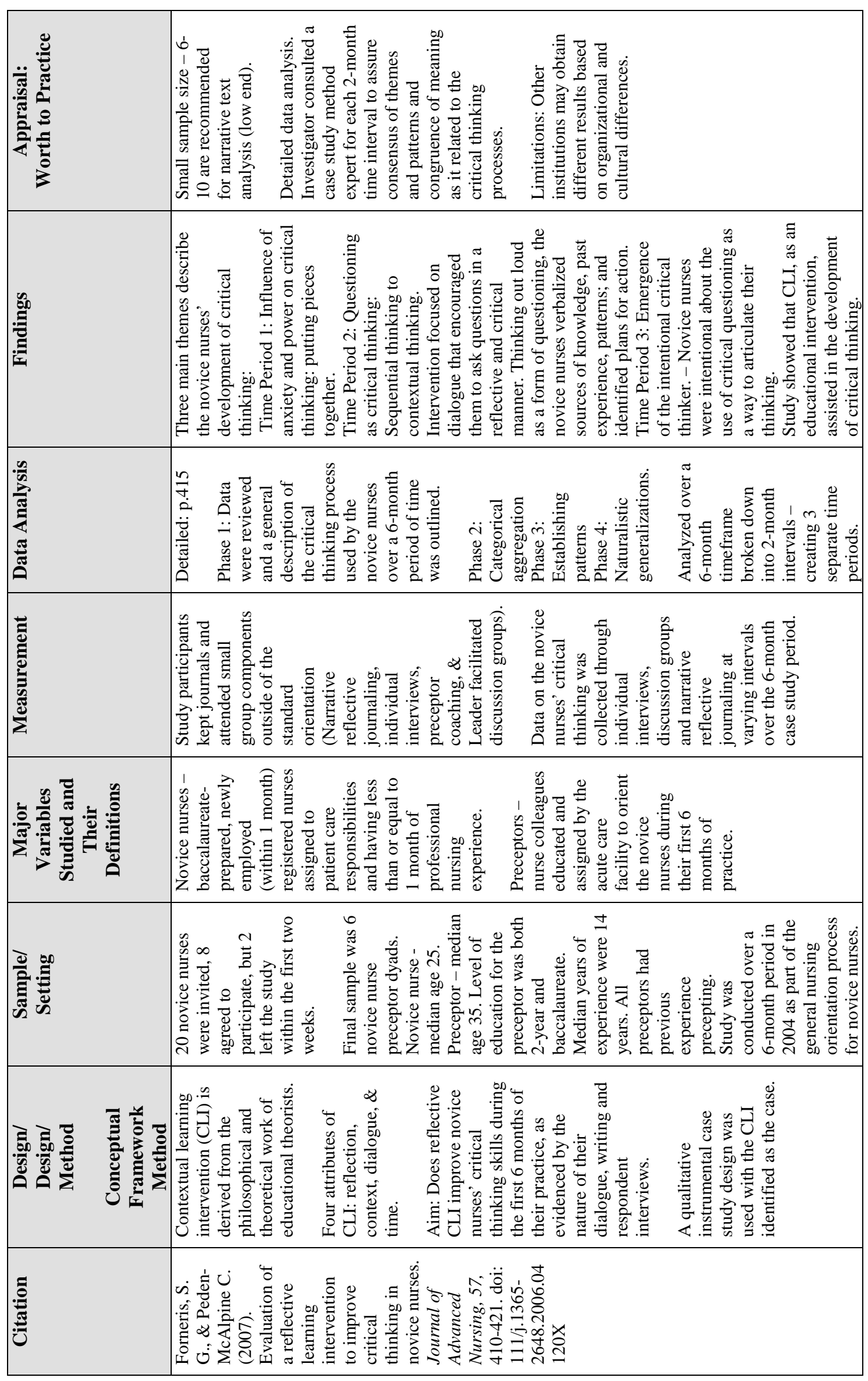




\begin{tabular}{|c|c|c|c|}
\hline 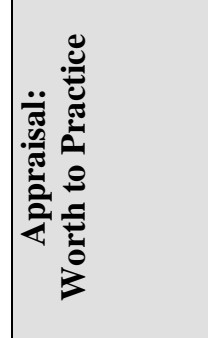 & 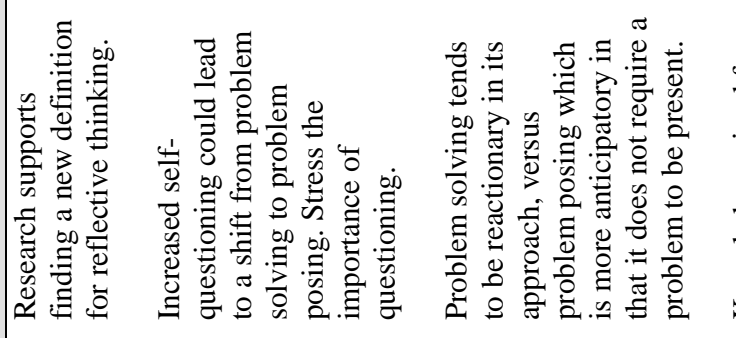 & 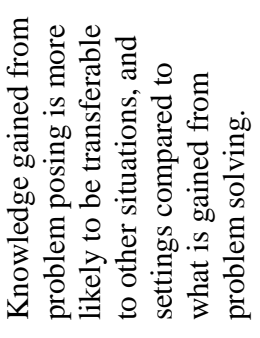 & 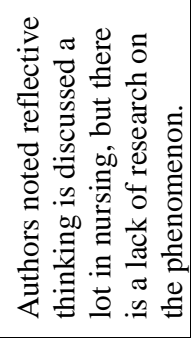 \\
\hline 点 & 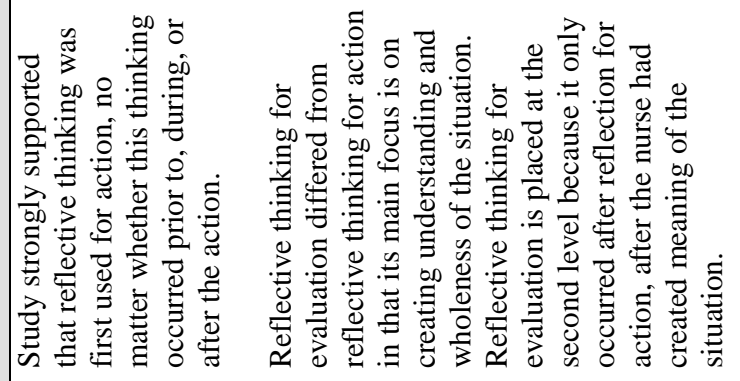 & 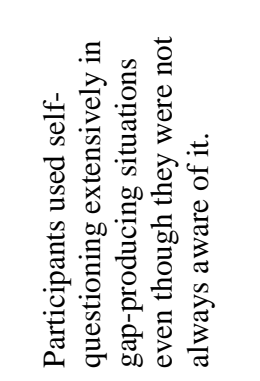 & \\
\hline 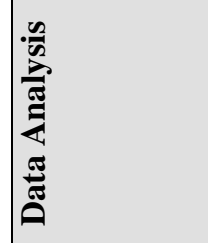 & 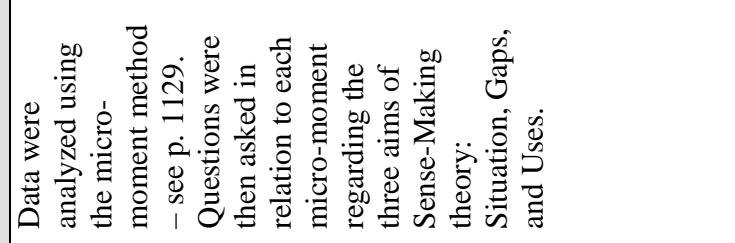 & & \\
\hline 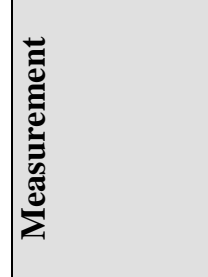 & 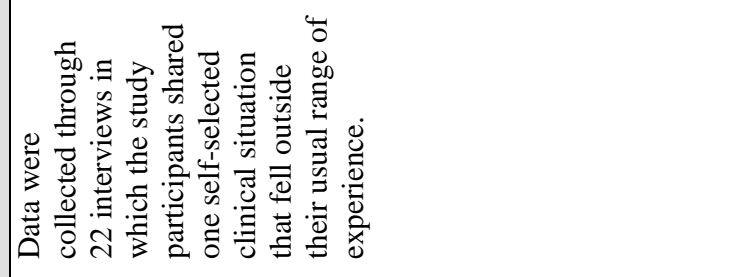 & & \\
\hline 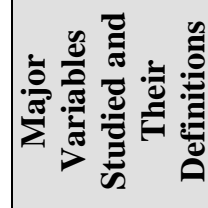 & & & \\
\hline 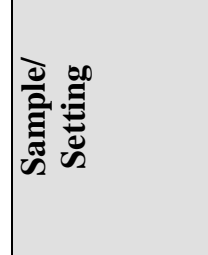 & 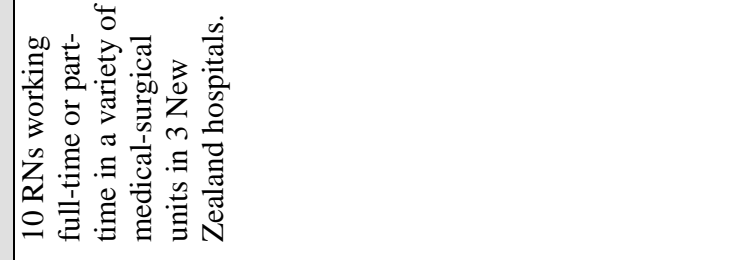 & & \\
\hline 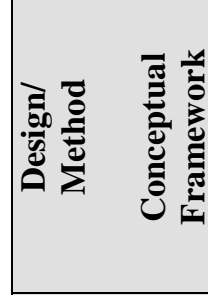 & 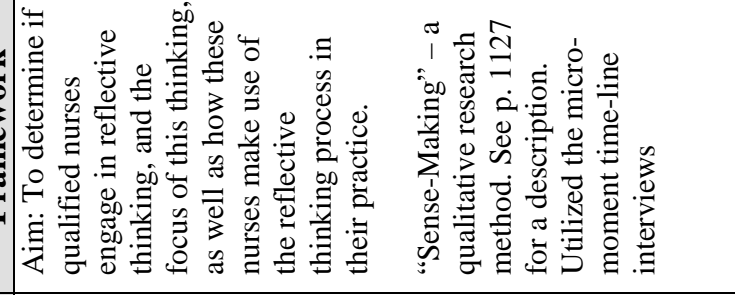 & & \\
\hline Uू & 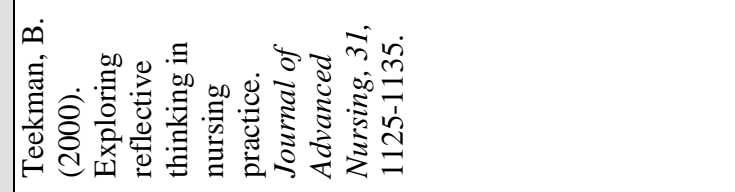 & & \\
\hline
\end{tabular}




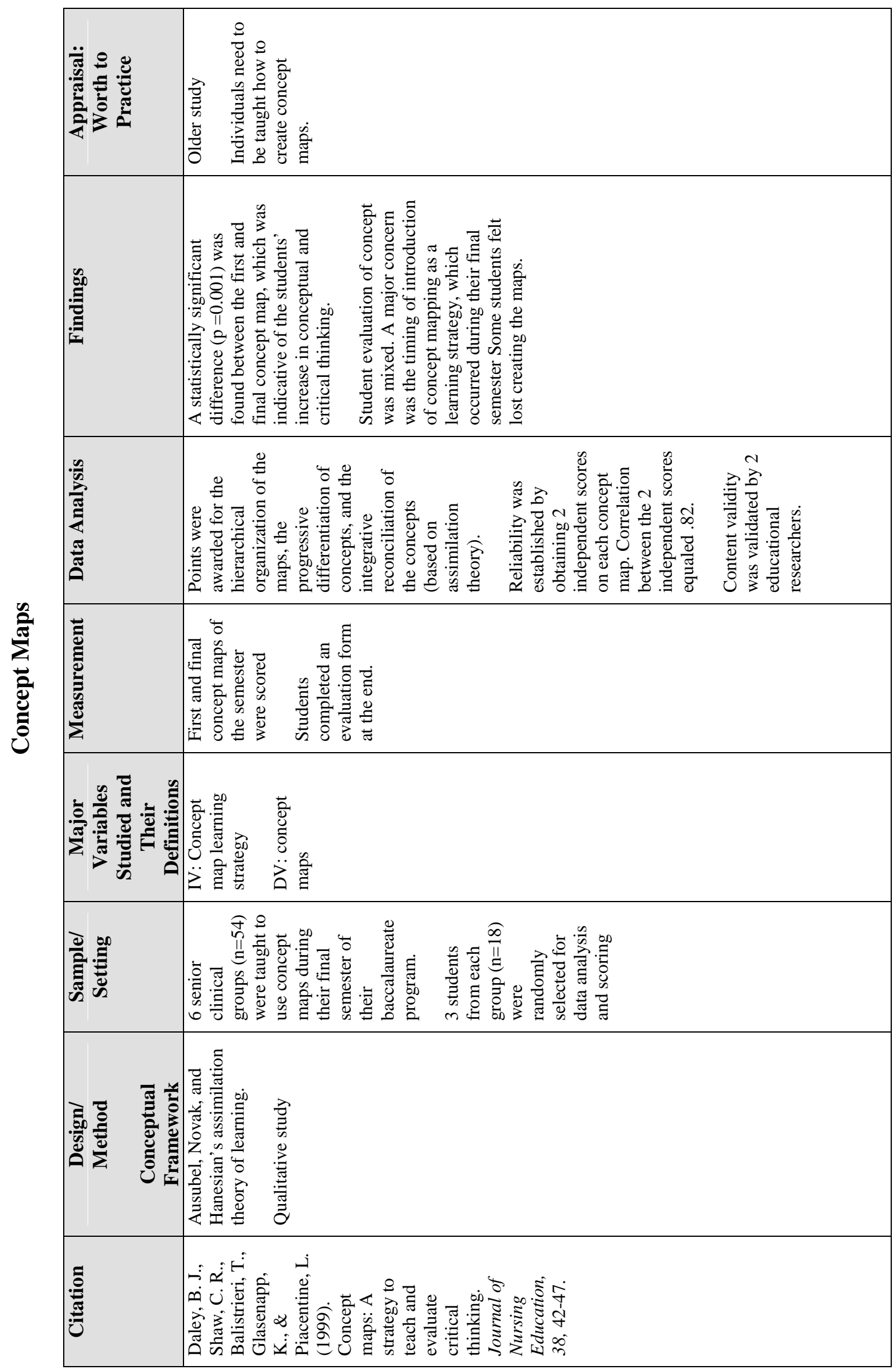




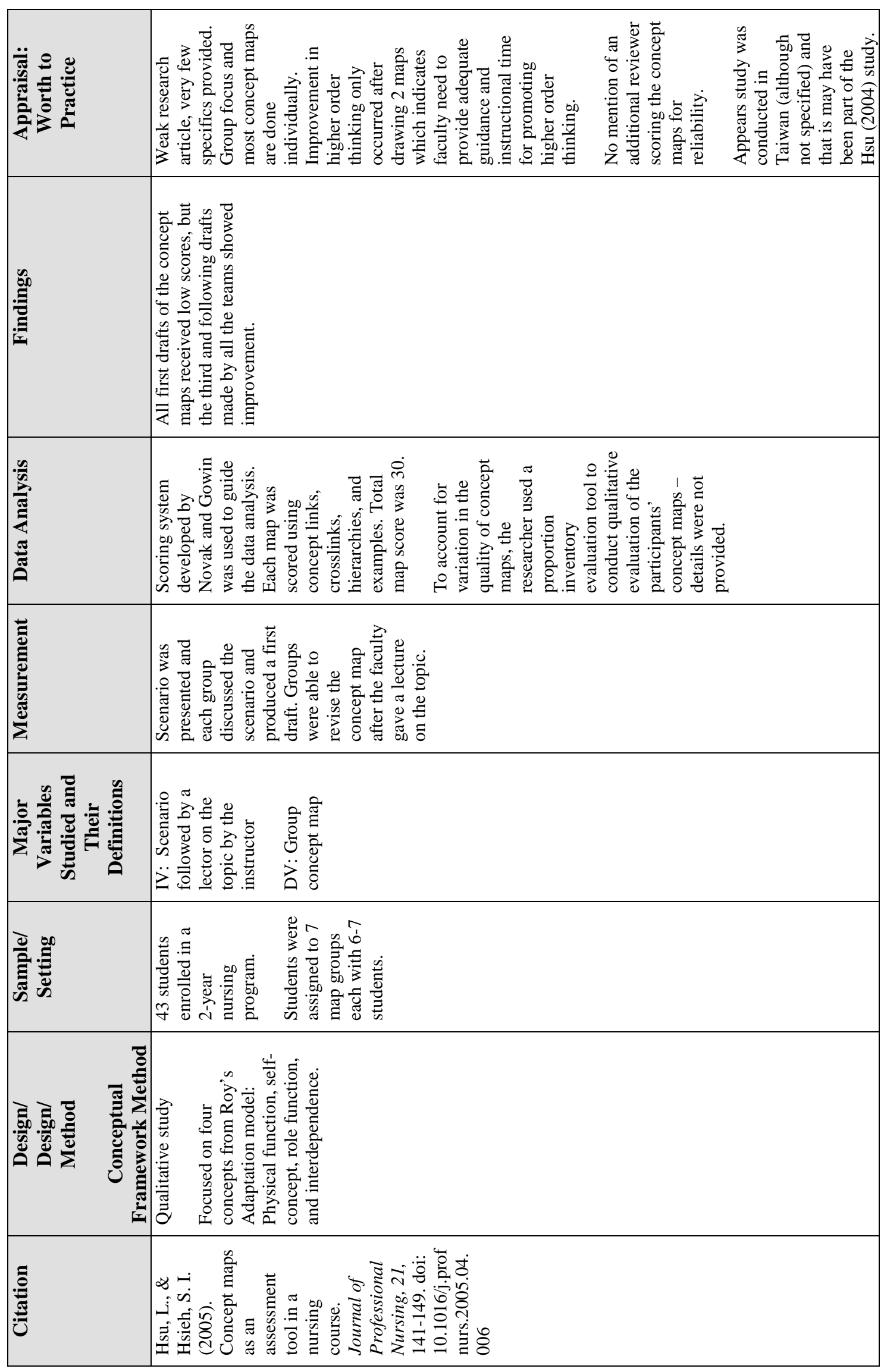




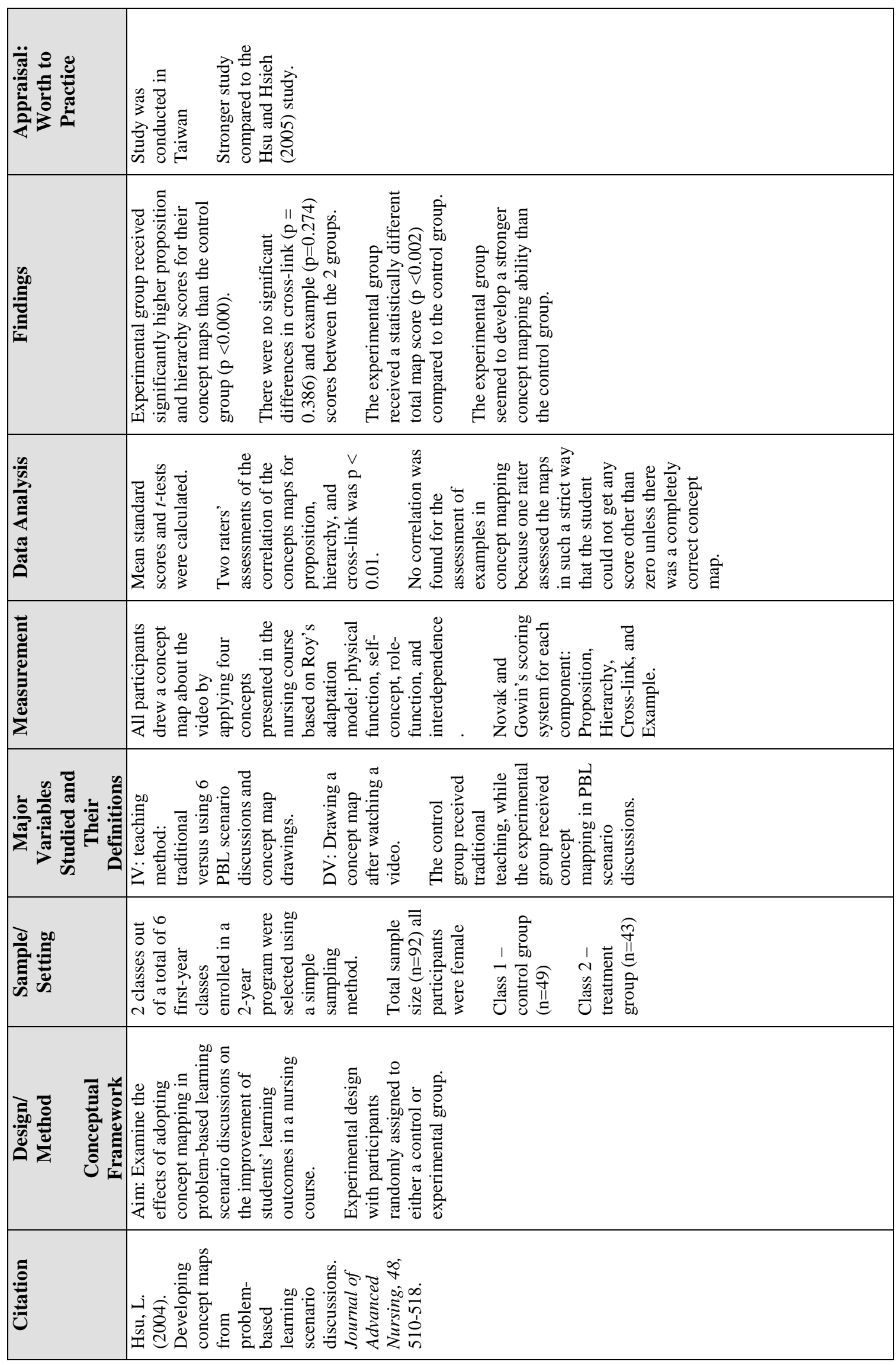




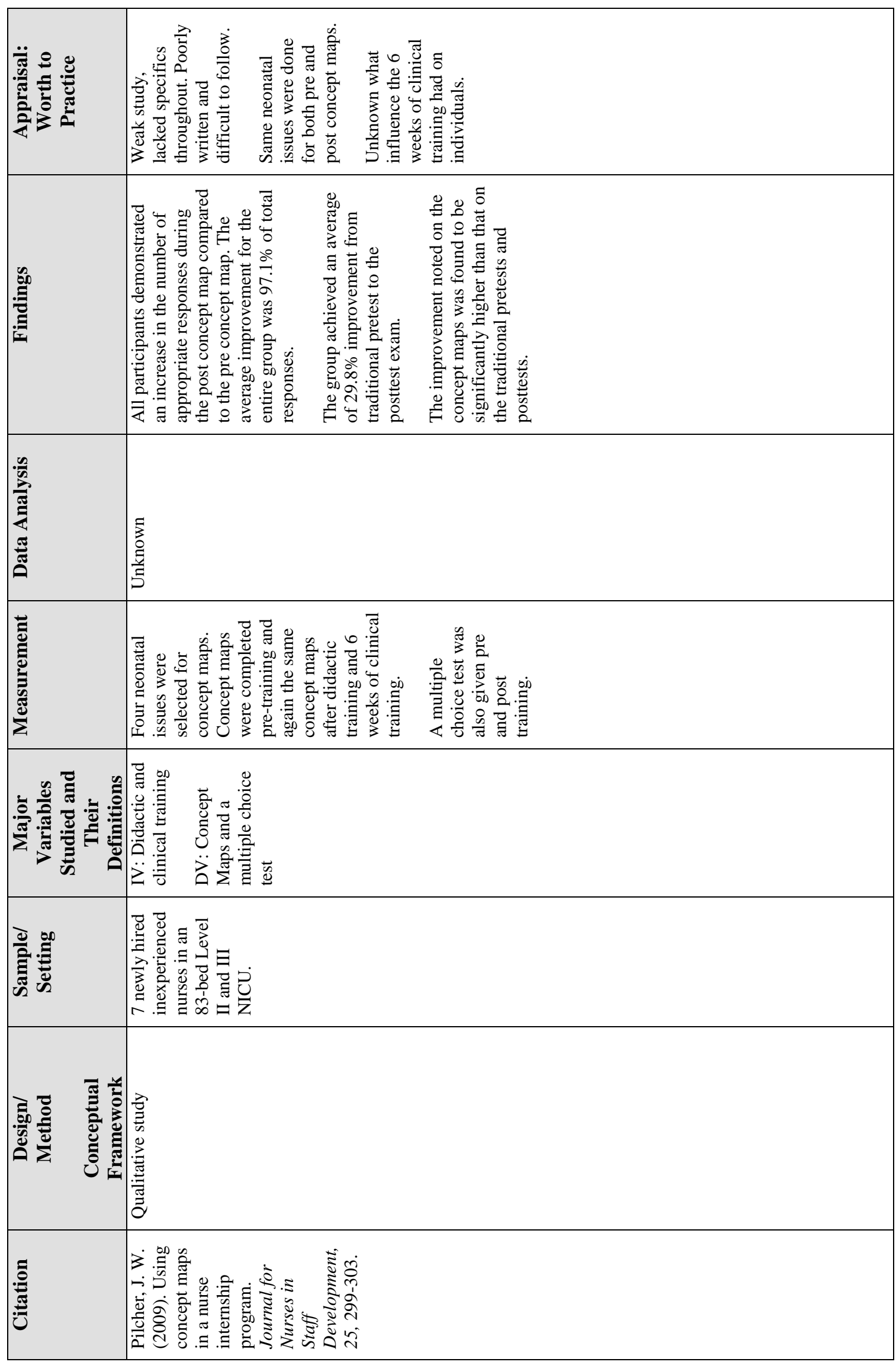




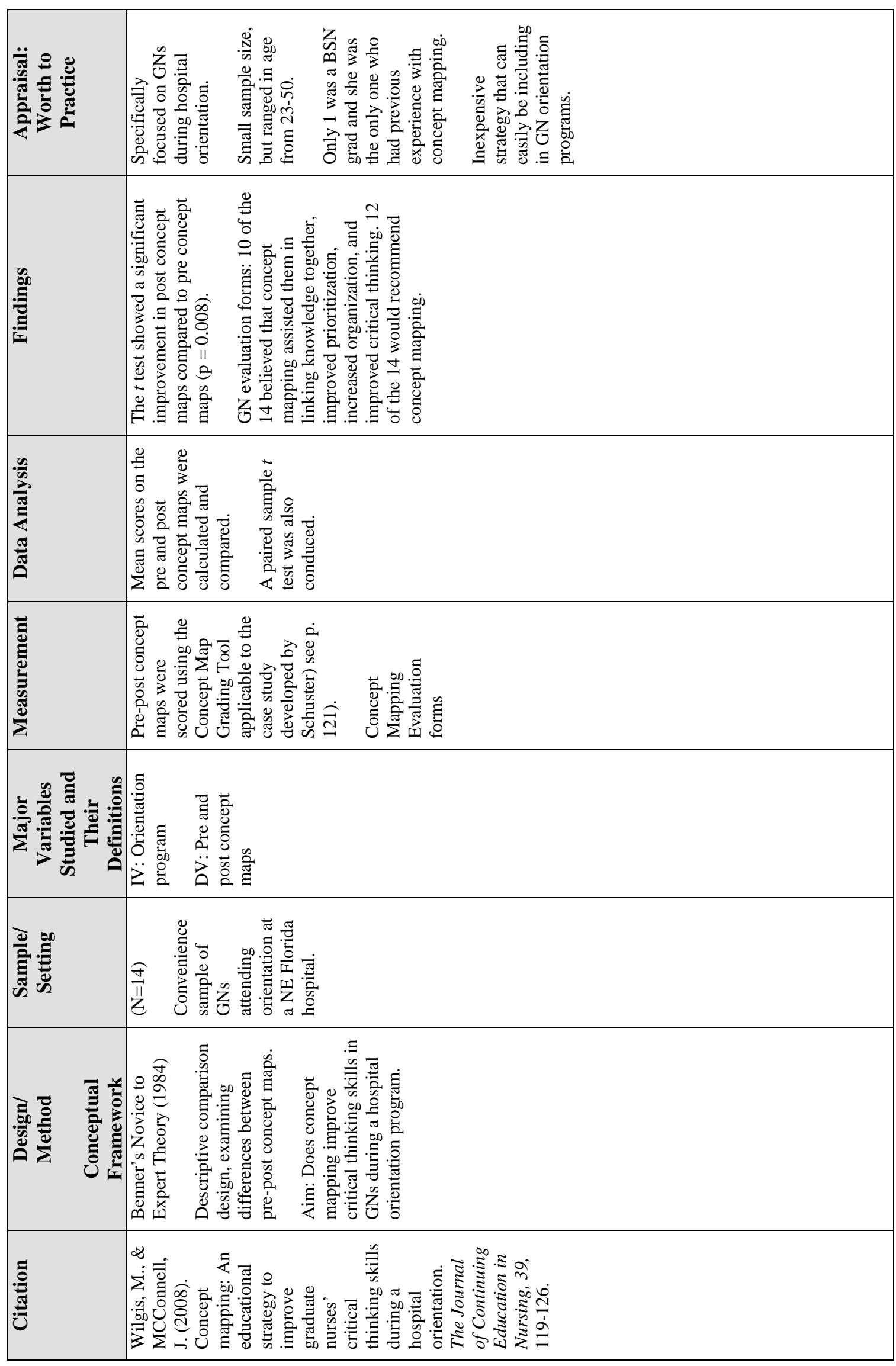




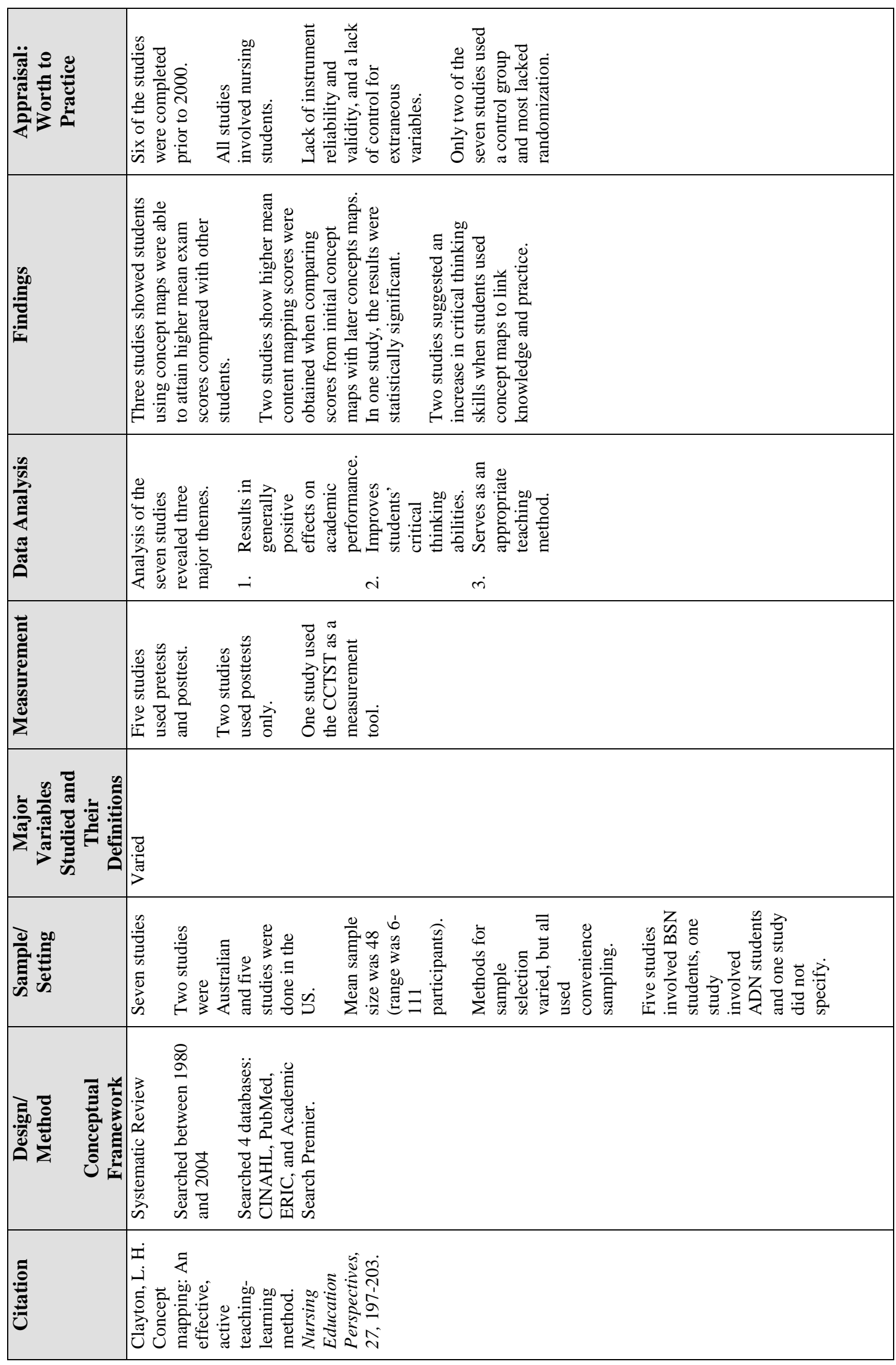




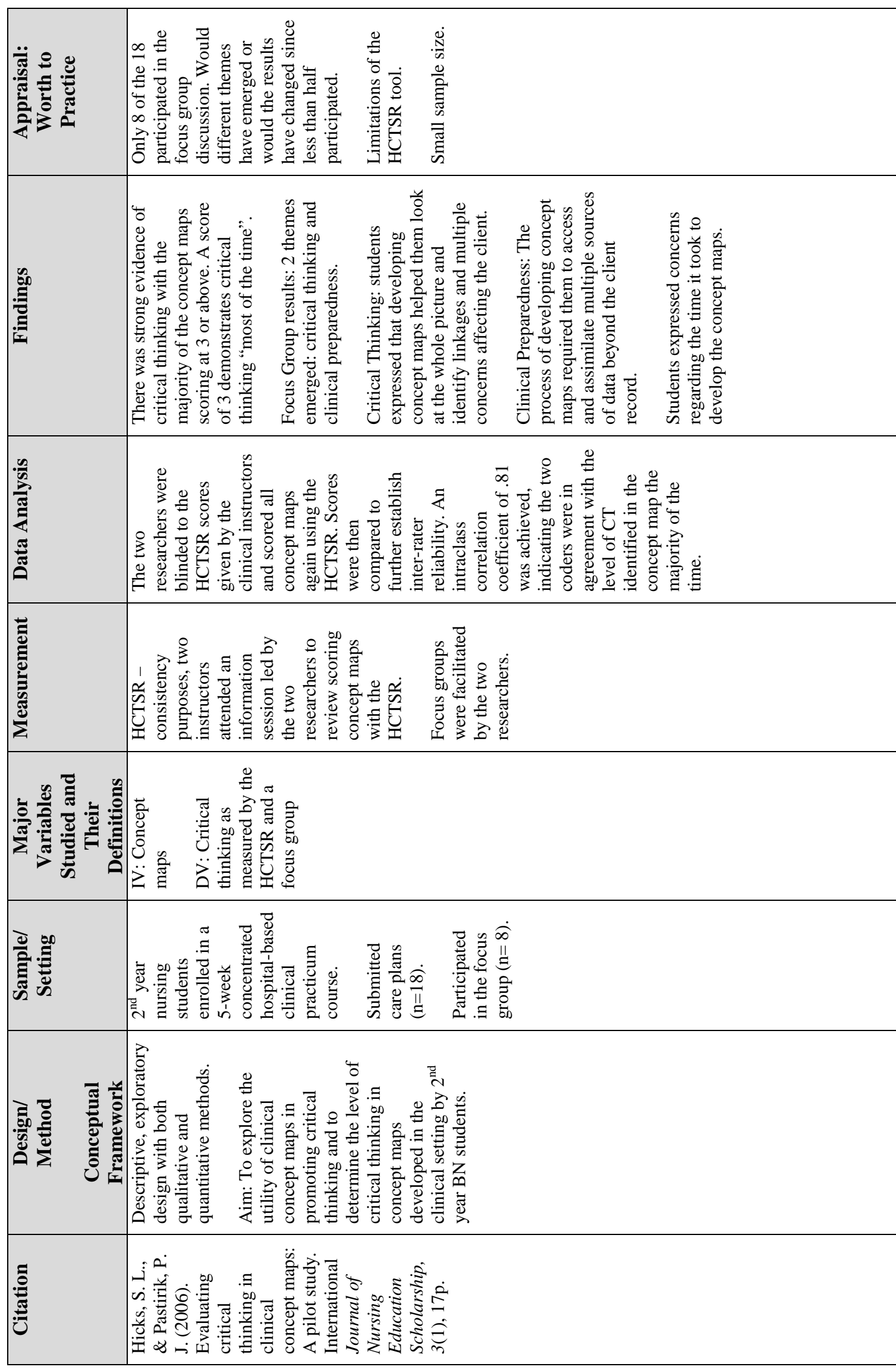




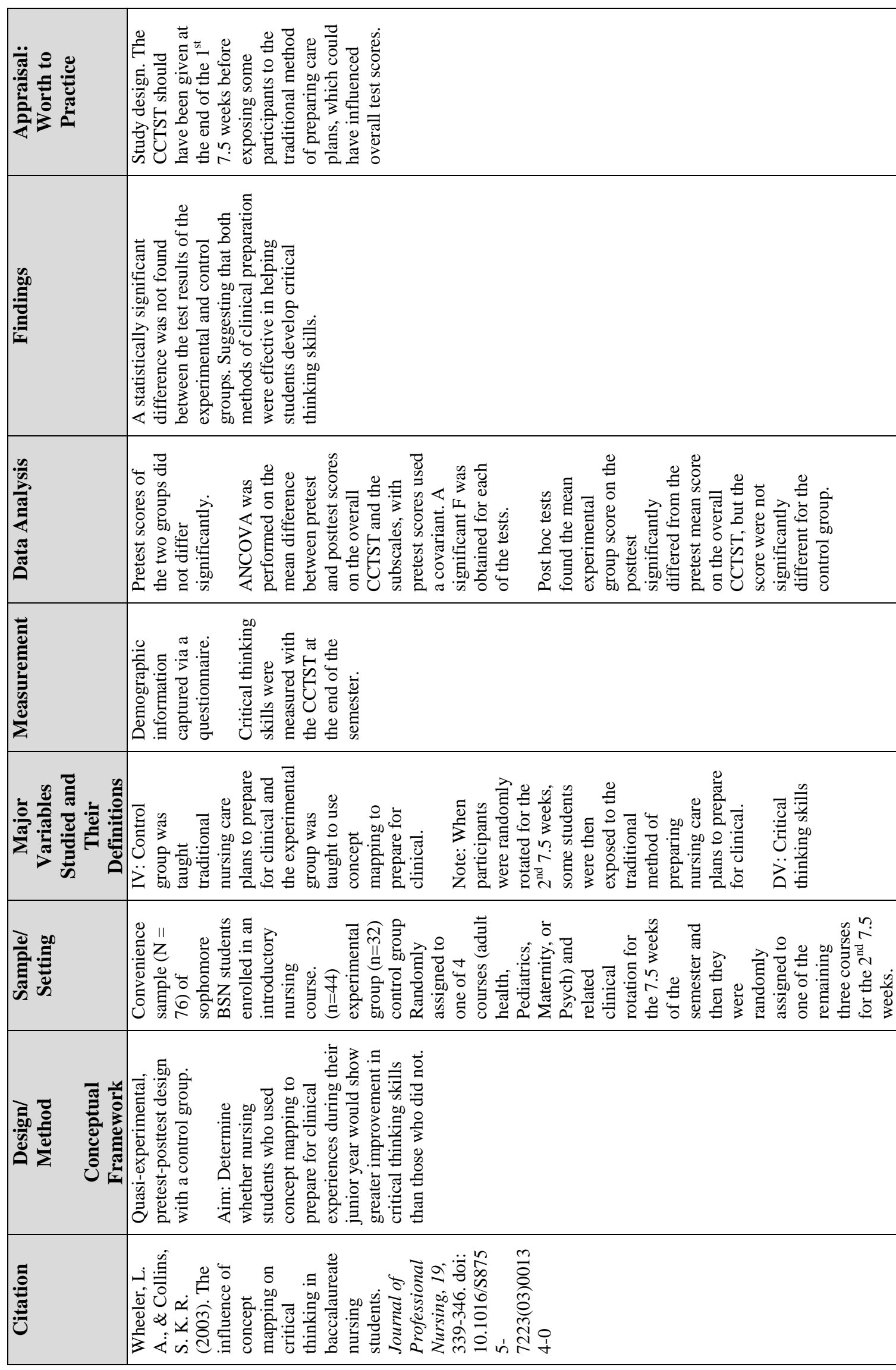




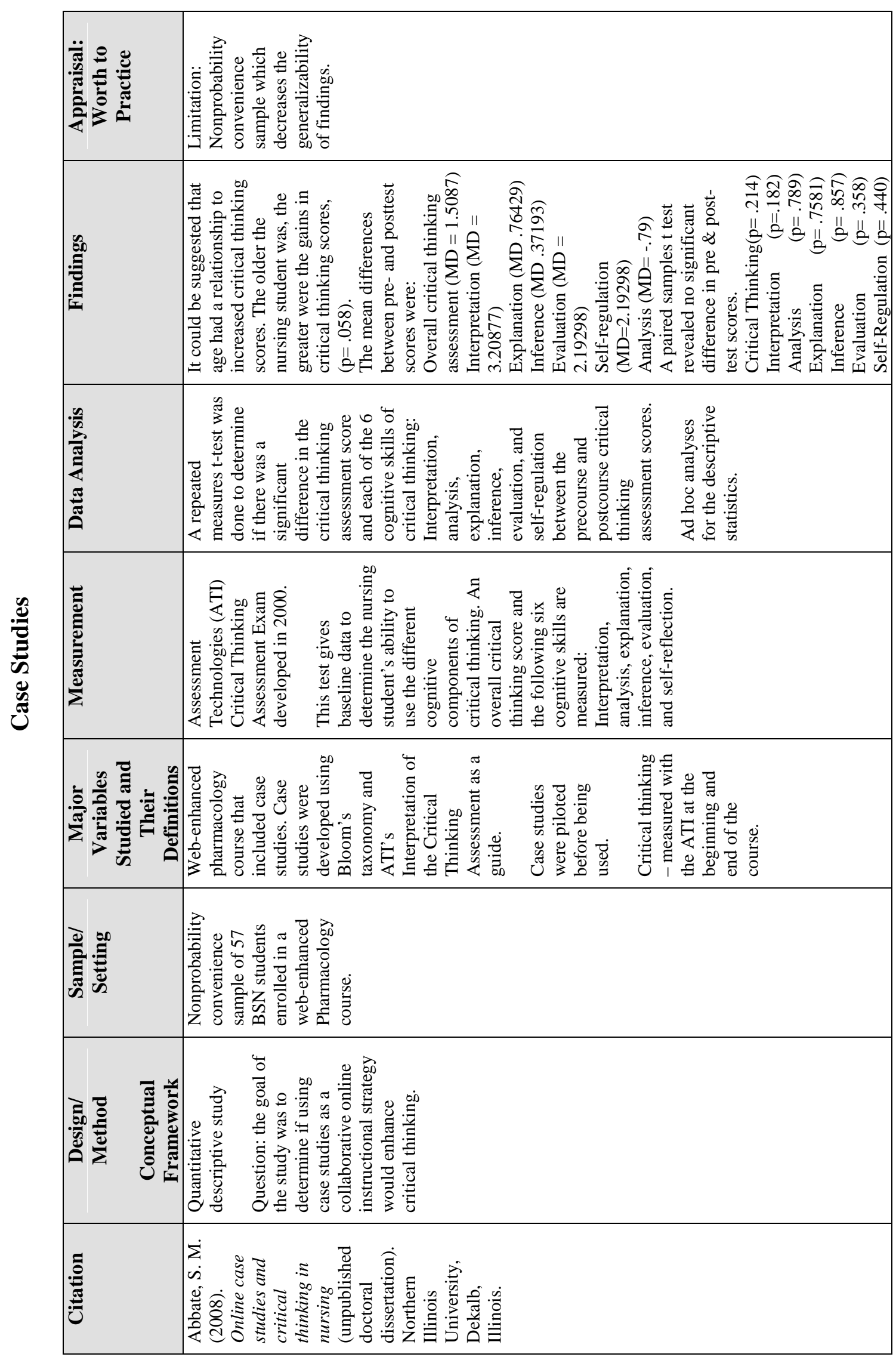




\begin{tabular}{|c|c|}
\hline 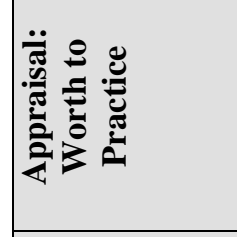 & 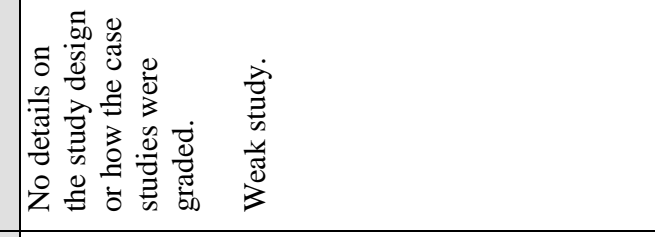 \\
\hline 要 & 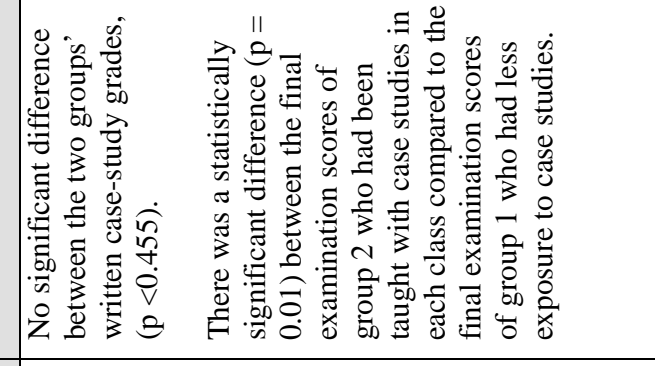 \\
\hline 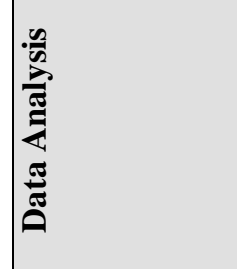 & 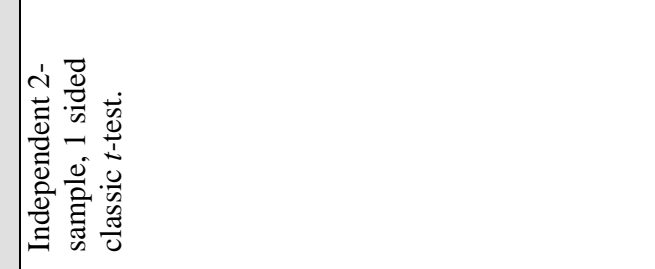 \\
\hline 离 & 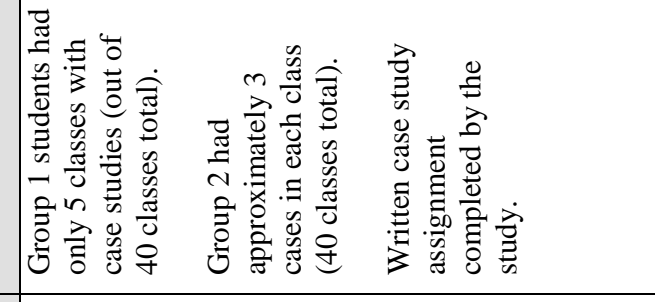 \\
\hline 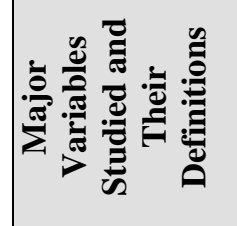 & 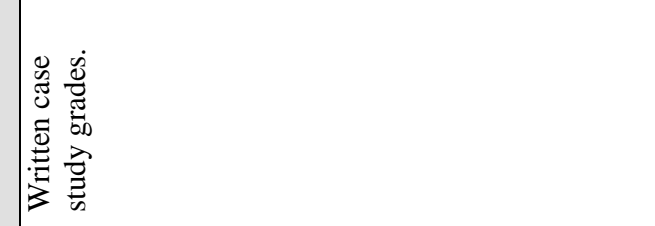 \\
\hline 这 & 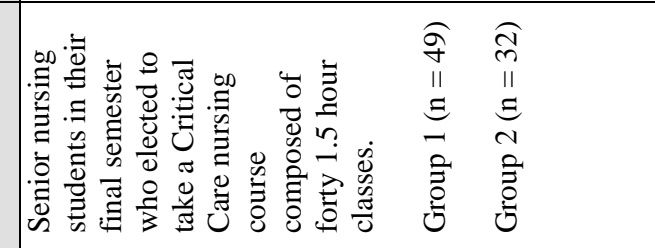 \\
\hline 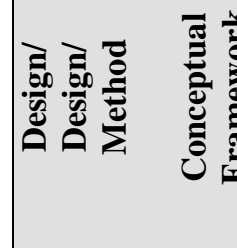 & 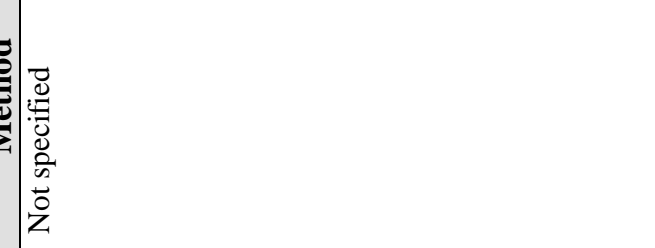 \\
\hline (5) & 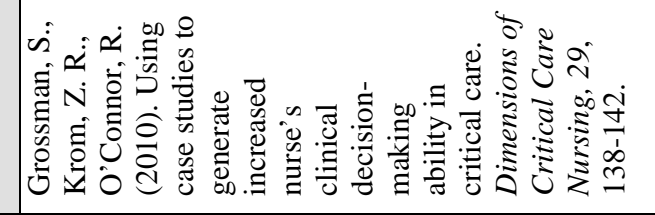 \\
\hline
\end{tabular}




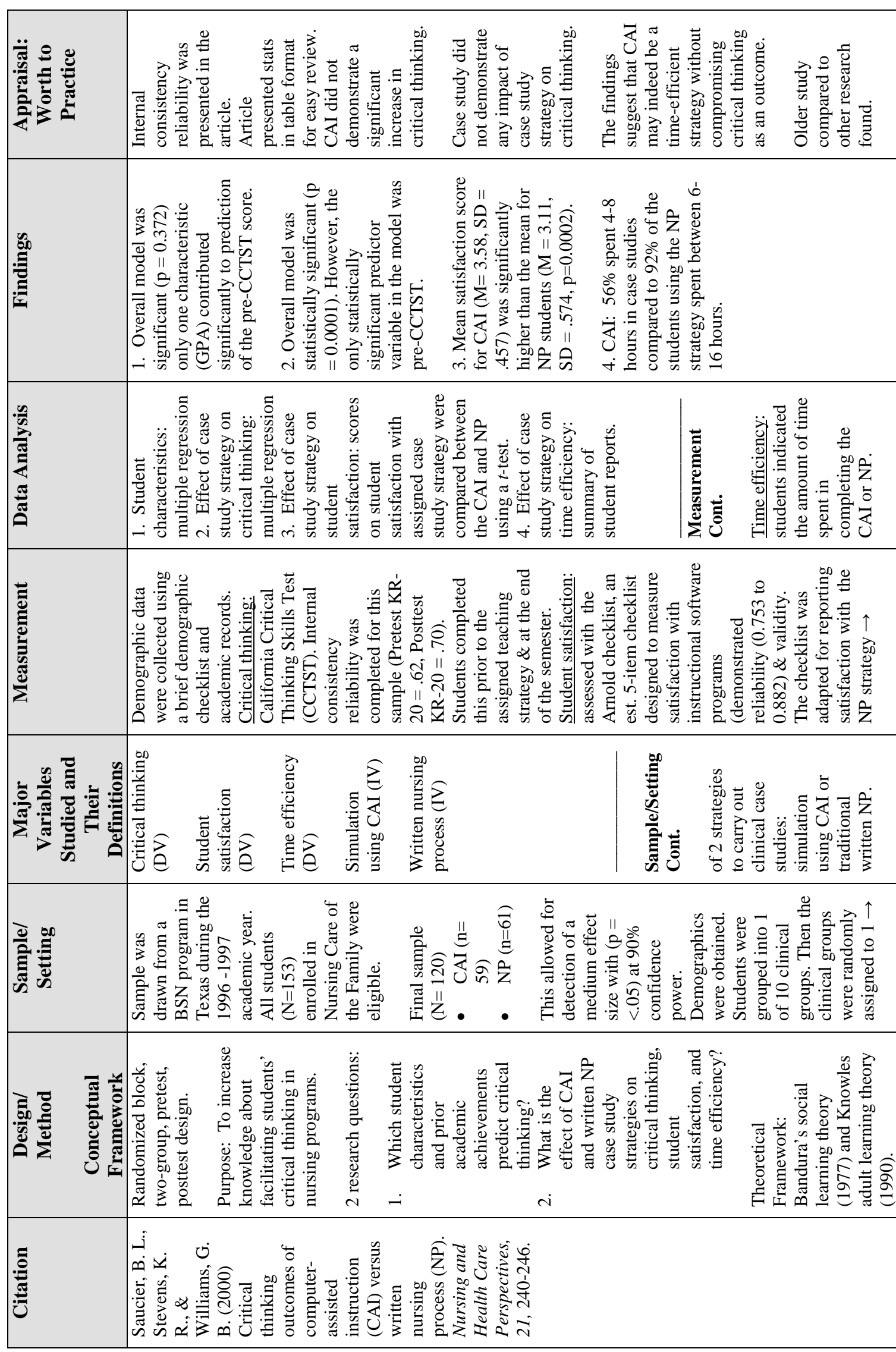




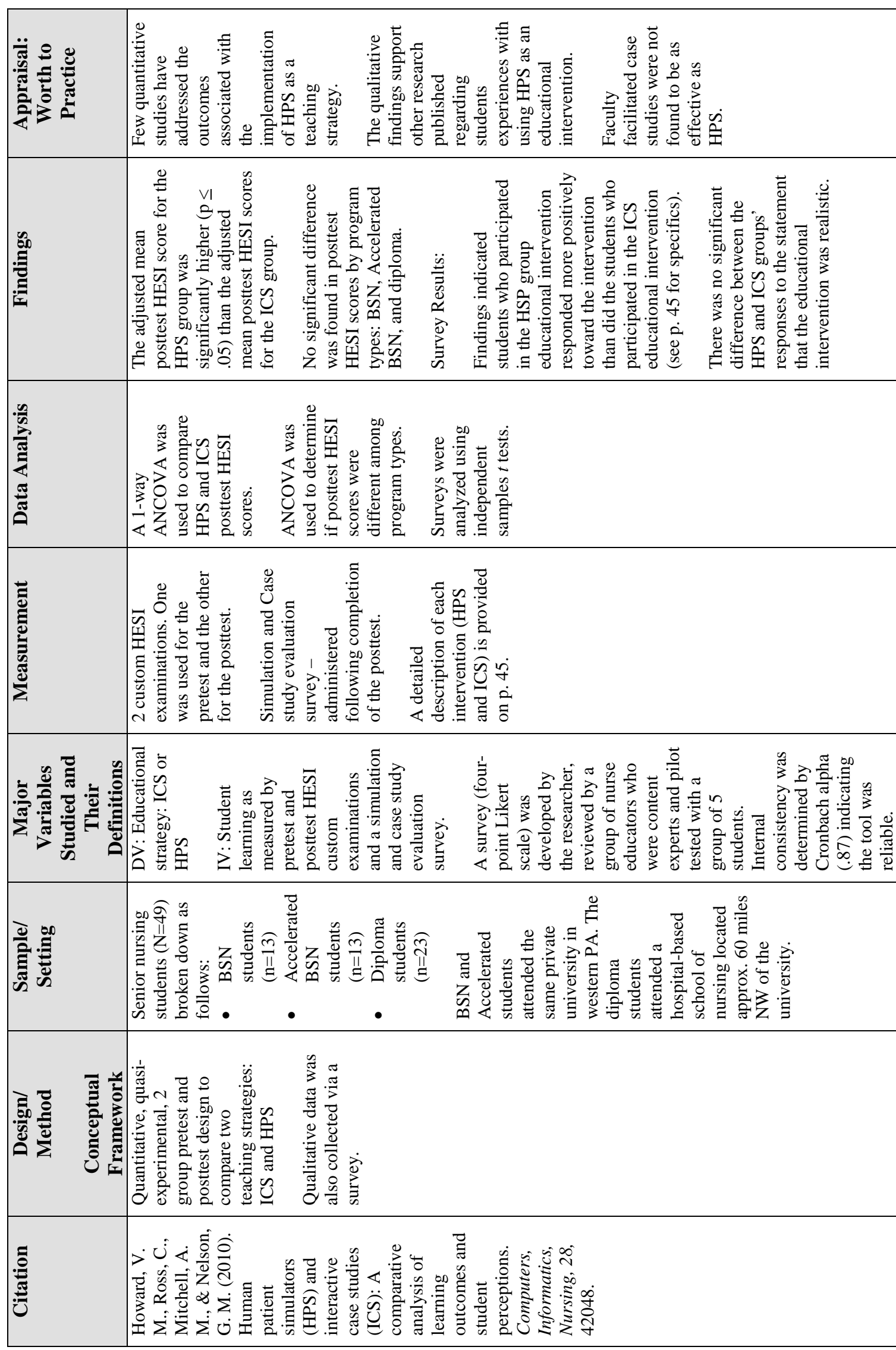




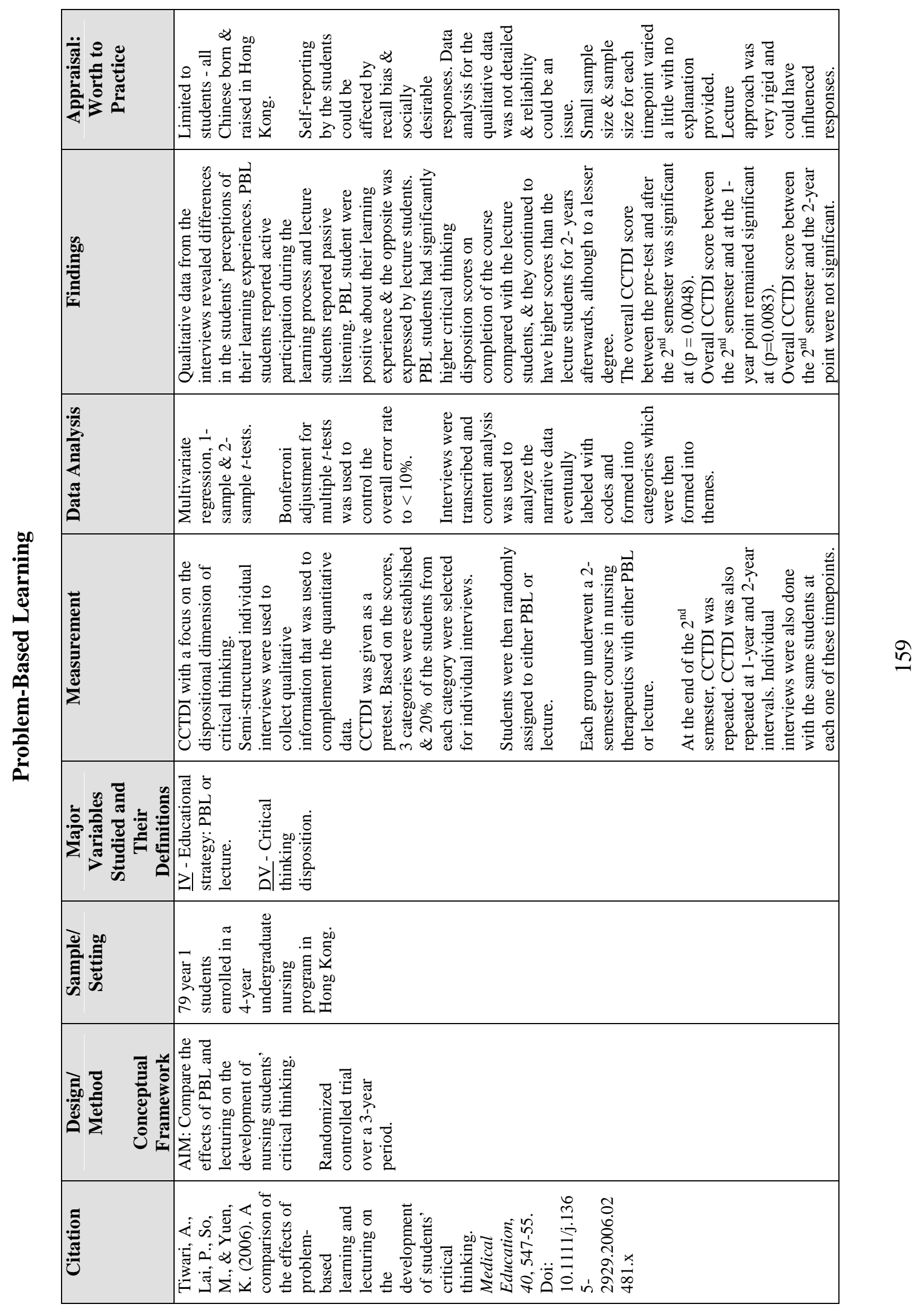




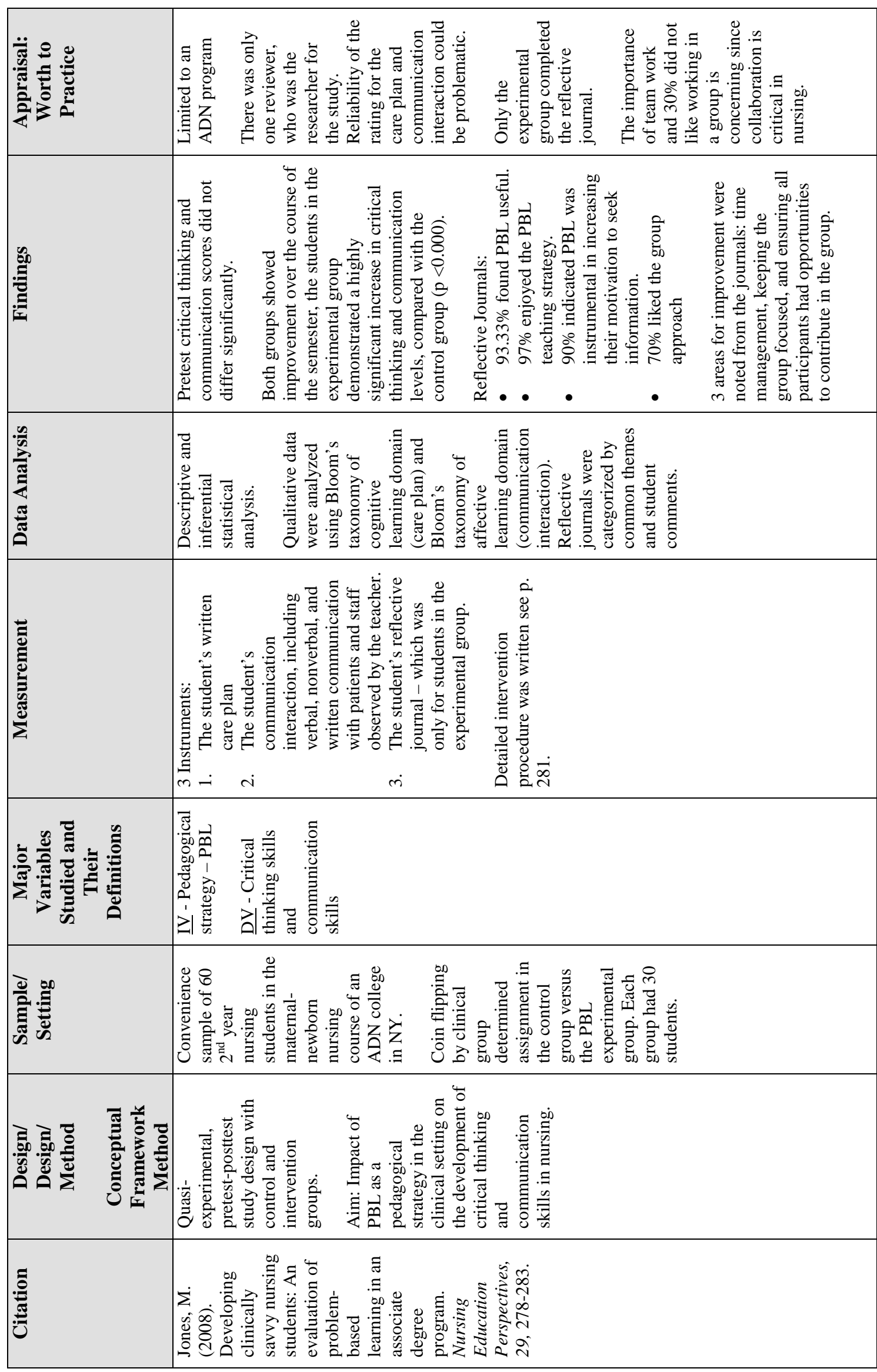




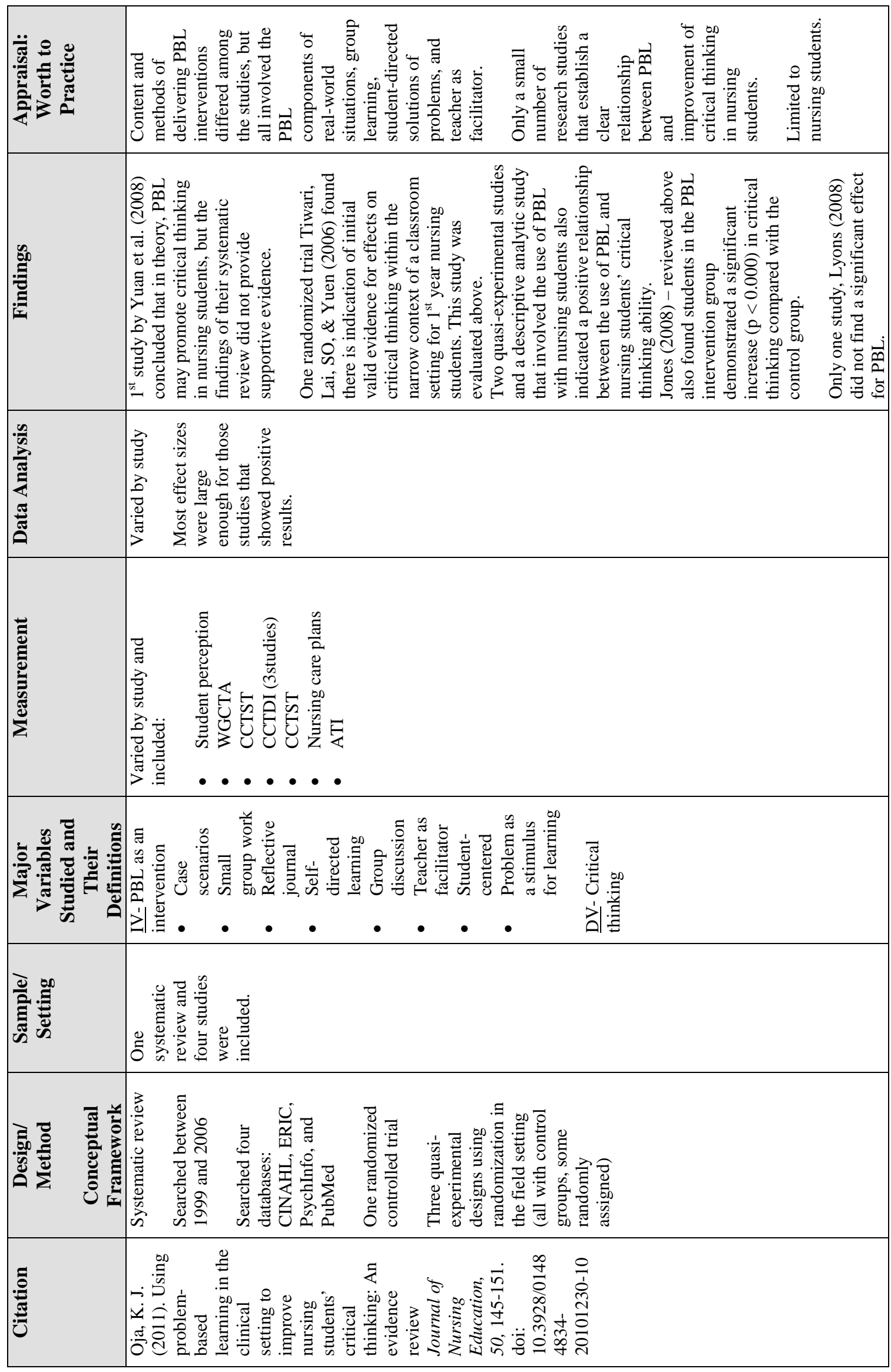




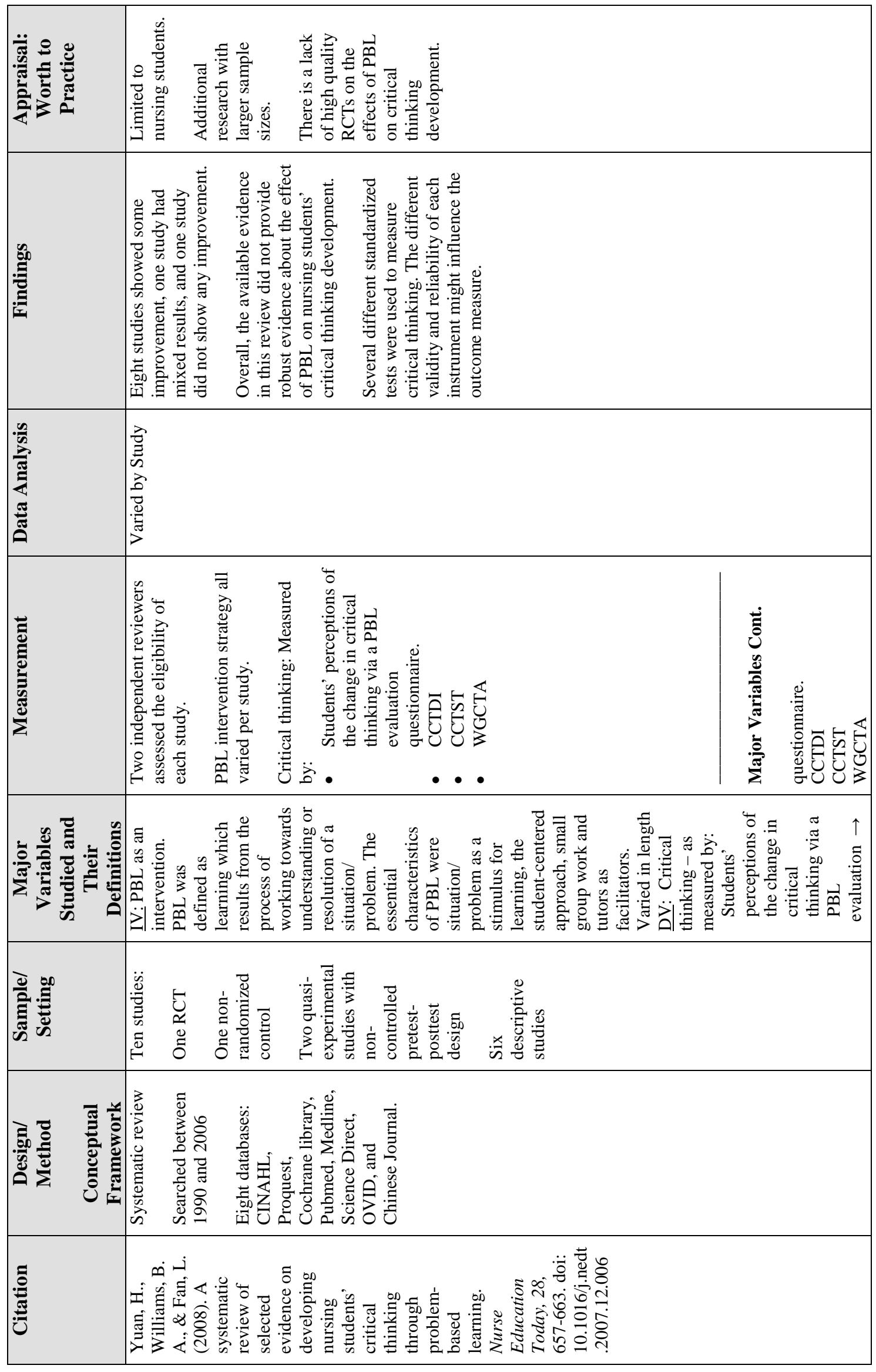




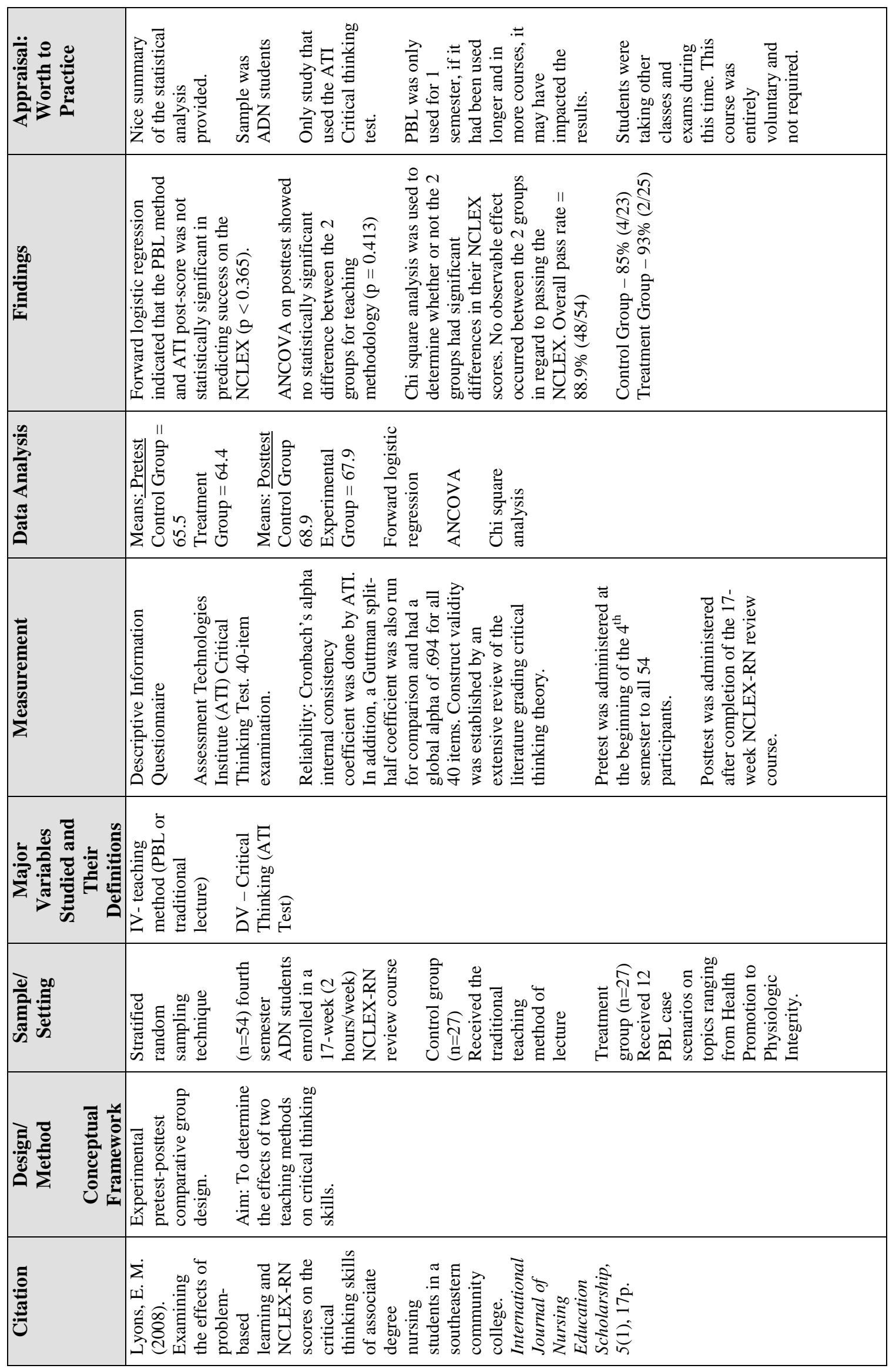




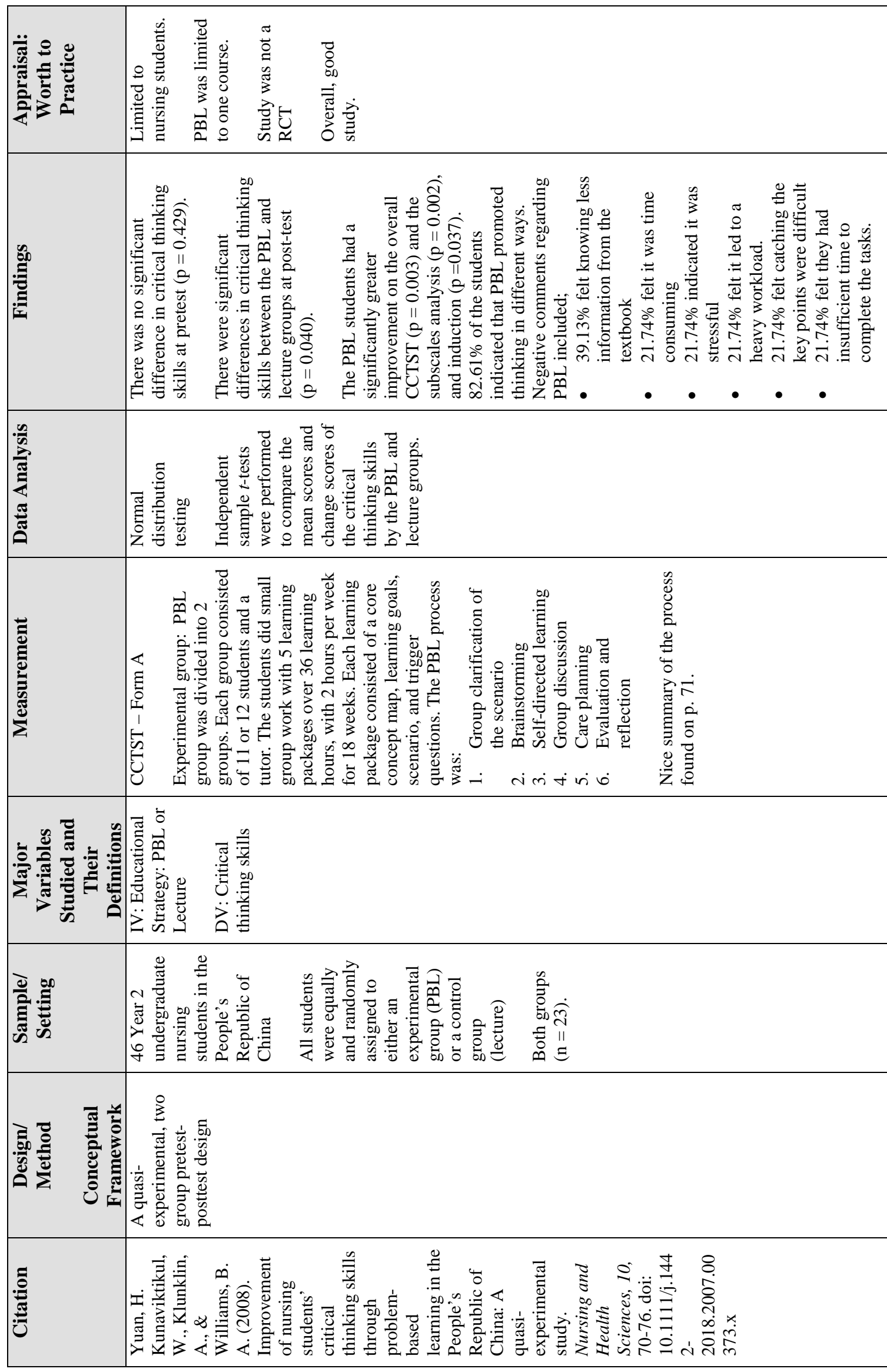




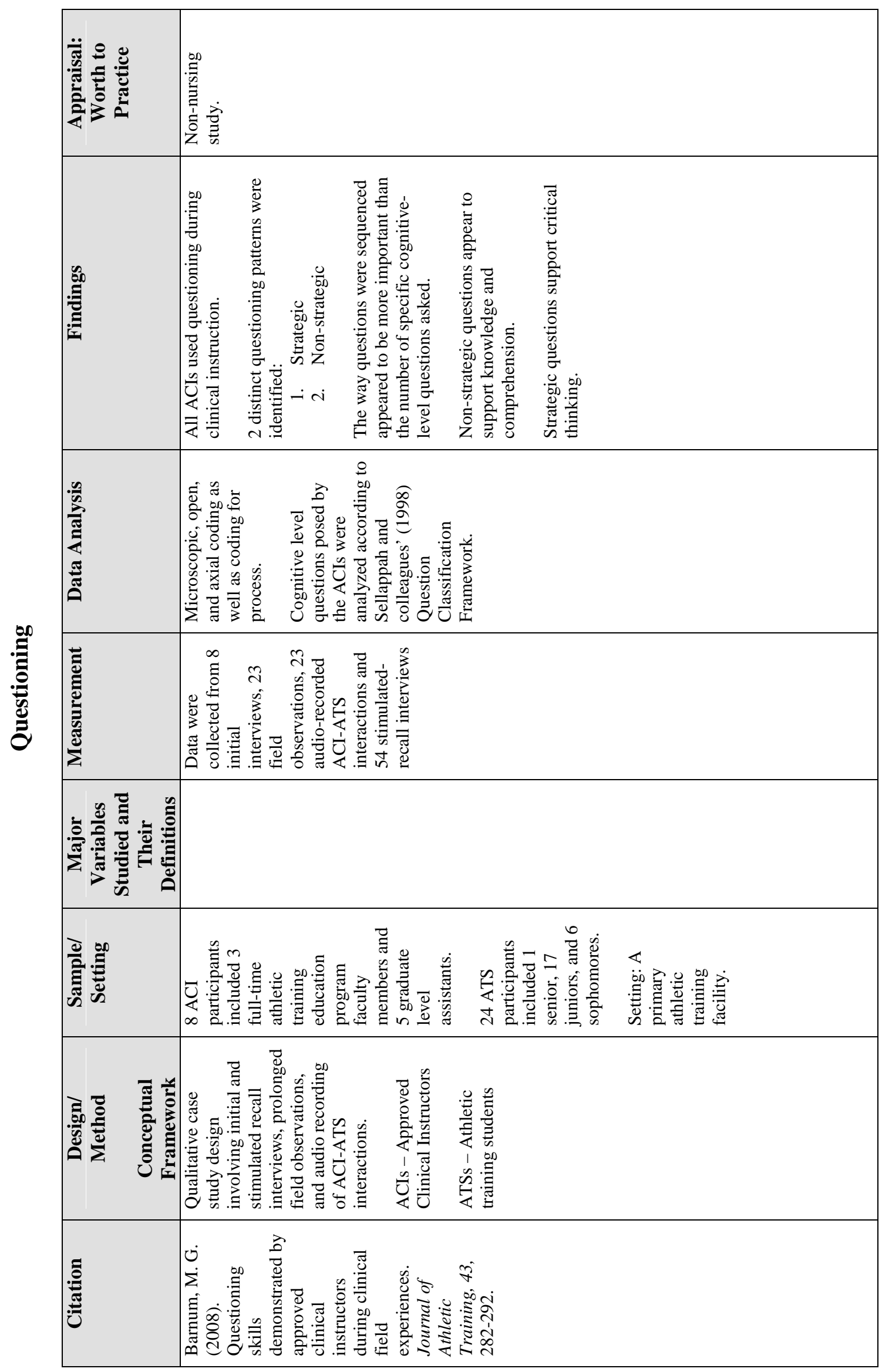




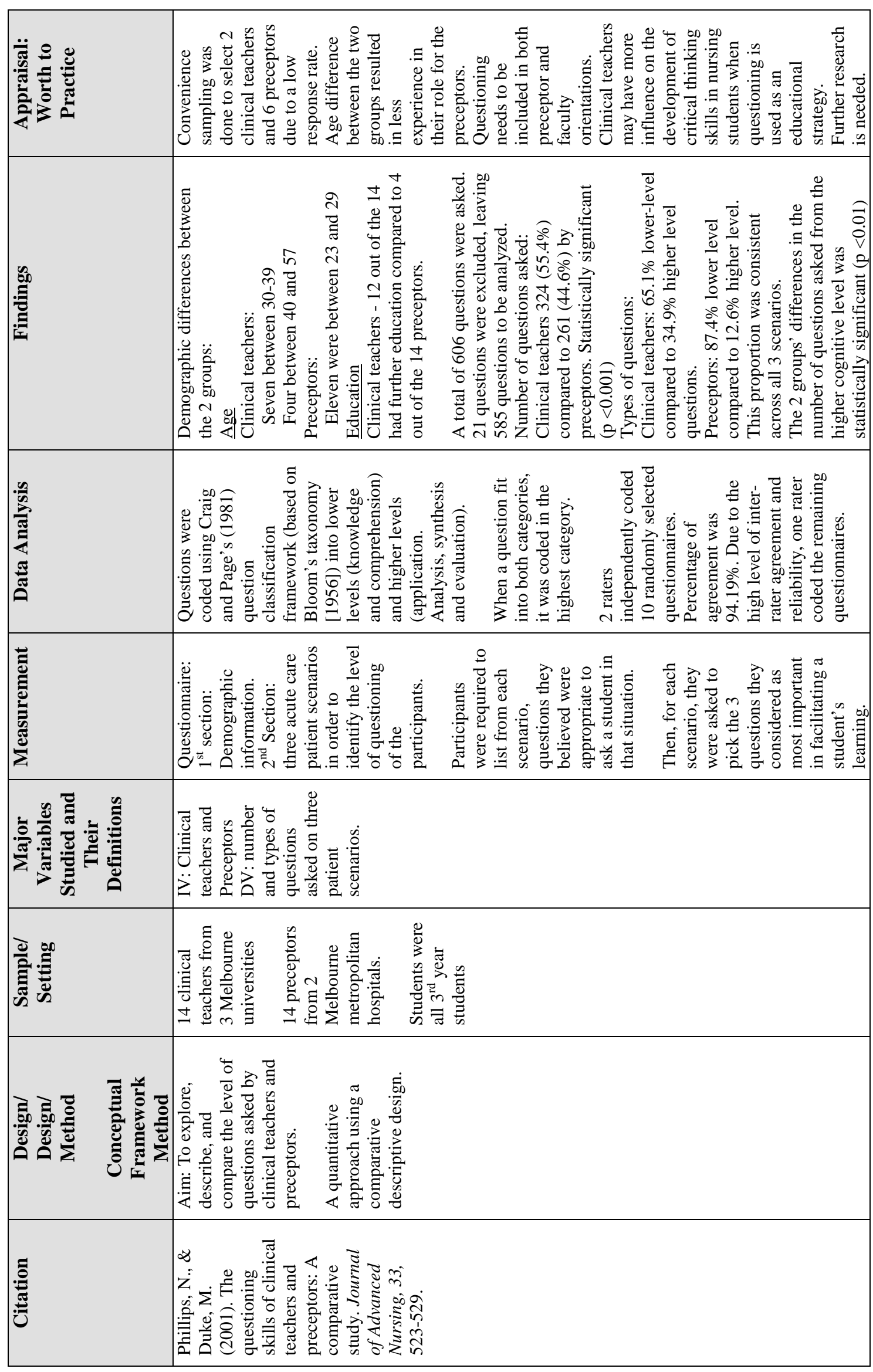




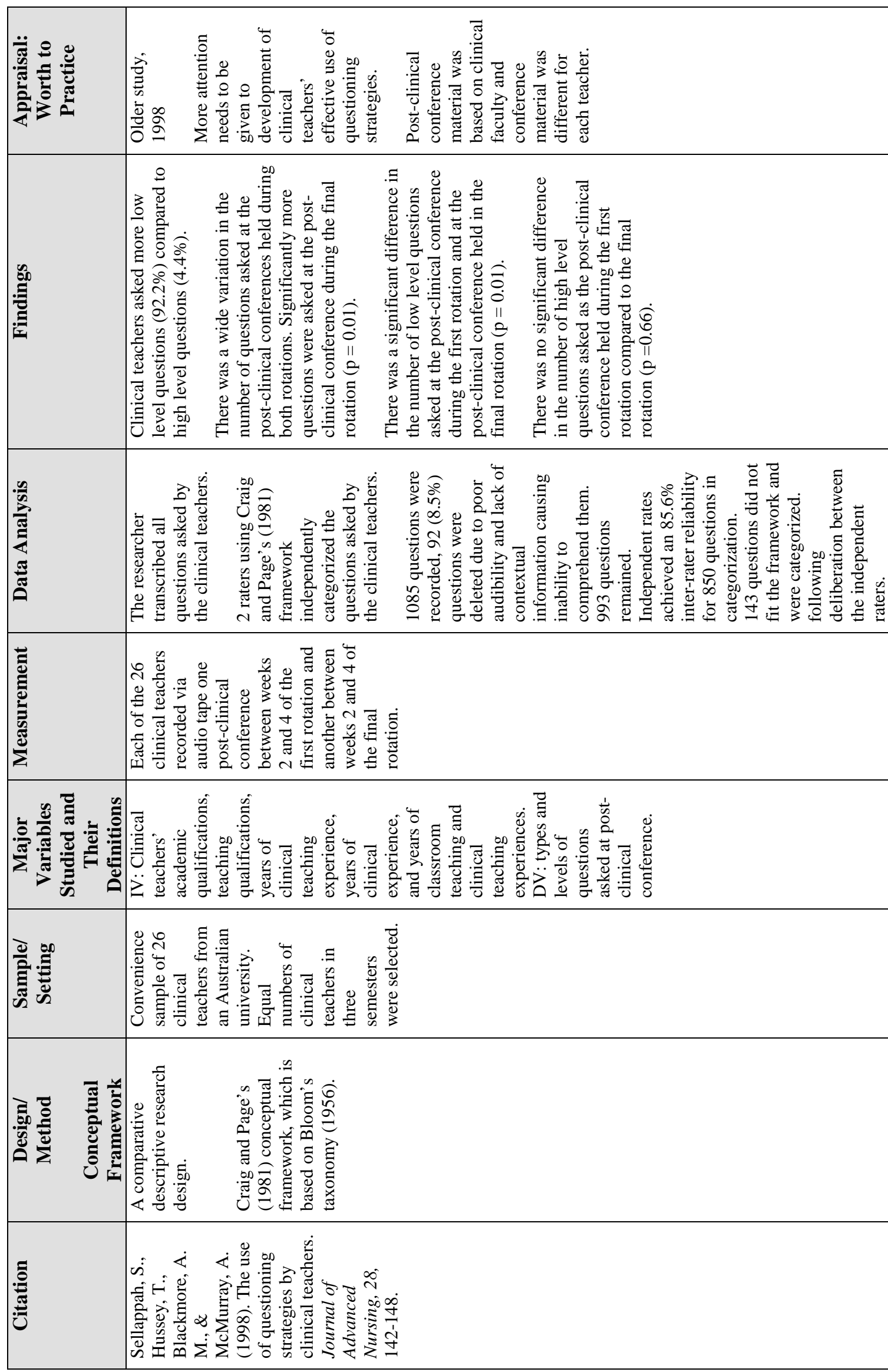




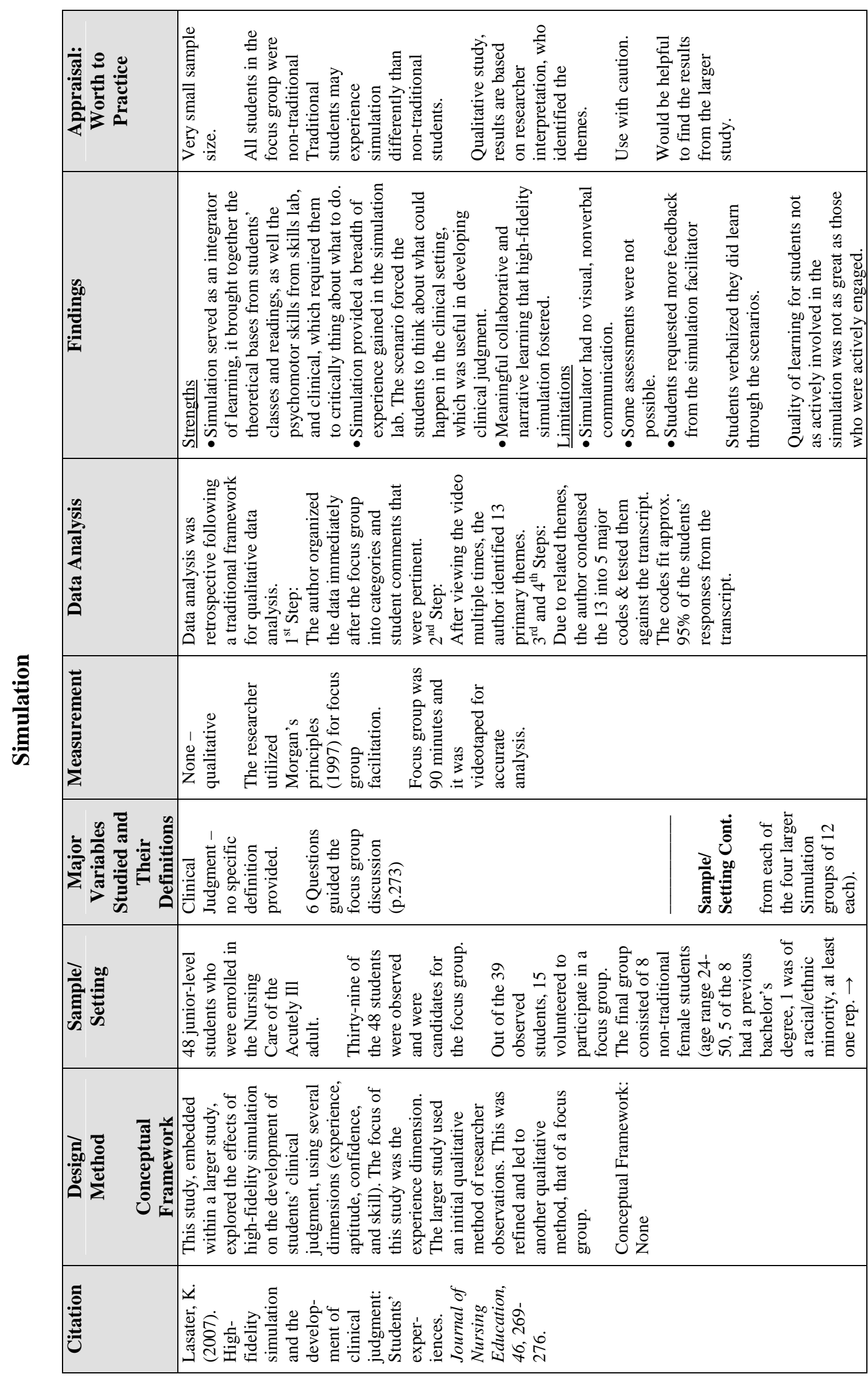




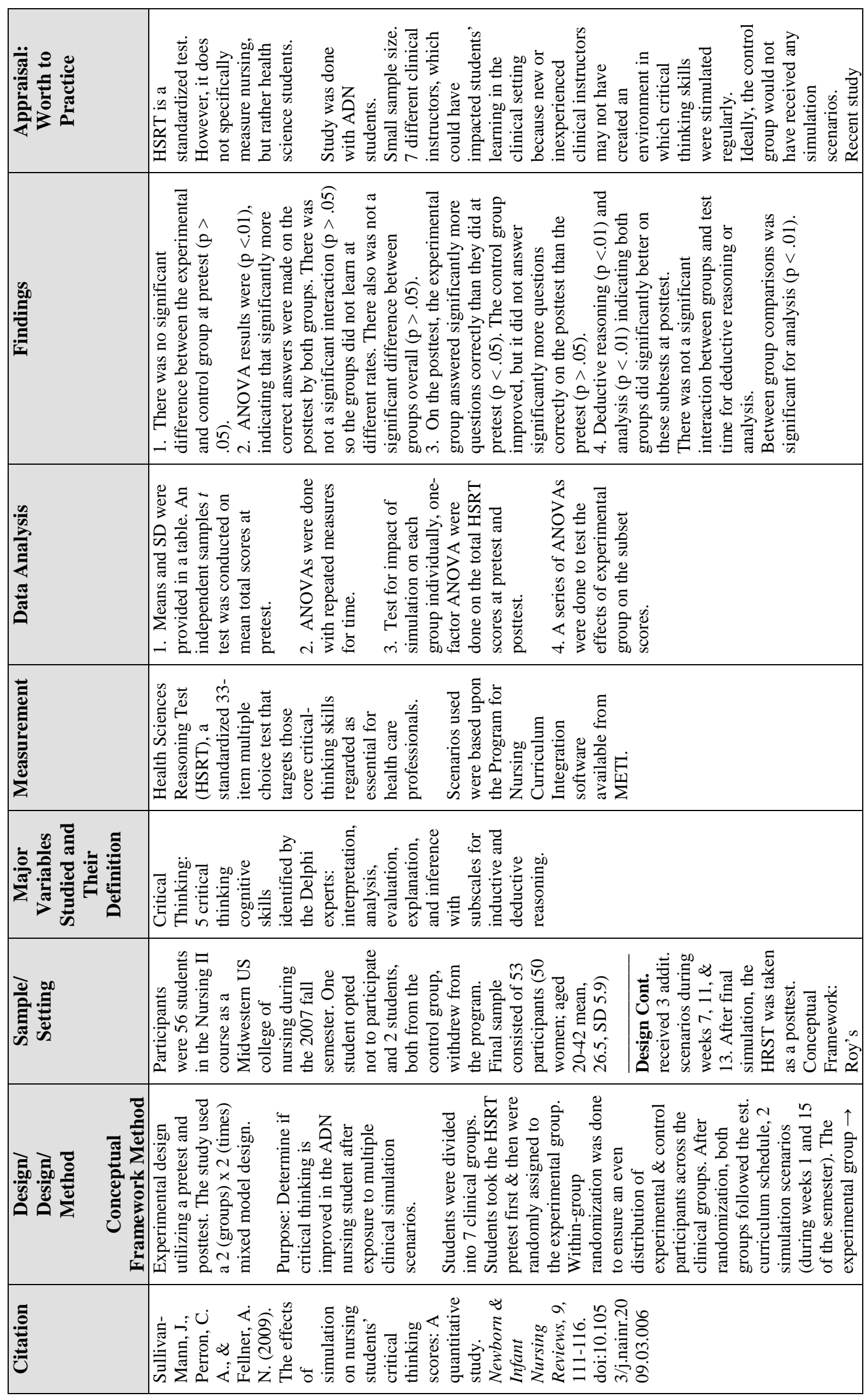




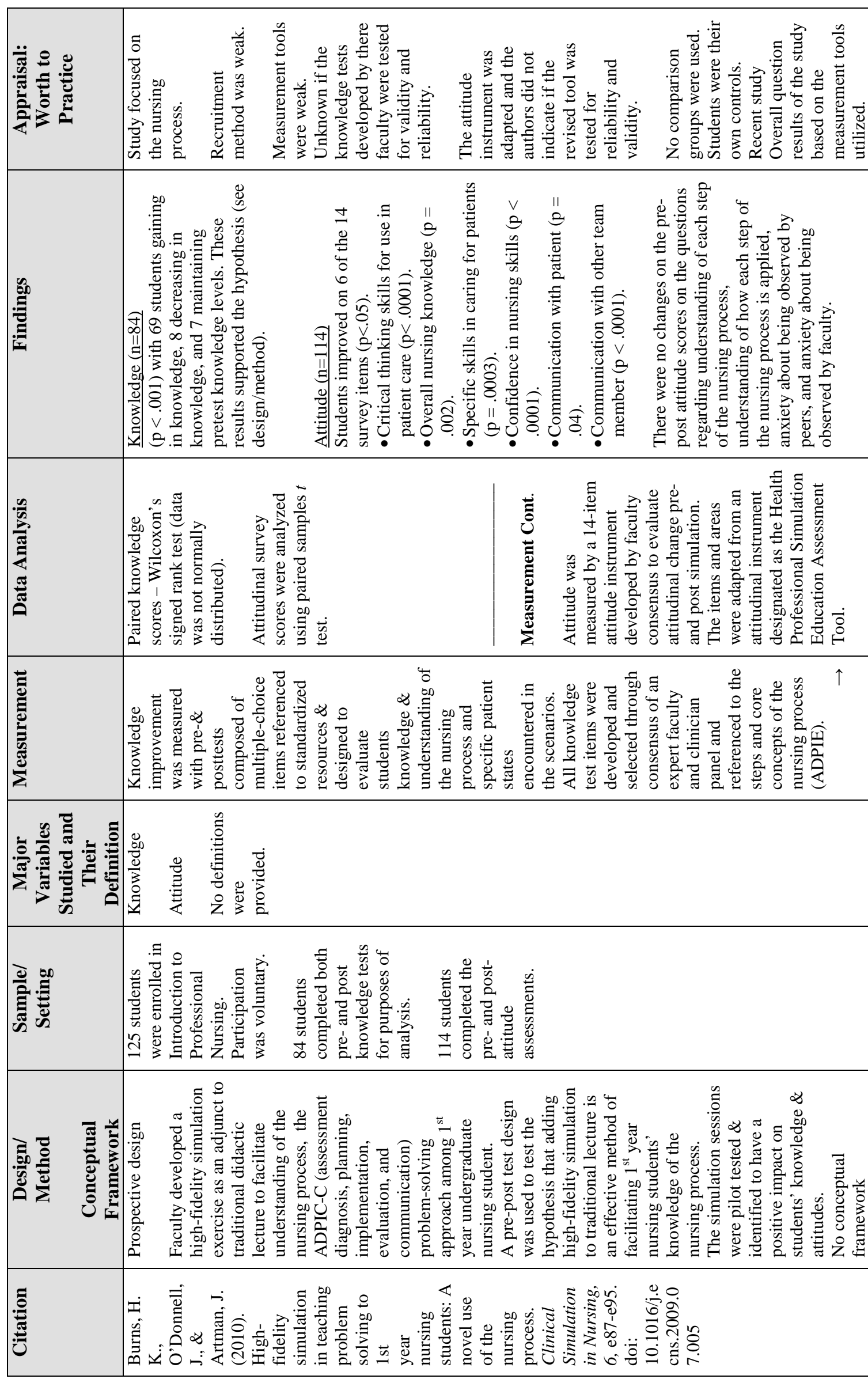




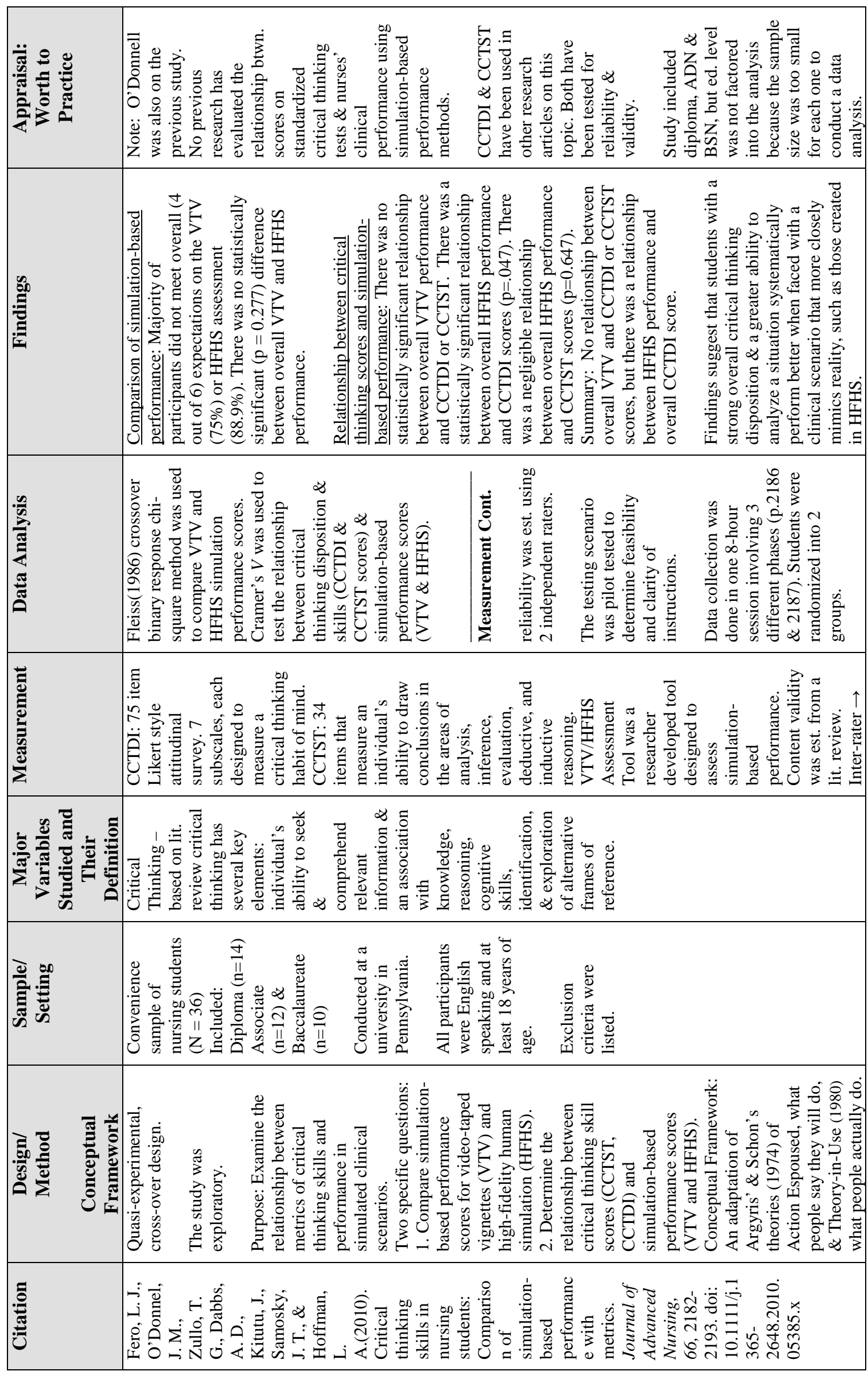




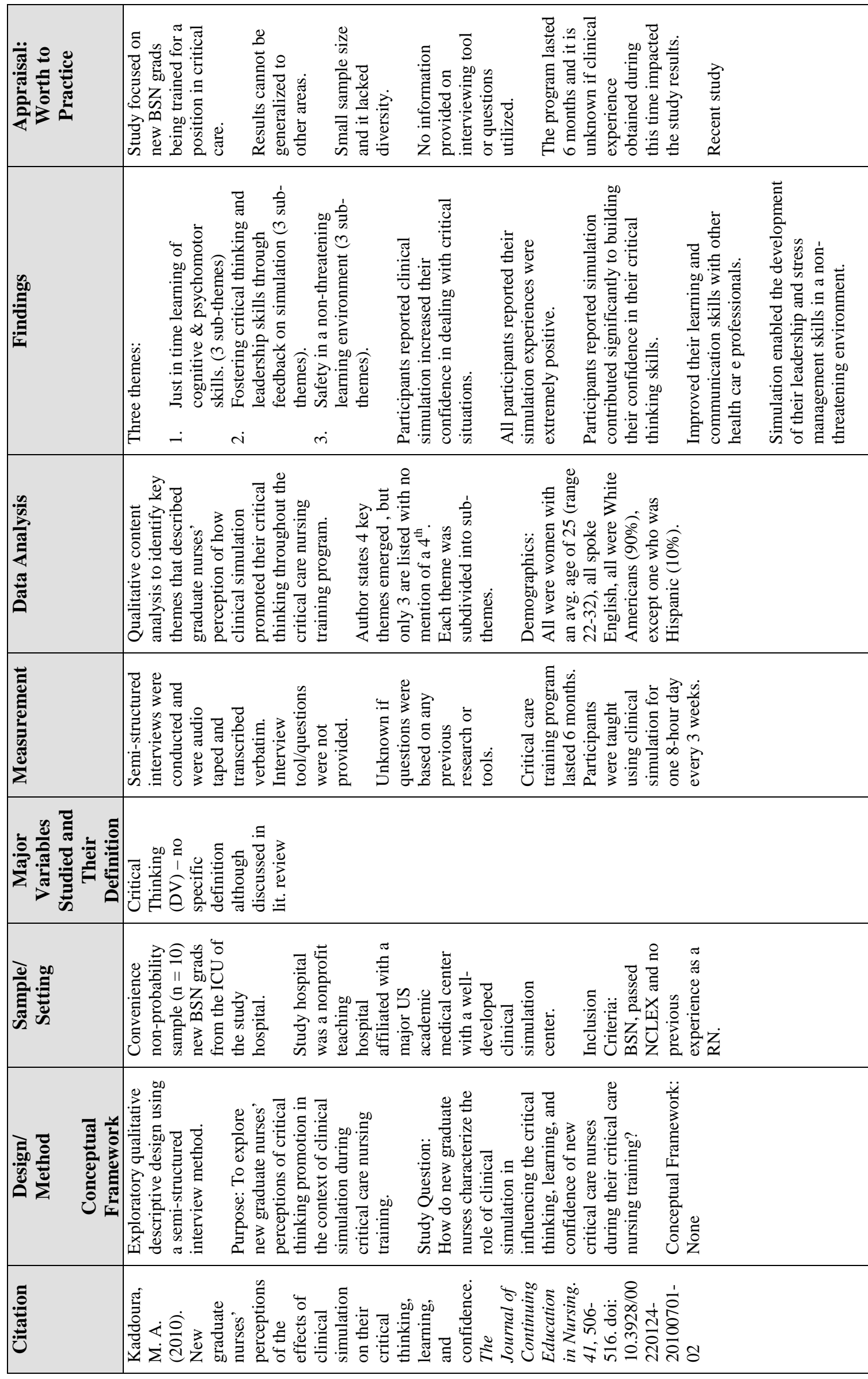




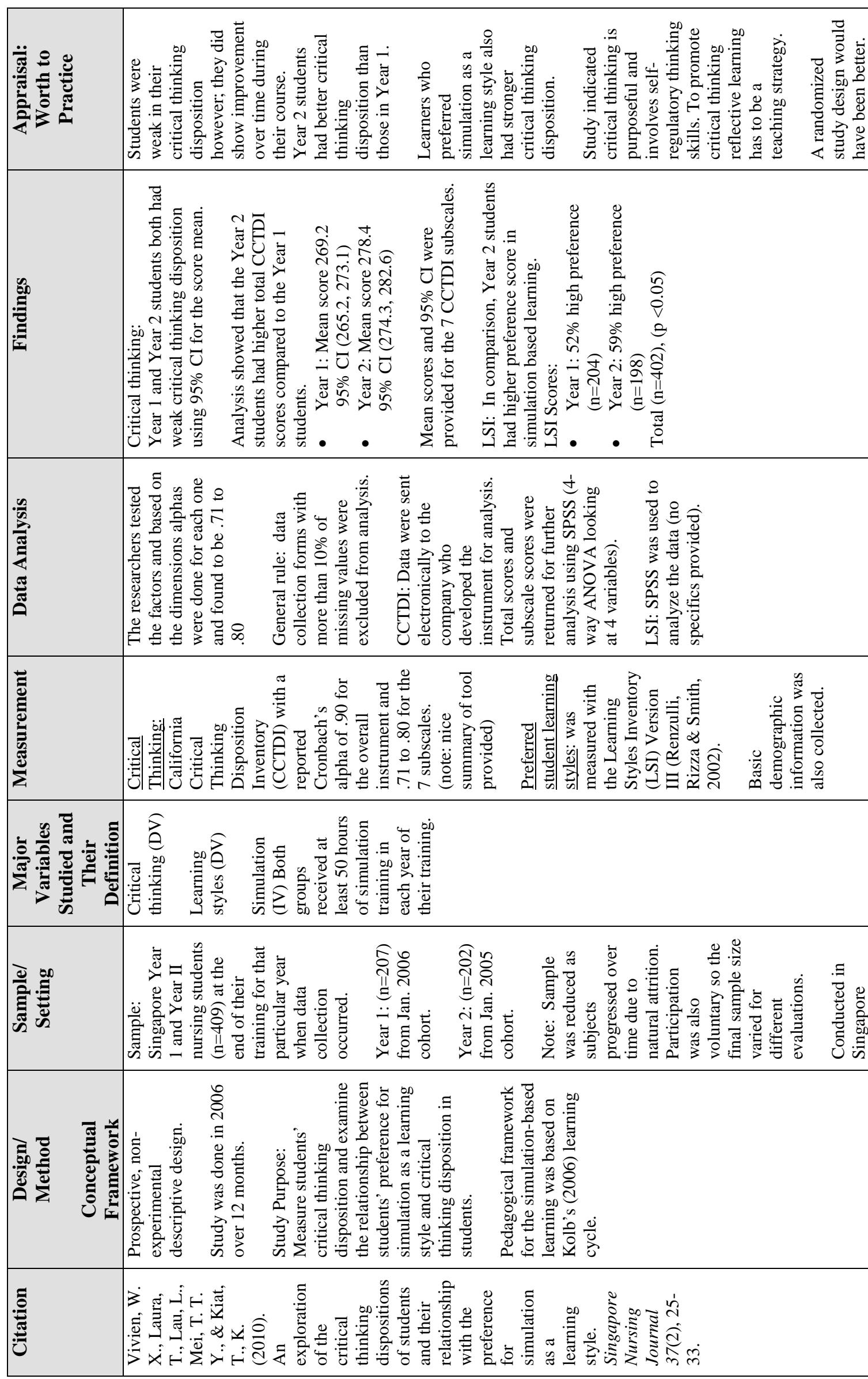




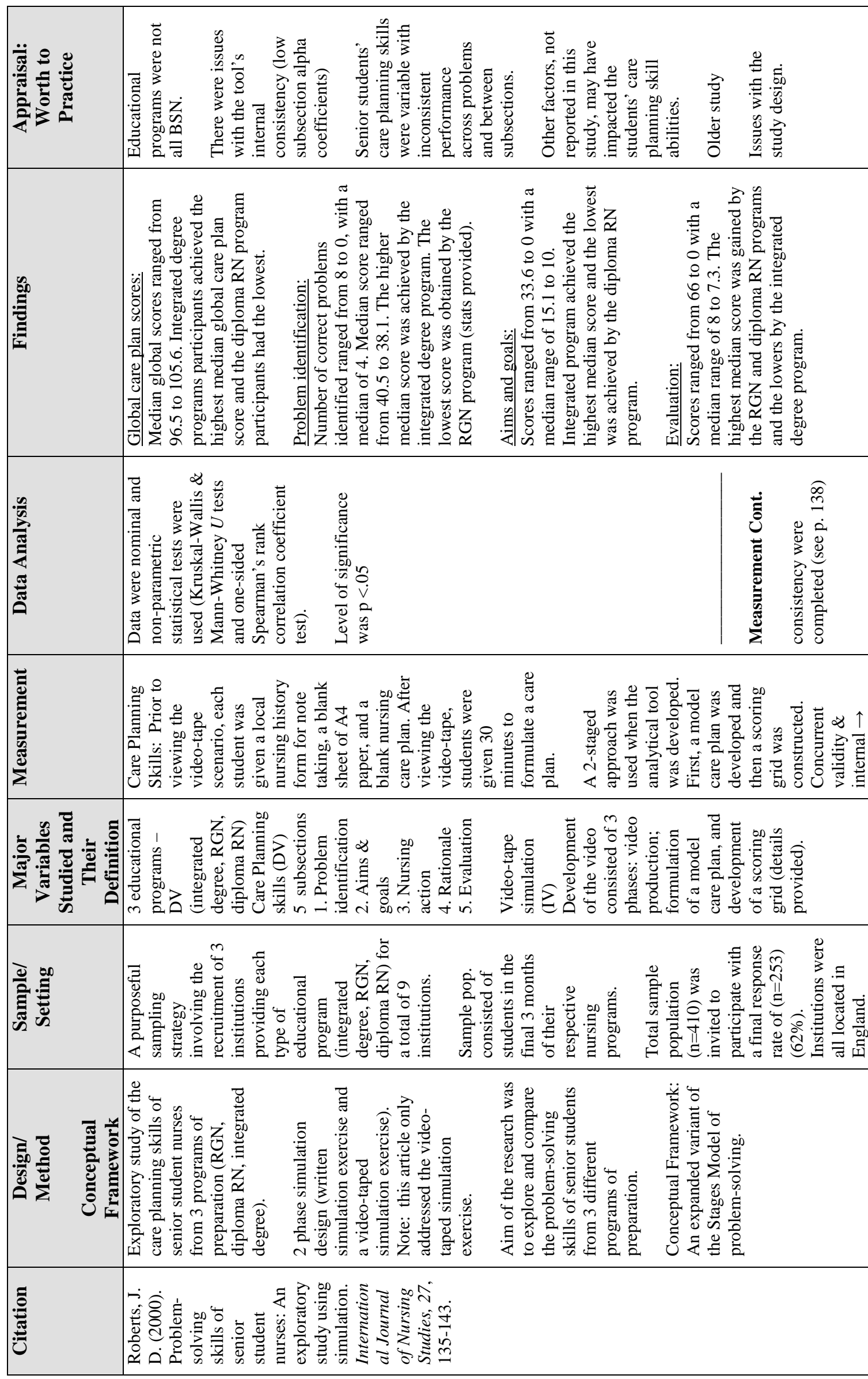




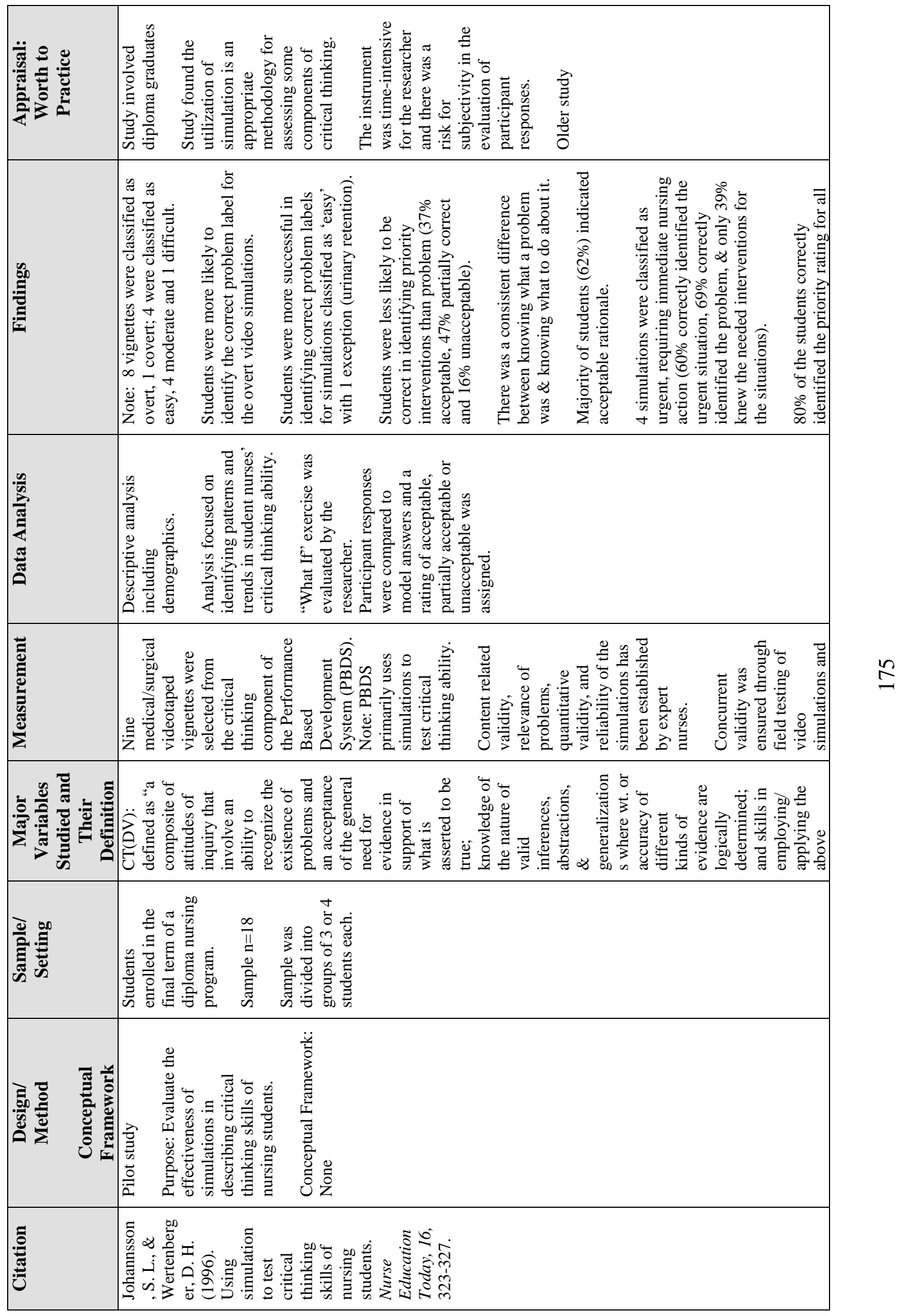




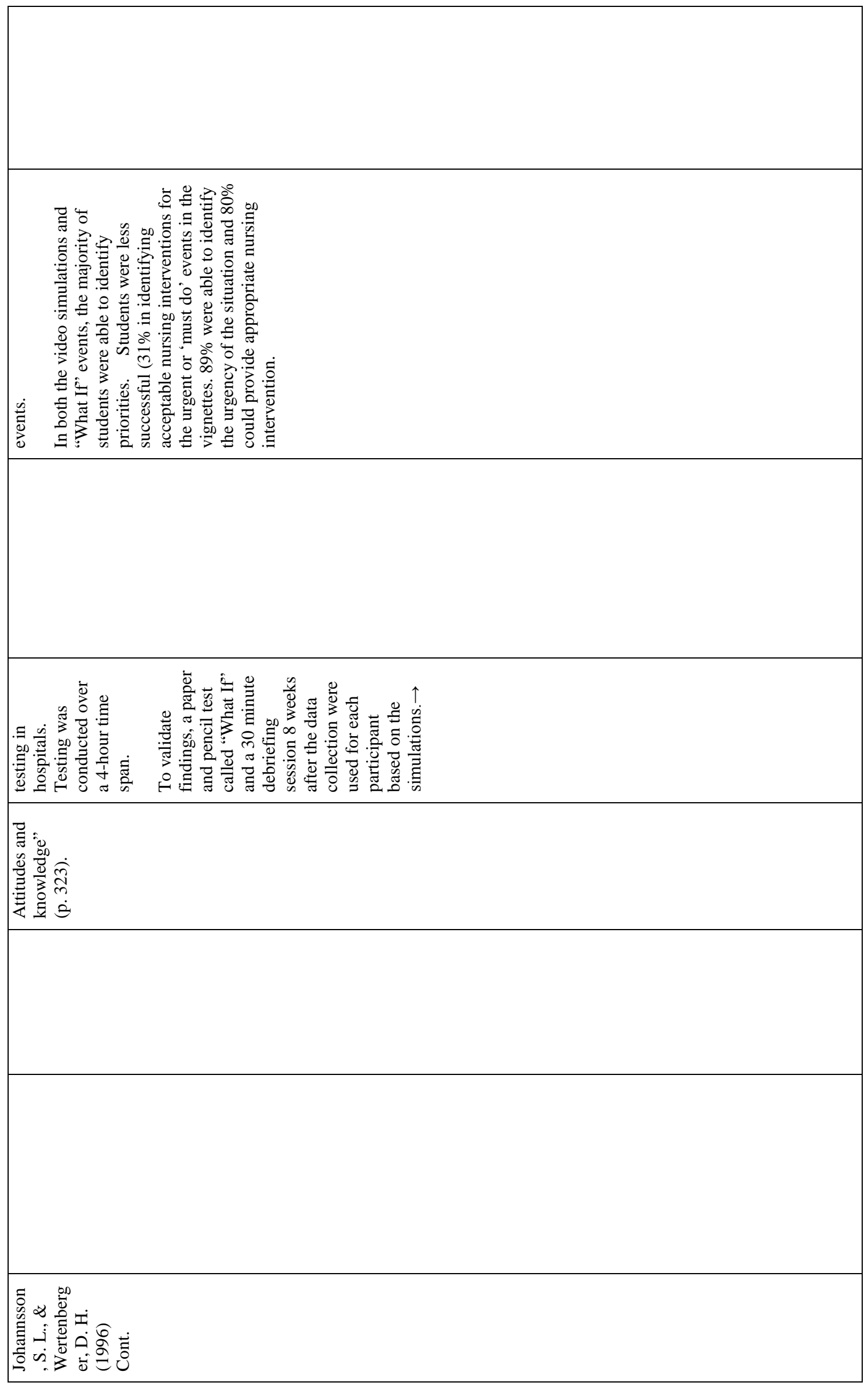




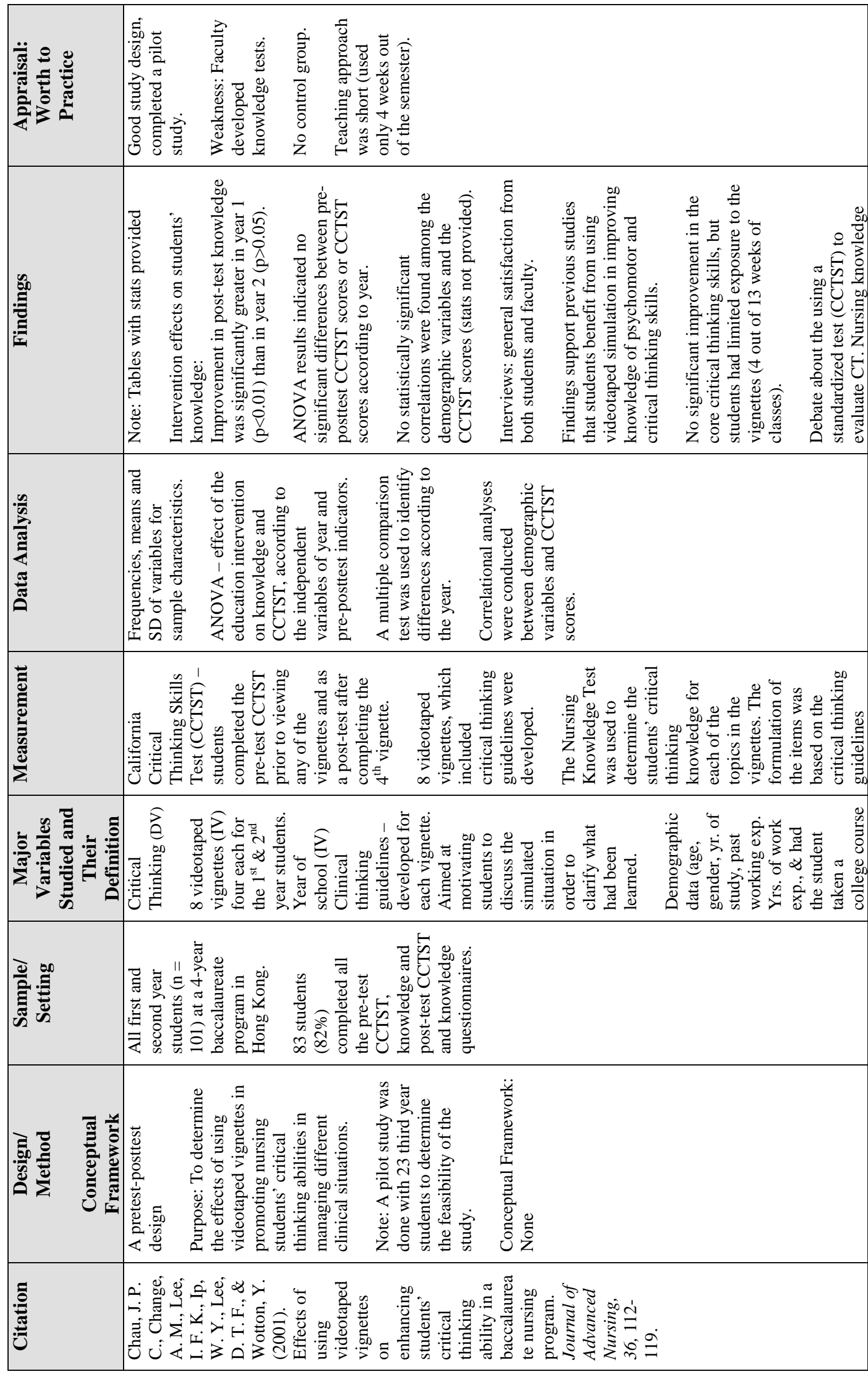




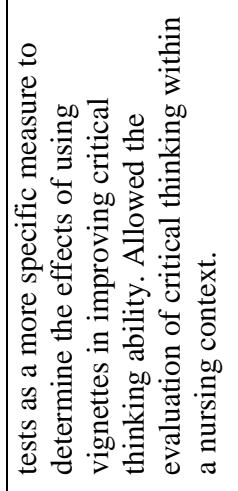

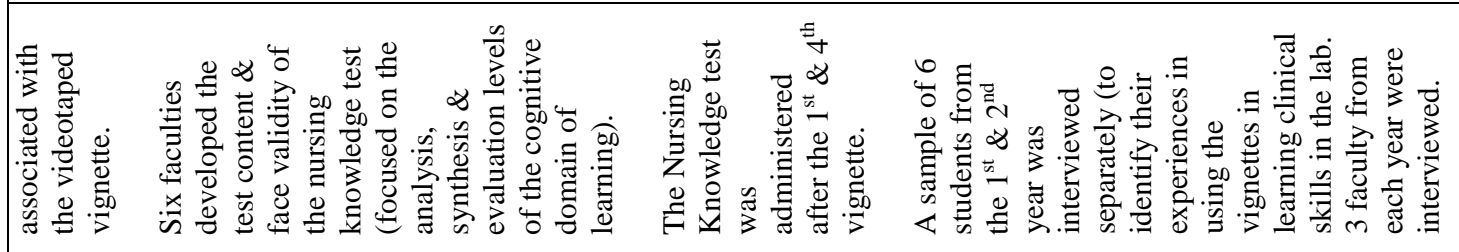

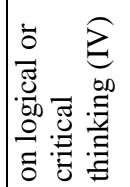

م هิ

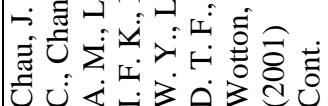




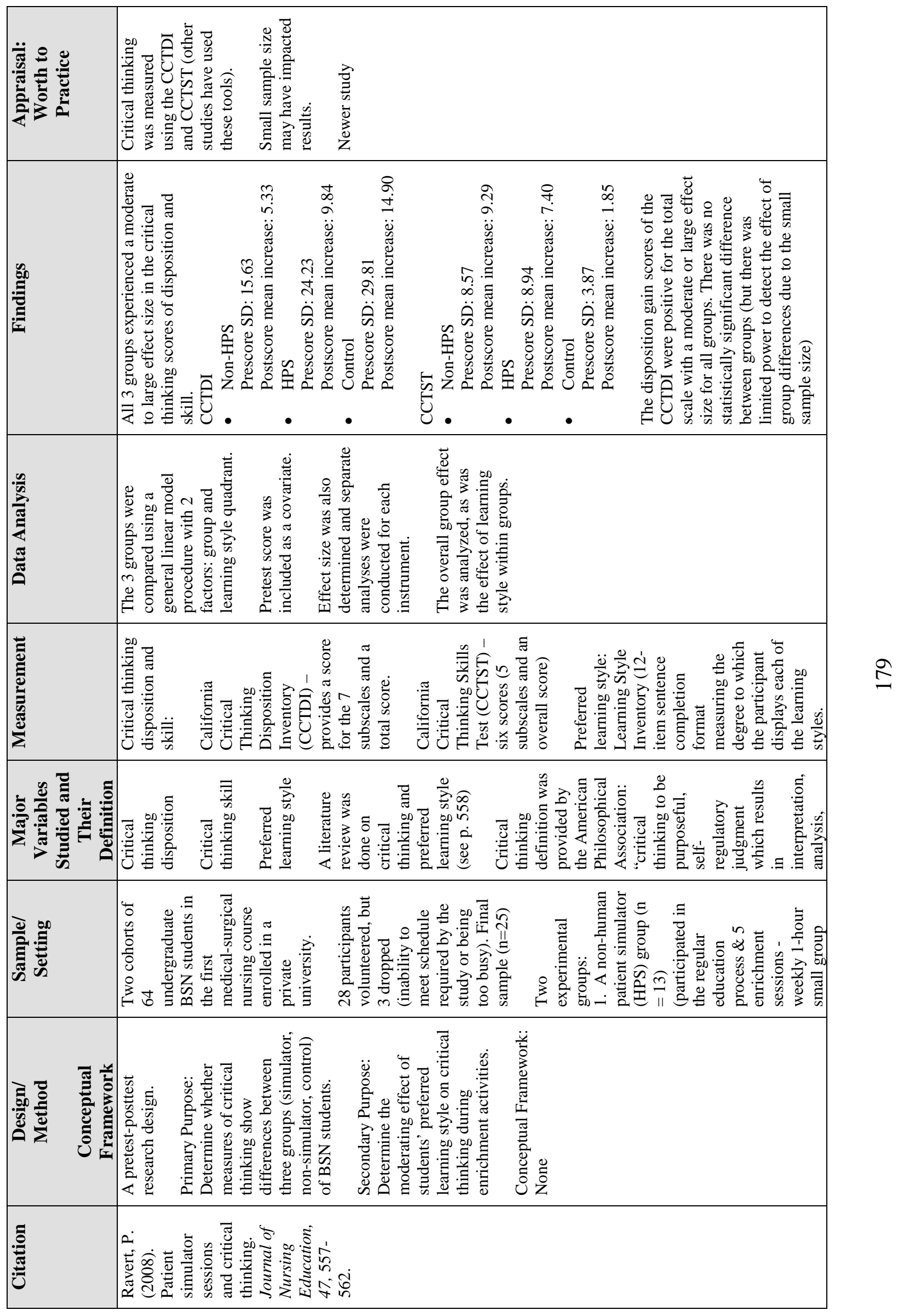




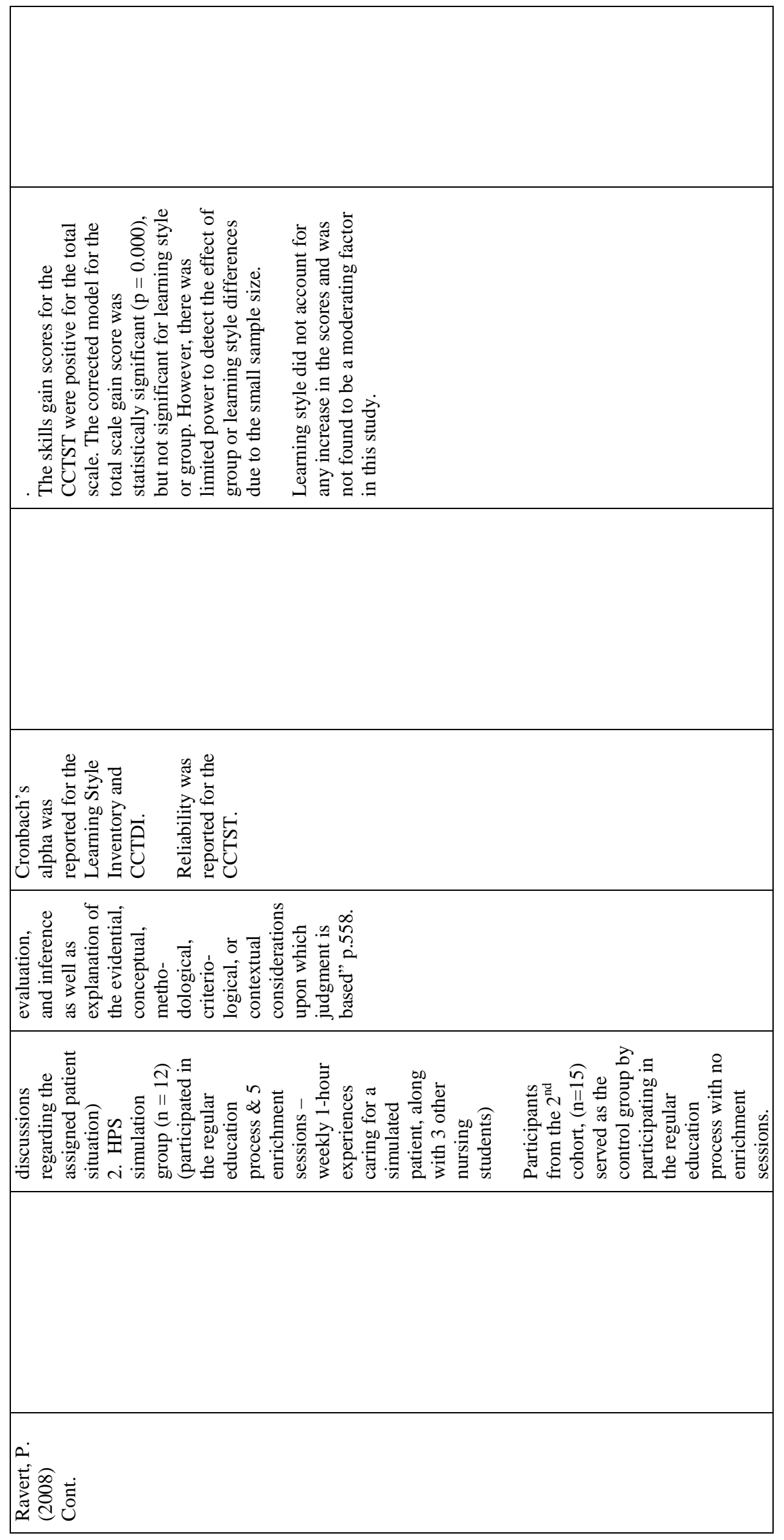




\section{Appendix B: Institutional Review Board Approval Letter}

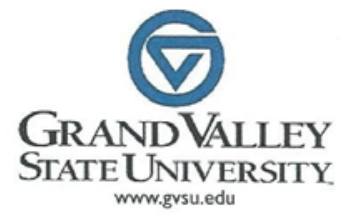

DATE:

TO:

FROM:

STUDY TITLE:

REFERENCE \#:

SUBMISSION TYPE:

ACTION:

EFFECTIVE DATE:

REVIEW TYPE:
June 15,2012

Barbara Hooper, MSN, BSN

Grand Valley State University Human Research Review Committee [341268-1] Using Case Studies and Vignettes to facilitate the development of critical thinking skills in new graduate nurses.

New Project

APPROVED

June 15, 2012

Exempt Review

Thank you for your submission of materials for this research study. The Human Research Review Committee has reviewed your submission and approved your research plan application under Exempt Review. This very well prepared and presented project is a research activity tied to a routine program evaluation and academic assessment of critical thinking skills in nursing staff. Exempt under 1-1 and 1-2. This approval is based on no greater than minimal risk to research participants. All research must be conducted in accordance with this approved submission.

Please insert the following sentence into your information/consent documents as appropriate. All project materials produced for participants or the public must contain this information.

\section{This EXEMPT research protocol has been approved by the Human Research Review} Committee at Grand Valley State University. File No. 341-268-1.

Exempt protocols do not require formal renewal. However, we do confirm on an annual basis that the research continues to meet the criteria for exemption and that there have been no significant changes in activity or key personnel. By June 15, 2013, please complete the brief Continuing Review Application Form, available in your IRBNet Project Designer, or from our website, www.gvsu.edu/hrrc, and submit this form via IRBNet.

Once study enrollment and data analysis have been concluded, please complete the Closed Protocol Reporting Form on our website, and upload a saved copy to IRBNet.

This project remains subject to the research ethics standards of HRRC policies and procedures pertaining to exempt studies.

Please note the following in order to comply with federal regulations and HRRC policy:

1. Any revision to previously approved materials must be approved by this office prior to initiation Please use the Change in Protocol forms for this procedure. This includes, but is not limited to changes in key personnel, study location, participant selection process, etc.

2. All UNEXPECTED PROBLEMS and SERIOUS ADVERSE EVENTS to participants or other parties affected by the research must be reported to this office within two days of the event occurrence. Please use the UP/SAE Report form.

3. All instances of non-compliance or complaints regarding this study must be reported to this office in a timely manner. There are no specific forms for this report type.

If you have any questions, please contact the HRRC Office, Monday through Thursday, at (616) 331-3197 or hrrc@gvsu.edu. The office observes all university holidays, and does not process applications during exam week or between academic terms. Please include your study title and reference number in all correspondence with this office. 
Appendix C: Organizational Institutional Review Board Exemption Letter

\author{
providing quality, compassionate care to everyone, every time
}

proving the health of the people in our communities by

June 5, 2012

Barbara L. Hooper, MSN, RN, NE-BC

Affiliate Faculty

Kirkhof College of Nursing

Cook-DeVos Center for Health Sciences

301 Michigan St. NE, Room 452

Grand Rapids, MI 49503-3314

Dear Ms Hooper,

This letter is being written to assure you and your faculty that Sparrow Hospital considers your project to be programmatic in nature and does not require that you obtain approval from our Institutional Research Review Committee. We are pleased that you are interested in carrying this project out at Sparrow and are supportive of your efforts.

Sincerely,

Director, Nursing Education, Practice, \& Research 


\section{Appendix D: Delegation Teaching Plan}

Facilitator: Barb Hooper

Date: August 8, 2012

Title: Delegation and Prioritization

Audience: New graduates attending the Nurse Residency Program

Time: 3 - 3.5 Hours

\section{Objectives:}

- Define delegation.

- Differentiate between responsibility and accountability.

- List the benefits of delegation.

- List the barriers to effective delegation.

- List the steps in the delegation process.

- Discuss the five "rights" of delegation.

- Describe the 4 C's of Communication.

- Describe the three levels of priority setting.

- Develop a plan for corrective action when delegates do not perform a task as delegated.

- Describe the legal parameters for RN delegation decisions in the state of Michigan.

Materials Needed: Audiovisual equipment (computer with internet access)

Room with chairs that can be moved

Patient Care Technician Job Description

Patient Care Competency Checklist 


\section{Methods:}

\begin{tabular}{|c|c|}
\hline Activity & $\begin{array}{c}\text { Time } \\
\text { Allotted }\end{array}$ \\
\hline Introduction and Review Objectives - Powerpoint & 5-10 minutes \\
\hline $\begin{array}{l}\text { Video: Delegating Effectively Part } 1 \\
\text { www.youtube.com/watch?v=57ceBVSFZRU0 } \\
\text { - After video is shown, review delegation in Michigan - PowerPoint } \\
\text { - Discussion }\end{array}$ & $\begin{array}{r}4: 12 \text { minutes } \\
5 \text { minutes } \\
5 \text { minutes }\end{array}$ \\
\hline $\begin{array}{l}\text { Video: Delegating Effectively Part } 2 \\
\text { www.youtube.com/watch?v=tmXDJ4ZknoI } \\
\text { - Case Study \#1 } \\
\text { - } \quad \text { Discussion }\end{array}$ & $\begin{array}{r}2: 09 \text { minutes } \\
10-15 \text { minutes } \\
5 \text { minutes }\end{array}$ \\
\hline $\begin{array}{l}\text { Video: Delegating Effectively Part } 3 \\
\text { www.youtube.com/watch?v=kWruaJHi4aU } \\
\text { - } \quad \text { Review } 3 \text { levels of priority setting - PowerPoint } \\
\text { - } \quad \text { Case Study \#2 } \\
\text { - } \quad \text { Discussion }\end{array}$ & $\begin{array}{r}7 \text { minutes } \\
5-10 \text { minutes } \\
5-10 \text { minutes } \\
5 \text { minutes }\end{array}$ \\
\hline $\begin{array}{l}\text { Video: Delegating Effectively Part } 4 \\
\text { www.youtube.com/watch?v=wBKm-dJXRVY } \\
\text { - } \text { Making the decision to delegate \& activities that should not be } \\
\text { delegated - PowerPoint } \\
\text { - Review and distribute Delegation Decision-making Tree } \\
\text { - Case Study \#3 and \#4 } \\
\text { - Discussion }\end{array}$ & $\begin{array}{r}\text { 3:23 minutes } \\
5 \text { minutes } \\
5 \text { minutes } \\
30 \text { minutes } \\
10 \text { minutes }\end{array}$ \\
\hline $\begin{array}{l}\text { Video: Delegating Effectively Part } 5 \\
\text { www.youtube.com/watch?v=U_Os1JI-oYQ } \\
\text { - Case Study \#5 } \\
\text { - Discussion }\end{array}$ & $\begin{array}{r}\text { 4:14 minutes } \\
\text { 5-10 minutes } \\
5 \text { minutes }\end{array}$ \\
\hline $\begin{array}{l}\text { Video: Delegating Effectively Part } 6 \\
\text { www.youtube.com/watch?v=wRAKRU3_AT0 } \\
\text { - } \quad \text { Case Study \#6 and \#7 } \\
\text { - } \quad \text { Discussion }\end{array}$ & $\begin{array}{r}4: 13 \text { minutes } \\
15-20 \text { minutes } \\
5 \text { minutes } \\
\end{array}$ \\
\hline Conclusion & 5-10 minutes \\
\hline
\end{tabular}




\section{Case Study \#1 (Break into groups of 2-3)}

You are the RN caring for 5 patients on 7-Neumann, a medical-surgical unit. After report, you huddle with your Patient Care Technician and appropriately delegate taking routine vital signs on 4 of the 5 patients. Later, as you're reviewing 2 of the patient's documentation you notice the Patient Care Technician has not done them. When you question her, she states she forgot. What responsibility does the RN have? What accountability does the Patient Care Technician have?

Discussion: Include in the discussion how the RN's communicates with the PCT.

Focus: Responsibility and Accountability

\section{Case Study \#2 (Break into groups of 2-3)}

You are working on 7 Foster and have 4 busy patients. The charge nurse just informed you that you are getting an admission from the Emergency Room. Ms. Q. has a tracheostomy and requires suctioning. You are working with Mr. R., one of your other patients, when the Patient Care Technician enters your room and indicates Ms. Q is requesting to be suctioned. You are busy finishing a dressing change on Mr. R. and your patient, Ms. K, down the hall is requesting pain medications. The Patient Care Technician states she can suction Ms. Q for you as she just learned how in school. You have worked with the Patient Care Technician multiple times in the past, you know she is very good, and she is attending the same academic program you did. You remember how thorough they were in the lab. What do you do?

Discussion: Right task to the right person based on the PCT's job description. They are not functioning in their student role and thus legally can not perform the task because they would be practicing outside of their scope of practice.

Focus: 5 Rights of Delegation (Right task, Right person) 


\section{Case Study \#3}

You are the RN caring for clients on 5-West, the medical-surgical oncology unit. You are working with a first-semester nursing student and a new nursing assistant who is also assigned to another RN on the unit. Your patients are listed below:

A. Mr. L., a 50-year old man, was transferred 2 days ago from the surgical intensive care unit following a tracheostomy and partial laryngectomy. He has a nasogastric (NG) tube and a tracheostomy tube and is currently receiving chemotherapy. He received radiation therapy prior to surgery.

B. Mr. N., a 68-year old man, presented to his physician with fever, weight loss, and painless axillary nodes. Following a lymph node biopsy, he was diagnosed with non-Hodgkin's lymphoma. He is receiving chemotherapy and is on neutropenic precautions. He currently is afebrile, in good spirits, and feels reasonably well.

C. Mr. B, is a 59-year old man, presented to his doctor with fatigue, difficulty swallowing, hoarseness, and heartburn and was subsequently diagnosed with esophageal cancer. He is currently receiving radiation therapy and chemotherapy. He is alert, conversant, and needs minimal assistance performing activities of daily living.

D. Ms. C., a 70-year old woman, went to her doctor for rectal bleeding and a change in bowel habits. She is 5 days post-operative for a bowel resection and colostomy. She is progressing well, but needs and likes companionship at the bedside.

\section{Questions}

1. You must assign the Patient Care Technician to help care for Nr. N. For this neutropenic patient, which factor has the most impact in assigning a Patient Care Technician and why?

a. Nursing assistant is in the first trimester of pregnancy.

b. Nursing assistant has had cold symptoms for days.

c. Nursing assistant has no experience with neutropenic precautions.

d. Nursing assistant has generalized fear of isolation clients.

Rationale: Staff and visitors with potentially communicable diseases should not enter Mr. N.’s protective environment. Pregnancy, inexperience, and fear to not automatically exclude staff members from this assignment. If the Charge RN has time and options for personnel, then opportunities for duty sharing for pregnant staff members and teaching the inexperienced and fearful can be explored.

Focus: Assignment 
2. In caring a patient with neutropenia, what tasks can be delegated to the Patient Care Technician? (Choose all that apply)

a. Take vital signs every 4 hours.

b. Report temperature elevation $>100.4^{\circ} \mathrm{F}$

c. Assess for sore throat, cough, or burning with urination.

d. Gather the supplies to prepare the room for protective isolation.

e. Report superinfections, such as candidiasis.

f. Practice good hand washing technique.

Rationale: Vital signs and reporting on specific parameters, good handwashing, and gathering equipment are within the scope of duties for a PCT. Assessing for symptoms of infection/superinfections is the responsibility of the RN

Focus: Delegation

3. Which task could be delegated to the Patient Care Technician for Mr. B.

a. Assist the patient with oral hygiene.

b. Observe the patient's response to feedings.

c. Facilitate expression of grief or anxiety.

d. Initiate daily weights.

Rationale: Oral hygiene is within the scope of responsibilities of the PCT. It is the responsibility of the nurse to observe response to treatments and to help the patient deal with loss or anxiety. The PCT can be directed to weigh the patient, but should not be expected to know when to initiate that measurement. Focus: Delegation

Focus: Delegation

4. Mr. B. is experiencing side effects of radiation therapy, which task would be the most appropriate to delegate to the Patient Care Technician?

a. Assist Mr. B. to identify patterns of fatigue.

b. Recommend participation in daily ambulation.

c. Report the amount and type of food consumed from the meal tray.

d. Check the skin for redness and irritation after the treatment.

Rationale: The nursing assistant can observe the amount that the patient eats (or what is gone from the tray) and report to the nurse. Assessing patterns of fatigue or skin reaction is the responsibility of the RN. The initial recommendation for exercise should come from the physician.

Focus: Delegation 
5. The first semester nursing student tells you that her clinical assignment for the day is to take vial signs and to do a patient history that will take about 1 or 2 hours to complete. Which patient would you recommend she NOT approach to fulfill her assignment and why?
a. Mr. L.
b. Mr. N.
c. Mr. B.
d. Ms. C.

Rationale: Mr. L is a recent transfer from SICU. His tracheostomy tube with secretions and the NG tube will make communication very tedious and overwhelming for him and the student. Mr. N., Mr. B., and Ms. C. are relatively stable patients who would be capable of speaking with a nursing student for a prolonged time.

Focus: Assignment 


\section{Case Study \#4}

You are the RN caring for 4 patients on 4-Foster. The patients are as follows:

1. Ms. H., a 36-year old woman admitted with a fever and a productive cough. She has a 15 pack-year history of smoking. She was admitted through the emergency department last night for pneumonia. Night shift reports, "She had a good night."

2. Ms. D., a 60-year old woman receiving IV antibiotics every 6 hours. She has an NG tube in place that will probably be removed tomorrow. She reports dull but continuous left lower quadrant pain. Bowel sounds are active. She has a history of alternating diarrhea and constipation. Last night she reported constipation, but not other complaints.

3. Mr. A., a 26-year old man, will be discharged in the afternoon. He had discharge teaching from the RN assigned to him yesterday regarding his infected wound secondary to a ruptured appendix; he wants a review of the wound care instructions before he leaves.

4. Ms. T., a 29-year old woman, appears wasted and malnourished. She has severe diarrhea and reports pre-defecation abdominal pain and generalized tenderness to palpation. She is receiving total parenteral nutrition (TPN) through a central line.

\section{Questions}

1. Which task(s) should you delegate to the Patient Care Technician? Choose all that apply.

a. Assist Ms. T. with perineal care after diarrheal episodes.

b. Transport Ms. H. to the radiology department.

c. Gently cleanse nares around Ms. D.'s NG tube.

d. Take dressing materials to Mr. A.’s room.

Rationale: Vital signs, transporting, and hygienic care are within the scope of the PCT's duties. The PCT could also take the dressing materials to Mr. A.'s room; however, you will have to give her a list of items. Mr. A. has asked for additional instructions about dressing changes, and you could easily combine the teaching with delivering the materials. In delegating duties, you must consider the complexity of each task and the overall efficient use of personnel.

Focus: Delegation

2. Which reporting task(s) is (are) appropriate to delegate to the Patient Care Technician? Choose all that apply.

a. Assess for perianal excoriation when cleaning Ms. T.

b. Report the quality and color of NG drainage for Ms. D. (Note: PCT could report the quantity if taught to measure Intake and Output).

c. Report if Ms. H.'s BP < 100/60 or pulse > 110/beats per minute

d. Report if any of the clients complain of pain. 
Rationale: PCT's can report on changes in VS; giving parameters is better than asking for general reports on any changes. The PCT can report that the patient is having pain, but is not expected to assess that pain. Skin assessment and evaluation of drainage are responsibilities of the RN. PCT's are often instructed to report any changes in skin condition that they not note throughout the shift subsequent to the RN's initial skin assessment.

\section{Focus: Delegation}

3. You are initiating an impaired gas exchange nursing care plan for Ms. H. Which intervention for cough enhancement should you delegate to the inexperienced Patient Care Technician?

a. Teach Ms. $\mathrm{H}$ about the importance of adequate fluid intake and hydration.

b. Assist Ms. H. to a sitting position with neck flexed, shoulders relaxed and knees flexed.

c. Remind Ms. H. to use the incentive spirometer every 1-2 hours while awake.

d. Encourage Ms. H. to take a deep breath, hold it for 2 seconds, then cough 2-3 times in succession.

Rationale: The PCT can remind the patient to perform actins that are already part of the plan of care. Assisting the patient into the best position to facilitate coughing requires specialized knowledge and understanding that are beyond the scope of the basic PCT. However, an experienced PCT could assist the patient with positioning after the PCT and the patient had been taught the proper technique. The PCT would still be under the supervision of the RN. Teaching patients about adequate fluid intake and techniques that facilitate coughing requires additional education and skill and is within the scope of the RN.

Focus: Delgation/Supervision

4. Which task can you delegate to the inexperienced Patient Care Technician for Ms. D. who has a NG tube?

a. Remove the NG tube per physician order.

b. Secure the tape if the Ms. D. accidentally dislodges the tube.

c. Disconnect the suction to allow Ms. D to ambulate to the toilet.

d. Reconnect the suction after Ms. D has ambulated.

e. None of the Above

Rationale: During removal of the tube, there is a potential for aspiration, so the nurse should perform this task. If the tube is dislodged, the nurse should recheck placement before it is secured. While disconnecting the tube from 
suction could be an appropriate task to delegate to an experience PCT, it would not be appropriate for an inexperienced PCT. Suction should be reconnected by the nurse, to that correct pressure is checked. If the PCT was permitted to reconnect the tube, the $\mathrm{RN}$ is still responsible for checking that the pressure setting is correct so why even have the PCT reconnect it?

Focus: Delegation

\section{Case Study \#5 (Break into groups of 2-3)}

You're working the day shift on 6-West, the orthopedic unit. Your assignment consists of the following patients:

Mr. V., a 26-year old man who was admitted with a fractured pelvis, fractured leg, and has multiple abrasions and cuts after being in a motorcycle accident two days ago. He had surgery yesterday to place pins in his leg. He is now in traction and is requiring frequent pain medications. He needs assistance with his ADL's.

Ms. $\mathrm{N}$ is an 87-year old woman who fell at home and fractured her right arm. She has dementia and keeps yelling for her daughter to come and help her. She requires frequent observation because she keeps trying to get out of bed.

Mr. D. is a 62-year old man who was admitted for a right hip replacement yesterday. He rested well during the night, but is anxious to have his foley removed and begin physical therapy.

Mr. L. is a 54-year old man who was admitted 3 days ago for a knee replacement. He is doing great and is anticipating being discharged either later today or in the morning, depending on how he does working with physical therapy on navigating steps. He likes to talk with all of the staff and prefers to have company in his room.

During the morning huddle, you delegate taking vital signs, bathing and linen changes on all 4 of your patients to the Patient Care Technician. In addition, you delegate feeding Ms. N since she is right handed. The Patient Care technician accepts the delegated responsibilities, but you notice around Noon that none of your patients have been bathed yet. You approached the Patient Care Technician to find out why no one is bathed. She explains to you that her other patients, assigned by Nurse Smith, are very busy and she's been cleaning up one particular patient who is suffering from diarrhea and she just hasn't had time to do any of the baths yet. What do you do? 
Discussion: It is important that once you delegate, you (as the RN) check in with the PCT at intervals to determine how they are performing because the RN remains accountable for the total care of the patients throughout the shift. Definition of supervision includes not only initial direction, but also "the provision of guidance and direction, oversight, evaluation and follow up by the licensed nurse for accomplishment of a nursing task delegated to nursing assistive personnel” (NCSBN, 2004).

If this had been done you would not have found out 4-5 hours later nothing had been completed yet. It's also important to explain to the PCT that they need to come back to you to explain what is going on in his/her assignment if he/she begins to feel overwhelmed. It is also important that you huddle as a team with the other RN or RNs at the beginning of the shift to determine a realistic work load for the PCT.

- Remember, ask for the PCT's input first. Ex. I noted that the vital signs for the first two patient aren't yet on the chart. Do you know what's been done”? rather than "WHY haven't those vital signs been recorded yet? At the end of the shift, the questions can be more global, as in "How did we do today? What would you do differently if we had it to do over again? What should I do differently tomorrow?

- Give credit for all that has been accomplished. You did a great job keeping Mr. $\mathrm{N}$ clean today with so many episodes of diarrhea. His family is very appreciative of our respect for his dignity and prompt attention to keeping him clean and dry.

- Offer observations or concerns. Ex. Vital signs are routinely recorded on the chart before the doctor's round so that we can see the big picture of the patients progress when they round.

- Ask for the PCT's idea on how to resolve the issue. "What are your thought on how you could order your work to get the vital signs on the EMR before 8:30 a.m."? or "What would you like to do with your work plan for tomorrow"?

- Agree on a course of action and plan for the future. "Tomorrow, you plan on charting the vital signs immediately after you take them. That sounds like a great plan. Tomorrow, if that is not working, let me know right away so we can develop another plan.

Focus: Monitoring delegation 


\section{Case Study \#6 (Break into groups of 2-3)}

You're working the night shift on 6-Neumann and every time you need help, you find the Patient Care Technician sitting on the computer surfing the web or sitting in the staff lounge. You become upset because you've been answering multiple call lights and now you're behind in passing your meds. What do you do?

Discussion: Utilize first party communication to address the issue with the PCT. What do you say? If the situation does not improve, what do you do? Go up the chain of command.

Focus: Developing a plan for corrective action when the Patient Care Technician does not perform a task as delegated.

\section{Case Study \#7 (Break into groups of 2-3)}

You're working on the night shift on 6-South. One of your patients, Mr. Z, is on suicide precautions and is assigned a sitter from the Staffing Office. You discuss with the sitter at the beginning of the shift that your patient has attempted suicide twice and is awaiting medical clearance for a bed over at St. Lawrence. As you enter the patient's room to do an assessment, you find the Sitter sound asleep in the chair wrapped up in a blanket. What do you do?

Discussion: Due to safety for your patient, the sitter has to be relieved of her duties, and while this is hard, the patient's safety is at risk. You can not guarantee that the sitter will not fall asleep again even though he/she states it won't happen again. Upon encountering the sitter, you should get the charge nurse or call the house supervisor. They should witness the sitter sleeping, wake the sitter up and send them home. How can you prevent this from happening in the future? Provide the sitter with a 5 minute walking break every 1-2 hours. It is hard to sit all night. Encourage the sitter to call you if they feel they need to get up to move around.

Focus: Developing a plan for corrective action when the Patient Care Technician does not perform a task as delegated and describe how delegation activities influence patient outcomes.

Note: Case Studies 2, 3, 4, and 5 were adapted from:

LaCharity, L. A., Kumagai, C. K., Bartz, B. (2006). Prioritization, delegation \& assignment: Practice exercise for medical-surgical nursing. St. Louis: Missouri: Mosby. 


\section{Appendix F: Demographic Data Questionnaire}

Please provide the following information by writing your answer on the line that is provided or by circling the appropriate response. Thank you.

For purposes of my being able to match your questionnaires before and after the case study and videotaped vignette session, please write the birthdate of your mother here:

$\underline{0} \frac{\bar{M}}{\mathrm{M}}{ }^{\prime} \overline{\mathrm{D}} \overline{\mathrm{D}}^{\prime} \overline{\mathrm{Y}} \frac{}{\mathrm{Y}} \frac{}{\mathrm{Y}} \overline{\mathrm{Y}}^{.}$

1. Age: Please list your age

2. Educational Preparation
a. ADN
b. BSN
c. Other (please specify)

3. Please list the school you attended for your nursing degree:

4. Please list any previous education you may have obtained (technical college, other degrees, certifications, etc.).

5. Previous healthcare related experience: Please circle any of the following that pertain to your past experience related in the medical field:
a. None
b. Nursing Assistant/Patient Care Technician
c. Pharmacy Technician
d. Surgical Technician
e. Laboratory Technician
f. Unit/Ward Secretary
g. Emergency Medical Technician
h. Other (please list):

6. Have you worked previously in a health care setting prior to accepting a position into the nurse residency program (nursing home, hospital, rehab, home care, etc.)? If you answered no, skip to question 9.
a. Yes
b. No 
7. If you answered Yes in question 7, please circle where you worked:
a. Hospital
b. Nursing Home
c. Rehabilitation Center
d. Home Care
e. Other, please specify

8. How long did you work in the above setting?

9. Have you had any prior experience with case studies and video vignettes during your academic preparation?
a. Yes
b. No

10. If Yes, please describe in writing a brief description of your experience. 


\section{References}

Abbate, S. M. (2008). Online case studies and critical thinking in nursing (Unpublished doctoral dissertation). Northern Illinois University, Dekalb, IL.

Aday, L. A., Begley, C. E., Lairson, D. R., \& Balkrishnan, R. (2004). Evaluating the healthcare system: Effectiveness, efficiency, and equity ( $3^{\text {rd }}$ ed.). Washington D. C.: Health Administration Press.

Agency for Healthcare Research and Quality (2012). HCAHPS fact sheet. Retrieved from http://www.hcahpsonline.org/files/HCAHPS\%20Fact\%20Sheet\%20May\%2020 12.pdf

American Association of Colleges of Nursing (2006). The essentials of doctoral education for advanced nursing practice. Retrieved from http://www.aacn.nche.edu/DNP/pdf/Essentials.pdf

American Association of Colleges of Nursing (2008). The essentials of baccalaureate education for professional nursing practice. Washington, DC: Author.

American Nurses Association (2004). Nursing: Scope and standards of practice. Washington D. C.: Author.

American Nurses Association (2009). Nursing administration: Scope and standards of practice. Silver Spring, Maryland: Author

American Nurses Association (2012). About NDNQI. Retrieved from https://www.nursingquality.org/FAQPagenew.aspx\#1

American Nurses Credentialing Center (2012). Magnet: Growth of the program. Retrieved from http://nursecredentialing.org/Magnet/ProgramOverview/Historyof TheMagnetProgram/growthoftheProgram.aspx

Anderson, L. W., \& Krathwohl, D. R. (2001). A taxonomy for learning, teaching, and assessing. Boston, MA: Allyn and Bacon.

Angel, B. F., Duffey, M., Belyea, M. (2000). An evidence-based project for evaluating strategies to improve knowledge acquisition and critical-thinking performance in nursing students. Journal of Nursing Education, 39, 219-228.

Assessment Technologies Institute (2002). Developmental and statistical report. Stillwell, KS: Author.

Ausubel, D. P., Novak, J. D., \& Hanesian, H. (1986). Educational psychology: A cognitive view ( $2^{\text {nd }}$ ed.). New York: Werbel and Peck. 
Banning, M. (2006). Nursing research: Perspectives on critical thinking. British Journal of Nursing, 15, 458-461.

Banning, M. (2008). Clinical reasoning and its application to nursing: Concepts and research studies. Nurse Education in Practice, 8, 177-183.

Barnum, M. G. (2008). Questioning skills demonstrated by approved clinical instructors during clinical field experiences. Journal of Athletic Training, 43, 284-292.

Bechtel, G. A., Davidhizar, R., \& Bradshaw, M. J., (1999). Problem-based learning in a competency-based world. Nurse Education Today, 19, 182-187.

Benner, P. (1984). From novice to expert: Excellence and power in clinical nursing practice. Menlo Park, CA: Addison-Wesley.

Benner, P. Hughes, R. G., \& Sutphen, M. (2008). Clinical reasoning, decision-making, and action: Thinking critically and clinically. In Hughes, R. (Ed.). Patient safety and quality: An evidence-based handbook for nurses (Chapter 6). Rockville, MD: Agency for Healthcare Research and Quality.

Benner, P., Sutphen, M., Leonard, V. \& Day, L. (2010). Educating nurses: A call for radical transformation. San Francisco, CA: Jossey-Bass.

Berkow, S., Virkstis, K., Steward, J., \& Conway, L. (2009). Assessing new graduate nurse performance. Nurse Educator, 34, 17-22.

Beyea, S. C., Von Reyn, L., Slattery, M. J. (2007). A nurse residency program for competency development using human patient simulation. Journal for Nurses in Staff Development, 23, 77-82.

Bloom, B. S. (1956). Taxonomy of educational objectives, handbook one: Cognitive domain. London, England: Longmans.

Bondy, K. N, Koenigseder, L. A., Ishee, J. H., \& Williams, B. G. (2001). Psychometric properties of the California critical thinking tests. Journal of Nursing Measurement, 9, 309-328.

Boswell, C. (2006). The art of questioning: Improving critical thinking. Annual Review of Nursing Education, 4, 291-304.

Boychuk-Duchscher, J. E. (1999). Catching the wave: Understanding the concept of critical thinking. Journal of Advanced Nursing, 29, 577-583.

Bratt, M. M. (2009). Retaining the next generation of nurses; The Wisconsin nurse residency program provides a continuum of support. The Journal of Continuing Education in Nursing, 40, 416-425. doi: 10.3928/00220124-20090824-05 
Broussard, L. (2008). Simulation-based learning: How simulators help nurses improve clinical skills and preserve patient safety. Nursing for Women's Health, 12, 521524.

Burns, H. K., O’Donnell, J., \& Artman, J. (2010). High-fidelity simulation in teaching problem solving to $1^{\text {st }}$-year nursing students: A novel use of the nursing process. Clinical Simulation in Nursing, 6, e87-e95. doi: 10.1016/j.ecns.2009.07.005

Butler, K. M. (2004). The use of critical reflection in baccalaureate nursing education. Nursing Leadership Forum, 8, 138-144.

Campbell, S. H. (2006). Clinical simulation. In Gaberson, K. B., \& Oermann, M. H. (Eds.), Clinical teaching strategies for nursing (pp. 123-140). New York: Springer Publishing.

Cant, R. P., \& Cooper, S. J. (2010). Simulation-based learning in nursing education: systematic review. Journal of Advanced Nursing, 66, 3-15. doi: 10.1111/j.13652648.2009.05240.x

Casey, K., Fink, R., Krugman, M, \& Propst, J. (2004). The graduate nurse experience. The Journal of Nursing Administration, 34, 303-311.

Chau, J. P. C., Change, A. M., Lee, I. F. K., Ip, W. Y., Lee, D. T. F., \& Wootton, Y. (2001). Effects of using videotaped vignettes on enhancing students' critical thinking ability in a baccalaureate nursing programme. Journal of Advanced Nursing, 36, 112-119.

Chunta, K. S., \& Katrancha, E. D. (2010). Using problem-based learning in staff development: Strategies for teaching registered nurses and new graduate nurses. The Journal of Continuing Education in Nursing, 41, 557-564. doi: 10.3928/00220124-20100701-06

Ciliska, D., DiCenso, A., Melnyk, B. M., Fineout-Overholt, E., Stetler, C. B., Cullen, L. Larrabee, J. H., Schultz, A. A., Rycroft-Malone, J., Newhouse, R. P., \& Dang, D. (2011). Models to guide implementation of evidence-based practice. In Melnyk, B. M., \& Fineout-Overholt, E. (Eds.), Evidence-based practice in nursing \& healthcare: A guide to best practice ( $2^{\text {nd }}$ ed., pp. 241-275). Philadelphia, PA: Lippincott Williams \& Wilkins.

Clayton, L. H. (2006). Concept mapping: An effective, active teaching-learning method. Nursing Education Perspectives, 27, 197-203.

Cohen, G. D. (2005). The mature mind: The power of the aging brain. New York, NY: Basic Books. 
Commission on Collegiate Nursing Education. (2009). Standards for accreditation of baccalaureate and graduate degree nursing programs. Retrieved from http://www.aacn.nche.edu/ccne-accreditation/standards09.pdf

Daley, B. J., Shaw, C. R., Balistrieri, T., Glasenapp, K., \& Piacentine, L. (1999). Concept maps: A strategy to teach and evaluate critical thinking. Journal of Nursing Education, 38, 42-47.

Daly, W. M. (2001). The development of an alternative method in the assessment of critical thinking as an outcome of nursing education. Journal of Advanced Nursing, 36, 120-130.

Day, L., \& Smith, E. L. (2007). Integrating quality and safety content into clinical teaching in the acute care setting. Nursing Outlook, 55, 138-143. doi: 10.1016/j.outlook.2007.02.002

Delaney, C. (2003). Walking a fine line: Graduate nurses' transition experiences during orientation. Journal of Nursing Education, 42, 437-443.

DeSanto-Madeya, S. (2007). Using case studies based on a nursing conceptual model to teach medical-surgical nursing. Nursing Science Quarterly, 20, 324-326. doi: $10.1177 / 0894318407307159$

Donabedian, A. (1997). The quality of care: How can it be assessed? Archives of Pathology \& Laboratory Medicine, 121, 1145-1150.

Donabedian, A. (2003). An introduction to quality assurance in health care. New York: Oxford University Press.

Durham, C. F., \& Alden, K. R. (2008). Enhancing patient safety in nursing education through patient simulation. In Hughes, R. (Ed.). Patient safety and quality: An evidence-based handbook for nurses (Chapter 51). Rockville, MD: Agency for Healthcare Research and Quality.

Dyess, S. M., \& Sherman, R. O. (2009). The first year of practice: New graduate nurses' transition and learning needs. The Journal of Continuing Education in Nursing, 40, 403-410. doi: 10.3928/00220124-20090824-03

Edman, L. R. O., Bart, W. M., Robey, J., \& Silverman, J. (2000, August). The Minnesota test of critical thinking: Development, analysis, and critical issues. Paper presented at the Annual Meeting of the American Psychological Association, Washington, D.C.

Edman, L. R. O., Bart, W. M., Robey, J., \& Silverman, J. (2004). Psychometric analysis of the Minnesota test of critical thinking. Psychological Reports, 95, 3-9. 
Edwards, S. L. (2007). Critical thinking: A two-phase framework. Nurse Education in Practice, 7, 303-314. doi: 10.1016/j.nepr.2006.09

Elsevier (2006, January 9). Health education systems incorporated (HESI) joins elsevier. Retrieved from http://webcache.googleusercontent.com/search?q=cache:yEMX8nyZxUJ:www.elsevier.com/wps/find/authored_newsitem.cws_home/companyne ws05_00378\%3Fnavopenmenu\%3D3+health+education+systems+inc.\&cd=2\&hl =en\&ct=clnk\&gl=us

Ennis, R. H., \& Weir, E. (1985). The Ennis-Weir crtical thinking essay test. Pacific Grove, CA: Midwest Publications.

Facione, N. C., \& Facione, P. A. (2011). The holistic critical thinking scoring rubric: HCTSR. Retrieved from http://insightassessment.com/9HCRSR.html

Facione, N. C., \& Facione, P. A. (2008). Critical thinking and clinical reasoning in the health sciences: An international multidisciplinary teaching anthology. Millbrae, CA: California Academic Press.

Facione, N. C., \& Facione, P. A. (1994). The California critical thinking skills test and the national league for nursing accreditation. Millbrae, CA: California Academic Press.

Facione, N. C., Facione, P. A., \& Sanchez, C. A. (1994). Critical thinking disposition as a measure of competent clinical judgment: The development of the California critical thinking disposition inventory. The Journal of Nursing Education, 33, 345-350.

Facione, N. C., Facione, P. A., \& Winterhalter, K. (2011). Health sciences reasoning test: HSRT test manual. Millbrae, CA: Insight Assessment

Facione, P. (1990). The California critical thinking skills test: College level technical report \#1 - experimental validation and content validity. Millbrae, CA: California Academic Press.

Fero, L. J., O’Donnell, J. M., Zullo, T. G., Devito-Dabbs, A., Kitutu, J., Samosky, J. T., \& Hoffman, L. A. (2010). Critical thinking skills in nursing students: Comparison of simulation-based performance with metrics. Journal of Advanced Nursing, 66, 2182-2193. doi: 10.1111/j.1365-2648.2010.05385.x

Fero, L. J., Witsberger, C. M., Wesmiller, S. W., Zullo, T. G., \& Hoffman, L. A. (2009). Critical thinking ability of new graduate and experienced nurses. Journal of Advanced Nursing, 65, 139-148. doi: 10.1111/j.1365-2648.04834.x

Ferrario, C. G. (2004). Developing nurses’ critical thinking skills with concept mapping. Journal for Nurses in Staff Development, 20, 261-267. 
Forneris, S. G. (2004). Exploring the attributes of critical thinking: A conceptual basis. International Journal of Nursing Education Scholarship, 1(1), 1-18. doi: 10.2202/1548-923X.1026

Forneris, S. G., \& Peden-McAlpine, C. (2006). Contextual Learning: A reflective learning intervention for nursing education. International Journal of Nursing Education Scholarship, 3(1), 20 p.

Forneris, S. G., \& Peden-McAlpine, C. (2007). Evaluation of a reflective learning intervention to improve critical thinking in novice nurses. Journal of Advanced Nursing, 57, 410-421. doi: 10.1111/j.1365-2648.2006.04120.x

Foundation for Critical Thinking (n.d.). Our concept and definition of critical thinking. Retrieved from http://www.criticalthinking.org/pages/our-concept-and-defintionof-critical- thinking/411

Garrett, B. M., \& Callear, D. (2001). The value of intelligent multimedia simulation for teaching clinical decision-making skills. Nurse Education Today, 21, 382-390.

Goode, C. J., \& Williams, C. A. (2004). Post-baccalaureate nurse residency program. The Journal of Nursing Administration, 34, 71-77.

Goodman, D. (1997). Application of the critical pathway and integrated case teaching method to nursing orientation. The Journal of Continuing Education in Nursing, 28, 205-210.

Grossman, S., Krom, Z. R., \& O’Connor, R. (2010). Using case studies to generate increased nurse's clinical decision-making ability in critical care. Dimensions of Critical Care Nursing, 29, 138-142.

Gul, R., B., \& Boman, J. A. (2006). Concept mapping: A strategy for teaching and evaluation in nursing education. Nursing Education in Practice, 6, 199-206. doi: 10.1016/j.nepr.2006.01.001

Halfer, D., \& Graf, E. (2006). Graduate nurse perceptions of the work experience. Nursing Economics, 24, 150-155.

Harding, M. (2010). Predictability associated with exit examinations: A literature review. Journal of Nursing Education, 49, 493-497. doi: 10.3928/01484834-20100730-01

Hatler, C., Stoffers, P., Kelly, L., Redding, K., \& Carr, L. L. (2011). Work unit transformation to welcome new graduate nurses. Nursing Economics, 29, 88-93.

Hessling, R. M., Traxel, N. M., \& Schmidt, T. J. (2012). Ceiling effect. Retrieved from http://srmo.sagepub.com/view/the-sage-encyclopedia-of-social-science-researchmethods/n102.xml 
Hicks-Moore, S. L. (2005). Clinical concept maps in nursing education: An effective way to link theory and practice. Nurse Education in Practice, 5, 348-352.

doi: 10.1016/j.nepr.2005.05.003

Hicks-Moore, S. L., \& Pastirik, P. J. (2006). Evaluating critical thinking in clinical concept maps: A pilot study. International Journal of Nursing Education Scholarship, 3(1), 17p.

Hinshaw, A. S. (2010). Forward to first edition. In Rubenfeld, M. G., \& Schefffer, B. K. (Eds.), Critical thinking tactics for nurse: Achieving the IOM competencies $\left(2^{\text {nd }}\right.$ ed.), (pp. vii-viii). Sudbury, MA: Jones and Bartlett.

Hoffman, J. J. (2008). Teaching strategies to facilitate nursing students' critical thinking. Annual Review of Nursing Education, 6, 225-236.

Hovancsek, M. T. (2007). Using simulations in nursing education. In Jeffries, P. R. (Ed.), Simulation in nursing education: From conceptualization to evaluation. (pp. 1-9). New York: National League for Nursing.

Howard, V. M. (2007). ). A comparison of educational strategies for the acquisition of medical-surgical nursing knowledge and critical thinking skills: human patient simulator vs. the interactive case study approach (Unpublished doctoral dissertation). University of Pittsburgh, Pittsburgh, Pennsylvania.

Howard, V. M., Ross, C., Mitchell, A. M., \& Nelson, G. M. (2010). Human patient simulators and interactive case studies: A comparative analysis of learning outcomes and student perceptions. Computers, Informatics, Nursing, 1, 42-48.

Hsu, L. (2004). Developing concept maps from problem-based learning scenario discussions. Journal of Advanced Nursing, 48, 510-518.

Hsu, L., \& Hsieh, S. I. (2005). Concept maps as an assessment tool in a nursing course. Journal of Professional Nursing, 21, 141-149. doi:

10.1016/j.profnurs.2005.04.006

Hughes, R. G. (2008). Patient safety and quality: An evidence-based handbook for nurses. Rockville, MD: Agency for Healthcare Research and Quality.

Hyland, J. R. \& Hawkins, M. C. (2009). High-fidelity human simulation in nursing education: A review of the literature and guide for implementation. Teaching and Learning in Nursing, 4, 14-21. doi: 10.1016/j.teln.2008.07.004

Hynes, P., \& Bennett, J. (2004). About critical thinking. Dynamics, 15(3), 26-29. 
Insight Assessment (2011). Health sciences reasoning test. Retrieved from http://www.insightassessment.com/Products /Critical-Thinking-SkillsTests/Health-Science-Reasoning-Test-HSRT

Institute of Medicine (1999). To err is human: Building a safer health system. Retrieved from http://www.iom.edu/reports

Institute of Medicine (2001). Crossing the quality chasm. Retrieved from http://www.iom.edu/reports

Institute of Medicine (2003). Keeping patients safe: Transforming the work environment for nurses. Retrieved from http://www.iom.edu/reports

Institute of Medicine (2011). About the IOM. Retrieved from http://www.iom.edu/AboutIOM.aspx

Interprofessional Education Collaborative Expert Panel (2011). Core competencies for interprofessional collaborative practice: Report of an expert panel. Washington, D.C.: Interprofessional Education Collaborative.

Jackson, M., Ignatavicius, D. D., \& Case, B. (2006). Conversations in critical thinking and clinical judgment. Sudbury, MA: Jones and Bartlett.

Jeffries, P. R. \& Rogers, K. J. (2007). Theoretical framework for simulation design. In Jeffries, P. R. (Ed.), Simulation in nursing education: From conceptualization to evaluation. (pp.21-33). New York: National League for Nursing.

Joel, L. A. (2007). Instructional methods. In Moyer, B. A., \& Witmman-Price, R. A. (Eds.), Nursing education: Foundations for practice cxcellence (183-211). Philadelphia, PA: F. A. Davis.

Johannsson, S. L., \& Wertenberger, D. H. (1996). Using simulation to test critical thinking skills of nursing students. Nurse Education Today, 16, 323-327.

Jones, C. B. (2008). Revisiting nurse turnover costs: Adjusting for inflation. The Journal of Nursing Administration, 38, 11-18.

Jones, M. (2008). Developing clinically savvy nursing students: An evaluation of problem-based learning in an associate degree program. Nursing Education Perspectives, 29, 278-283.

Kaddoura, M. A. (2010). New graduate nurses’ perceptions of the effects of clinical simulation on their critical thinking, learning, and confidence. The Journal of Continuing Education in Nursing, 41, 506-516. doi: 10.3928/0022012420100701-02 
Kaiser Health News (2011). Research roundup: The cost of medical errors, unreasonable rate increases. Retrieved from http://www.kaiserhealthnews.org/DailyReports/2011?april/08/KHN-040811-Research-Roundups.aspx

Kautz, D. D., Kuiper, R. A., Pesut, D. J., Knight-Brown, P., \& Daneker, D. (2005). Promoting clinical reasoning in undergraduate nursing students: Application and evaluation of the outcome present state test (OPT) model of clinical reasoning. International Journal of Nursing Education Scholarship, 2(1), 21p.

Kintgen-Andrews, J. (1991). Critical thinking and nursing education: Perplexities and insights. Journal of Nursing Education, 30, 152-157.

Kowalczyk, N., Hackworth, R., \& Case-Smith, J. (2012). Perceptions of the use of critical thinking teaching methods. Radiologic Technology, 83, 226-236.

Knowles, M. S., Holton, E. F., \& Swanson, R. A. (1998). The adult learner: The definitive classic in adult education and human resource development. Houston: Gulf.

Krautscheid, L., Kaakinen, J., \& Warner, J. R. (2008). Clinical faculty development: Using simulation to demonstrate and practice clinical teaching. Journal of Nursing Education, 47, 431-434.

LaCharity, L. A., Kumagai, C. K., Bartz, B. (2006). Prioritization, delegation \& assignment: Practice exercise for medical-surgical nursing. St. Louis: Missouri: Mosby.

Lapkin, S., Levett-Jones, T., Bellchambers, H., \& Fernandez, R. (2010). Effectiveness of patient simulation manikins in teaching clinical reasoning skills to undergraduate nursing students: A systematic review. Clinical Simulation in Nursing, 6, e207e222. doi: 10.1016/j.ecns.2010.05.005

Lavandera, R., Whalen, D. M., Perkel, L. K., Hackett, V., Molnar, D., Steffey, C., Hershorin, I. R., Rafalko, S., Little, D. J., \& Harris, J. (2011). Value-added of HESI exam as a predictor of timely first-time RN licensure. International Journal of Nursing Education Scholarship, 8(1), 12p. doi: 10.2202/1548-923X.2152

Lyons, E. M. (2008). Examining the effects of problem-based learning and NCLEX-RN scores on the critical thinking skills of associate degree nursing students in a sourtheastern community college. International Journal of Nursing Education Scholarship, 5(1), 17p. 
Maneval, R., Fowler, K. A., Kays, J. A., Boyd, T. M., Shuey, J., Harne-Britner, S., \& Mastrine, C. (2012). The effect of high-fidelity patient simulation on the critical thinking and clinical decision-making skills of new graduate nurses. The Journal of Continuing Education in Nursing, 43, 125-134. doi: 10.3928/0022012420111101-02

Mangena, A., \& Chabeli, M. M. (2005). Strategies to overcome obstacles in the facilitation of critical thinking in nursing education. Nurse Education Today, 25, 291-298. doi: 10.1016/j.nedt.2005.01.012

Melnyk, B. M., \& Fineout-Overholt, E. (Eds.) (2011). Evidence-based practice in nursing \& healthcare: A guide to best practice $\left(2^{\text {nd }}\right.$ ed.). Philadelphia, PA: Lippincott Williams \& Wilkins.

Messecar, D. C. (2007). The art and science of nursing education. In Moyer, B. A., \& Witmman-Price, R. A. (Eds.), Nursing education: Foundations for practice excellence (33-53). Philadelphia, PA: F. A. Davis.

Morrison, S., Adamson, C., Nibert, A., \& Hsia, S. (2008). HESI exams: An overview of reliability and validity. Computer Informatics Nursing, 22, 220-226.

Myers, S., Reidy, P. French, B., McHale, J., Chisholm, M., Griffin, M. (2010). Safety concerns of hospital-based new-to-practice registered nurse and their preceptors. The Journal of Continuing Education in Nursing, 41, 163-171. doi: 10.3928/00220124-20100326-02

Michigan Department of Community Health (2012). Task force on nursing practice: Final report and recommendations. Lansing: Michigan Public Health Institute.

National Council of State Boards of Nursing (2010). Delegating effectively parts 1-6. Retrieved from http://youtube.com/user/NCSBInteract?feartuere=watch

National Council of State Boards of Nursing (2012a). NCLEX examinations. Retrieved from https://www.ncsbn.org/nclex.htm

National Council of State Boards of Nursing (2012b). Joint statement on delegation: American nurses association and the national council of state boards of nursing. Retrieved from http://ncsbn.org/Joint_statement.pdf

National League for Nursing (2005). Core competencies of nurse educators with task statements. Retrieved from http://nln.org/facultydevelopment/pdf/corecompetencies.pdf

National League for Nursing (2011). Critical thinking in clinical nursing practice $-R N$ information bulletin. Retrieved from http://dev.nln.org/testprodecuts/pdf/CTinfobulletin.pdf 
National League for Nursing (2012). Testing services. Retrieved from https://www.nln.org/testingservices/pdf/RN_Order_Form.pdf

Nelson, E. C., Batalden, P. B., Huber, T. P., Johnson, J. K., Godfre, M. M., Headrick, L. A., \& Wasson, J. H. (2007). Success characteristics of high-peforming microsystems. In Nelson, E. C., Batalden, P. B., \& Godfrey, M. M. (Eds.), Quality by design: A clinical microsystems approach (pp. 3-33). San Francisco, CA: Jossey-Bass.

Notarianni, M. A., Curry-Lourenco, K., Barham, P., \& Palmer, K. (2009). Engaging learners across generations: The progressive professional development model. The Journal of Continuing Education in Nursing, 40, 261-266.

doi: 10.9999/00220124-20090522-07

Oermann, M., Truesdell, S., \& Ziolkowski, L. (2000). Strategy to assess, develop, and evaluate critical thinking. The Journal of Continuing Education in Nursing, 31, 155-160.

Ogrinc, G. S., Headrick, L. A., Moore, S. M., Barton, A. J., Dolansky, M. A., \& Madigosky, W. S. (2012). Fundamentals of health care improvement: A guide to improving your patients' care ( $2^{\text {nd }}$ ed.). Oakbrook Terrace, Illinois: Joint Commission Resource, Inc.

Oja, K. J. (2011). Using problem-based learning in the clinical setting to improve nursing students' critical thinking: An evidence review. Journal of Nursing Education, 50, 145-151. doi: 10.3928/01484834-20101230-10

O’Sullivan, P. S., Blevins-Stephens, W. L., Smith, F. M., \& Vaughan-Wrobel, B. (1997). Addressing the National League for Nursing critical-thinking outcome. Nurse Educator, 22, 23-29.

Panns, W., Sermeus, W., Hieweg, R., \& Van der Schans, C. (2010). Determinants of the accuracy of nursing diagnoses: Influence of ready knowledge, knowledge sources, disposition toward critical thinking and reasoning skills. Journal of Professional Nursing, 26, 232-241.

Performance Assessment Network (2011). The Watson-Glaser critical thinking appraisal. Retrieved from http://www.pantesting.com/products/PsychCorp/WGCTA.asp

Pesut, D. J. (2001). Clinical judgment: Foreground/background. Journal of Professional Nursing, 17, 215.

Phillips, N., \& Duke, M. (2001). The questioning skills of clinical teachers and preceptors: A comparative study. Journal of Advanced Nursing, 33, 523-529. 
Pilcher, J. W. (2009). Using concept maps in a nurse internship program. Journal for Nurses in Staff Development, 25, 299-303.

Plack, M. M., \& Santasier, A. (2004). Reflective practice: A model for facilitating critical thinking skills within an integrative case study classroom experience. Journal of Physical Therapy Education, 18(1), 4-12.

Polit, E. F., \& Beck, C. T. (2012). Nursing research: Generating and assessing evidence for nursing practice $\left(9^{\text {th }}\right.$ ed.). Philadelphia, Pennsylvania: Lippincott Williams \& Wilkins.

Popil, I. (2011). Promotion of critical thinking by using case studies as teaching method. Nurse Education Today, 31, 204-207. doi: 10.1016/j.nedt.2010.06.002

Profetto-McGrath, J. (2005). Critical thinking and evidence-based practice. Journal of Professional Nursing, 21, 364-371. doi: 10.1016/j.profnurs.2005.10.002

Ravert, P. (2008). Patient simulator sessions and critical thinking. Journal of Nursing Education, 47, 557-562.

Rochmawati, R., \& Wiechula, R. (2010). Education strategies to foster health professional students' clinical reasoning skills. Nursing and Health Sciences, 12, 244-250. doi: 10.111/j.1442-2018.2009.00512.x

Rubenfeld, M. G., \& Scheffer, B. K. (Ed.). (2010). Critical thinking tactics for nurses: Achieving the IOM competencies ( $2^{\text {nd }}$ ed.). Sudbury, MA: Jones and Bartlett.

Saucier, B. L., Stevens, K. R., \& Williams, G. B. (2000). Critical thinking outcomes of computer-assisted instruction versus written nursing process. Nursing and Health Care Perspectives, 21, 240-246.

Scheffer, B. K., \& Rubenfeld, M. G. (2000). A concensus statement on critical thinking in nursing. Journal of Nursing Education, 39, 352-359.

Schon, D. A. (1987). Educating the reflective practitioner: Toward a new design for teaching and learning in the professions. San Francisco, CA: Jossey-Bass.

Schumacher, L., B. (2004). The impact of utilizing high-fidelity computer simulation on critical thinking abilities and learning outcomes in undergraduate nursing students (Unpublished doctoral dissertation). Duquesne University, Pittsburgh, PA.

Schuster, P. (2002). Concept mapping: A critical-thinking approach to care planning. Philadelphia, PA: F.A. Davis. 
Sellappah, S., Hussey, T., Blackmore, A. M., \& McMurray, A. (1998). The use of questioning strategies by clinical teachers. Journal of Advanced Nursing, 28, 142-148.

Setter, R., Walker, M., Connelly, L. M., \& Peterman, T. (2011). Nurse residency graduates' commitment to their first positions. Journal for Nurses in Staff Development, 27, 58-64. doi: 10.1097/NND.0b013e31820eee49

Sewell, E. A. (2008). Journaling as a mechanism to facilitate graduate nurses' role transition. Journal for Nurses in Staff Development, 24, 49-52.

Shell, R. (2001). Perceived barriers to teaching for critical thinking by BSN nursing faculty. Nursing and Health Care Perspectives, 22, 286-291.

Shepherd, I. A., Kelly, C. M., Skene, F. M., \& White, K. T. (2007). Enhancing graduate nurses' health assessment knowledge and skills using low-fidelity adult human simulation. Simulation in Healthcare, 2, 16-24.

Simpson, E., \& Courtney, M. (2002). Critical thinking in nursing education: Literature review. International Journal of Nursing Practice, 8, 89-98.

Smith, A. (1998). Learning about reflection. Journal of Advanced Nursing, 28, 891-898.

Spurlock, D. R., \& Hunt, L. A. (2008). A study of the usefulness of the HESI exit exam in predicting NCLEX-RN failure. Journal of Nursing Education, 47, 157-166.

Staib, S. (2003). Teaching and measuring critical thinking. Journal of Nursing Education, 42, 498-508.

Steen, J. E., Gould, E. W., Raingruber, B., \& Hill, J. (2011). Effect of student nurse intern position on ease of transition from student nurse to registered nurse. Journal for Nurses in Staff Development, 27, 181-186. doi: 10.1097/NND.0b013e3181a68acc

Stone, C. A., Davidson, L. J., Evans, J. L., \& Hansen, M. A. (2001). Validity evidence for using a general critical thinking test to measure nursing students' critical thinking. Holistic Nursing Practice, 15(4), 65-74.

Sullivan-Mann, J., Perron, C. A., \& Fellner, A. N. (2009). The effects of simulation on nursing students' critical thinking scores: A quantitative study. Newborn \& Infant Nursing Reviews, 9, 111-116. doi: 10.1053/j.nainr.2009.03.006

Teekman, B. (2000). Exploring reflective thinking in nursing. Journal of Advanced Nursing, 31, 1125-1135.

Think Watson (2012). The gold standard critical thinking test. Retrieved from http://www.thinkwatson.com/assessments/watson-glaser 
Thompson, C., \& Stapley, S. (2011). Do educational interventions improve nurses’ clinical decision making and judgment? A systematic review. International Journal of Nursing Studies, 48, 881-893. doi: 10.1016/j.ijnurstu.2010.12.005

Titler, M. G., Kleiber, C., Steelman, V., Rakel, B. A., Budreau, G., Everett, L. Q., et al. (2001). The Iowa model of evidence-based practice to promote quality care. Critical Care Nursing Clinics of North America, 13, 497-509.

Tiwari, A., Lai, P., So, M., \& Yuen, K. (2006). A comparison of the effects of problembased learning and lecturing on the development of students' critical thinking. Medical Education, 40, 547-554. doi: 10.1111/j.365-2929.2006.02481.x

Tomey, A. M. (2003). Learning with cases. The Journal of Continuing Education in Nursing, 34, 34-38.

Twibell, R., Ryan, M., \& Hermiz, M. (2005). Faculty perceptions of critical thinking in student clinical experiences. Journal of Nursing Education, 44, 71-79.

Ulrich, B., Krozek, C., Early, S., Ashlock, C. H., Afria, L. M., \& Carman, M. L. (2010). Improving retention, confidence, and competence of new graduate nurses: Results for a 10-year longitudinal database. Nursing Economics, 28, 363-375.

U.S. Department of Labor. (2010). Registered nurses: Occupational outlook handbook. Retrieved from http://www.bls.gov/oco/ocos083.htm

U.S. National Library of Medicine. (2012). Fact sheet: Medical subject headings $(\mathrm{MeSH})$. National Institutes of Health. Retrieved from: http://www.nlm.nih.gov/pubs/factsheets/mesh.html

Vaughan-Wrobel, B. C., O’Sullivan, \& Smith, L. (1997). Evaluating critical thinking skills of baccalaureate nursing students. Journal of Nursing Education, 36, 485-488.

Wangensteen, S., Johansson, I. S., Bjorkstrom, M. E., \& Nordstrom, G. (2010). Critical thinking dispositions among newly graduated nurses. Journal of Advanced Nursing, 66, 2170-2181. doi: 10.1111/j.1365-2648.2010.05282.x

Wells, S. H., Warelow, P. J., Jackson, K. L. (2009). Problem based learning (PBL): A conundrum. Contemporary Nurse, 33, 191-201.

Wheeler, L. A., \& Collins, S. K. R. (2003). The influence of concept mapping on critical thinking in baccalaureate nursing students. Journal of Professional Nursing, 19, 339-346. doi: 10.1016/S8755-7223(03)00134-0 
Wilgis, M., \& McConnell, J. (2008). Concept mapping: An educational strategy to improve graduate nurses' critical thinking skills during a hospital orientation program. The Journal of Continuing Education in Nursing, 39, 119-126.

Wotton, K., Davis, J., Button, D., \& Kelton, M. (2010). Third-year undergraduate nursing students' perceptions of high-fidelity simulation. Journal of Nursing Education, 49, 632-639. doi: 10.3928/014834-20100831-01

Yuan, H., Kunaviktikul, W., Klunklin, A., \& Williams, B. A. (2008). Improvement of nursing students' critical thinking skills through problem-based learning in the People's Republic of China: A quasi-experimental study. Nursing and Health Sciences, 10, 70-76. doi: 10.1111/j.1442-2018.2007.00373.x

Yuan, H., Williams, B. A., \& Fan, L. (2008). A systematic review of selected evidence on developing nursing students' critical thinking through problem-based learning. Nurse Education Today, 28, 657-663. doi. 10.1016/j.nedt.2007.12.006 